\title{
Integrating economic costs \\ into global biodiversity conservation priorities: \\ Sensitivity of prioritization to the use of differing cost indicators
}

\author{
Dissertation \\ zur Erlangung des Doktorgrades \\ der Fakultät für Agrarwissenschaften \\ der Georg-August-Universität Göttingen
}

\author{
vorgelegt von \\ Georg Barth \\ geboren in Braunschweig
}

Göttingen, Februar 2016 
D 7

1. Referent: Prof. Dr. Rainer Marggraf

2. Korreferent: Prof. Dr. Holger Kreft

3. weiteres Mitglied des Promotionskomitees: Prof. Dr. Jan Barkmann

Tag der mündlichen Prüfung: 8. Februar 2016 




\section{Summary}

Protected area systems that are ecologically representative and effectively managed are essential tools for the conservation and sustainable use of biodiversity worldwide. However, global protected area coverage and management effectiveness is highly insufficient, even in areas of global biodiversity significance. Under the Convention on Biological Diversity (CBD), governments committed to improve management effectiveness and expand the global coverage of protected areas from $13 \%$ to $17 \%$ of land area by 2020, targeting especially areas of particular importance for biodiversity. It is important for the feasibility of conservation to identify spatial priorities that are cost-effective, that is to meet intended biodiversity targets while minimizing, as far as possible, conservation costs.

To date, global-scale analyses of cost-effective priorities either accounted for management costs of protected areas associated with required staff and infrastructure, or for opportunity costs associated with forgone agricultural production. Management costs are the main costs paid by conservation organizations, while a large part of agricultural opportunity costs is paid by local land users. Therefore, the choice of the cost type has important normative implications on whose costs have standing in the prioritization process. Furthermore, different methods were proposed to approximate agricultural opportunity costs, and the choice of the agricultural opportunity cost indicator itself may influence prioritization results. However, the sensitivity of priority areas for global biodiversity conservation towards these normative and methodological degrees of freedom remains unclear.

The general aim of this thesis is to increase the transparency of cost-effective prioritization at the global-scale, and to investigate the robustness of its results by reassessing priorities for differing types and indicators of conservation costs.

Chapter I of this thesis provides an overview on the thesis background, motivation and aim. In chapter II, it is investigated how focusing on management costs or on agricultural opportunity costs differently affects the selection of cost-effective priority areas for global biodiversity conservation. The results of this analysis demonstrate that prioritization needs to include both management and opportunity costs because focusing on either cost type alone results in undue cost burdens to conservation organizations or to local land users, which compromises the success of conservation. Further, it is concluded that remapping priority areas based on several 
alternative cost scenarios can not only ensure overall cost-effective selection of sites, but also ensure that trade-offs between costs to different stakeholder groups are transparently identified, which could lead to overall more equitable and economically feasible outcomes. Finally, it was also found that two commonly used prioritization approaches, minimum set and maximum coverage, differ markedly in their degree of sensitivity towards diverging cost data. In chapter III, it is investigated how commonly used indicators to approximate agricultural opportunity costs differently influence the selection of priority areas. It was discovered that the different indicators of agricultural opportunity costs are only weakly to moderately correlated spatially. Most importantly, it was found that that cost-effective selection of global priority areas according to one cost indicator shifted priorities to areas with high costs according to any of the other indicators. These results show that outcomes from current state-of-the-art approaches for minimizing agricultural opportunity costs of global biodiversity priority areas are inconclusive because cost-effectiveness varies widely depending on which cost indicator is considered, while at the same time it is uncertain how well each cost indicator reflects the actual agricultural opportunity costs of conservation. In chapter IV, it is reviewed that previous global prioritization analyses commonly relied on economic returns from past agricultural lands (mid 1990s) to account for agricultural opportunity costs of conservation. However, opportunity costs do not only include the benefits currently obtained from a site but also those that could have been obtained in the future. While the extension path of agricultural land cannot be exactly predicted, the scenario analyses presented in this chapter clearly illustrate that cost-effectiveness of global prioritization may be improved substantially by more fully using available knowledge on possible pathways of agricultural expansion during the $21^{\text {th }}$ century. 


\section{Acknowledgments}

First of all I want to thank my supervisor Prof. Dr. Rainer Marggraf (Georg-AugustUniversität Göttingen) for giving me the opportunity to pursue my doctoral research, for welcoming me into his working group, and for giving me the freedom I needed to do my research. Sincere thanks also to my co-supervisor Prof. Dr. Holger Kreft (Georg-AugustUniversität Göttingen) for his very constructive advice and comments, and for always being cheerful to communicate with.

I am most grateful to Prof. Dr. Jan Barkmann (Hochschule Darmstadt - University of Applied Sciences) who initially sparked my interest in the economics of biodiversity, since then has supported me tremendously throughout many years, and provided me with essential advice and feedback regarding this thesis. Thank you Jan!

Sincere thanks also to Dr. Carsten Meyer (German Centre for Integrative Biodiversity Research, iDiv) for providing me with essential data, for his swift and detailed responses to my questions, and in particular for providing me with very profound comments on our paper manuscripts. Thank you very much also to Takuya Iwamura (Stanford University) for kindly sharing his data. I would like to give a special thanks to Prof. Dr. Goddert von Oheimb (Technische Universität Dresden) for heartedly welcoming me into the Biodiversity and Nature Conservation chair in Tharandt. Thank you very much also to all the colleagues of the research chair for their support and for allowing me to come to the office each day with positive expectations.

Thanks to my colleagues at the Environmental and Resource Economics group at the GeorgAugust-Universität Göttingen for exchange of ideas, companionship and support. Especially, I would like to thank Christine Schwenkner for her friendship and for her kind, reliable support. A special thanks also goes to my fellow doctoral candidates and fellow sufferers Stefan, Vladi, and Yves for their companionship.

I am utmost grateful to the German Federal Environmental Foundation (DBU) for awarding me with a doctoral scholarship, and for organizing many enjoyable and informative meetings with my fellow scholarship holders.

I also would like to thank my friends in Göttingen, in partiuclar, Antje, Jana, Jannis, Kahli, Patrick, Rebecca, Romina, Sebastian, Simon, Talin, and Tobi. Even though working towards the completion of this thesis was quite tough at times, your friendship helped me a lot to stay positive and motivated! Especially with this in mind, I would like to thank you Lina with all my heart for your unconditional and loving support. Finally, I give my deepest possible gratitude to my caring parents Angelika and Lothar, whose great support I could always count on. 


\section{Table of contents}

Summary

Acknowledgments......................................................................................... vii

Chapter I: General introduction ...............................................................

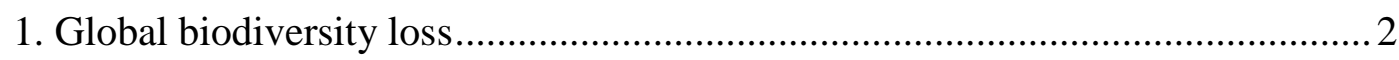

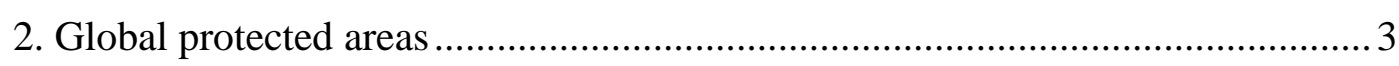

3. Global biodiversity conservation priority areas ……………………….......... 5

4. Integrating economic costs into global conservation prioritization ...................... 6

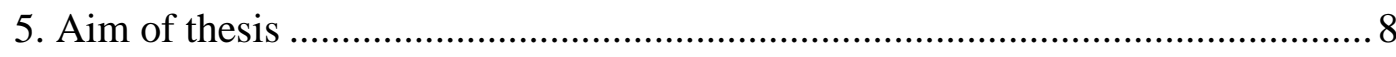

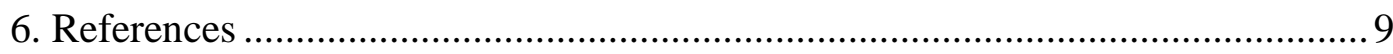

\section{Chapter II: Cost-effective priority areas for global biodiversity} conservation: Trade-offs between management and agricultural

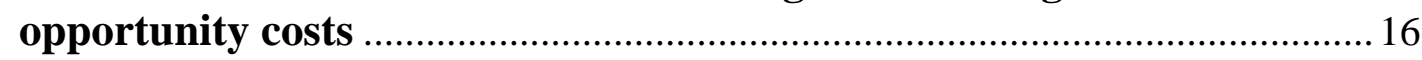

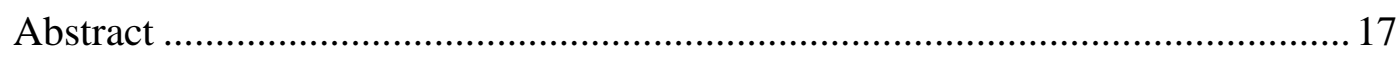

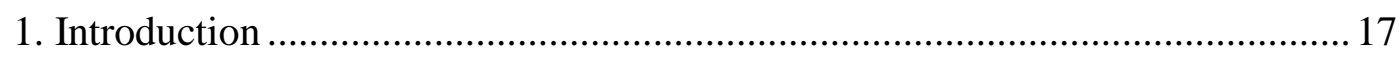

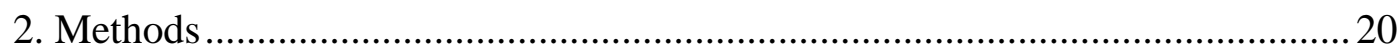

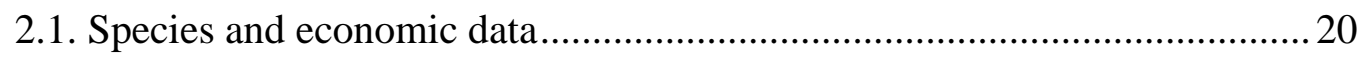

2.2. Conservation prioritization analyses ........................................................ 21

2.3. Comparison of cost data and prioritization scenarios .................................. 23

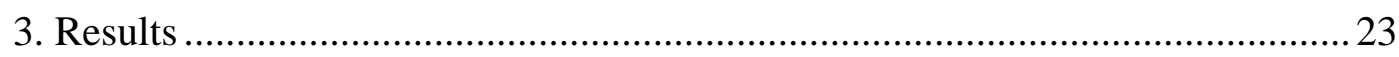

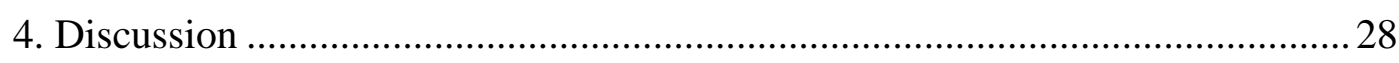

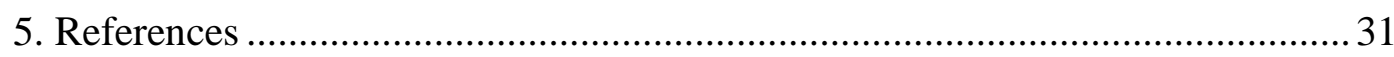

Chapter III: Divergent indicators of agricultural opportunity costs lead to inconclusive global conservation priorities.................................................... 37

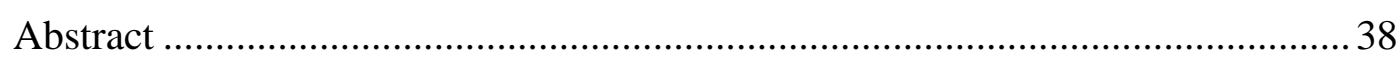

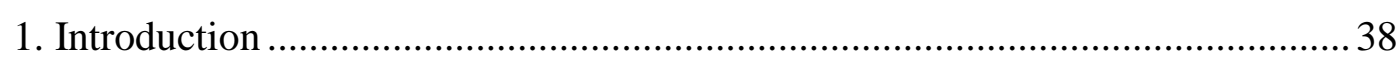

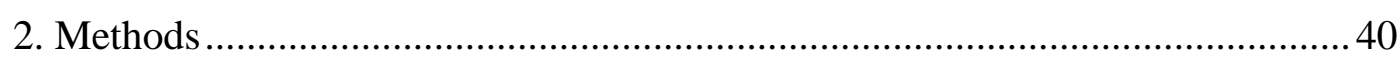

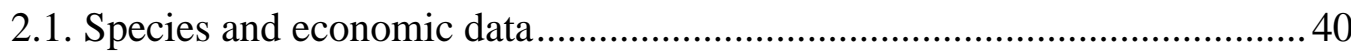

2.2. Conservation prioritization analyses ................................................... 42

2.3. Comparison of conservation prioritization scenarios ..................................... 43

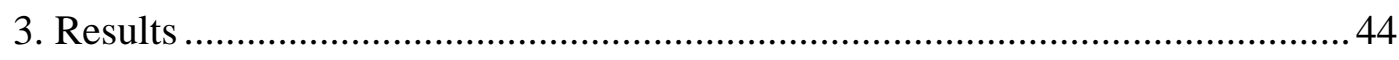

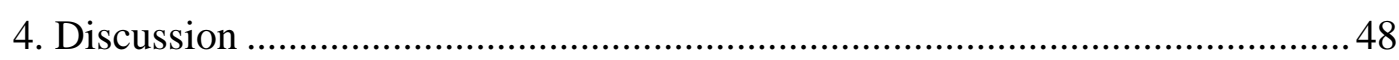

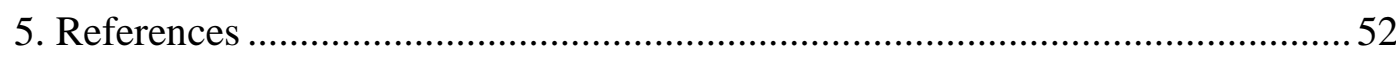




\section{Chapter IV: Cost-effective priorities for global biodiversity conservation}

require consideration of possible pathways of agricultural expansion ... 57

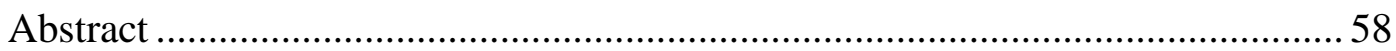

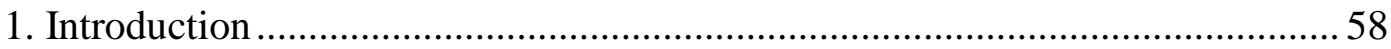

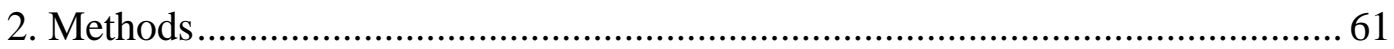

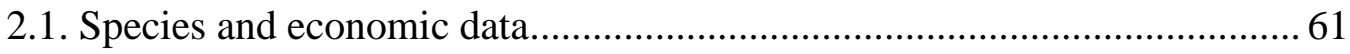

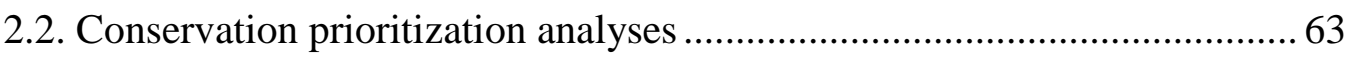

2.3. Comparison of conservation prioritization scenarios and cost data............ 64

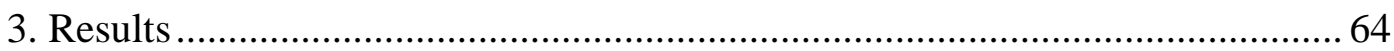

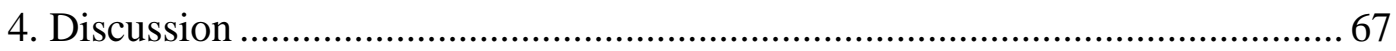

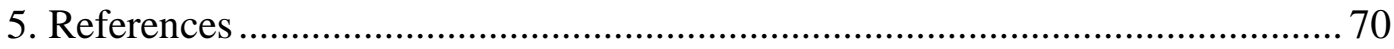

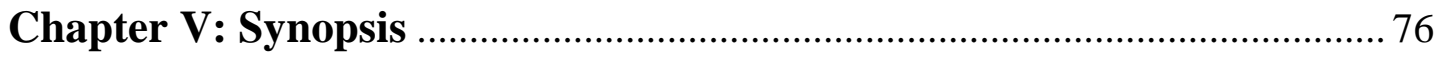

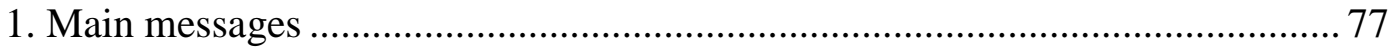

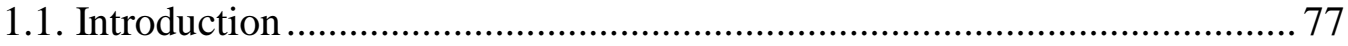

1.2. Differences between management and agricultural opportunity costs ....... 78

1.3. Differences among varying indicators of agricultural opportunity costs .... 79

1.4. Differences among varying scenarios of agricultural extent..................... 80

1.5. Comparison of minimum set and maximum coverage prioritization ......... 82

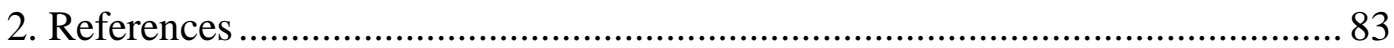





\section{Chapter I}

\section{General introduction}

Georg Barth ${ }^{1}$

${ }^{1}$ Environmental and Resource Economics, Georg-August-Universität Göttingen, 37077 Göttingen, Germany 


\section{Global biodiversity loss}

Largely because of rapidly growing reliance on industrialized forms of agriculture and fossil fuels, interlinked with population growth, human activities are drastically changing the Earth system (Millennium Ecosystem Assessment 2005; Rockström 2009). The inadvertent consequences of global environmental change are deleterious and potentially even disastrous for human well being and wildlife (Millennium Ecosystem Assessment 2005; Rockström et al. 2009).

Since the United Nations Conference on the Environment and Development held in 1992, biodiversity has become a key term in international environmental science and policy alike (Potthast 2007). Biodiversity refers collectively to the diversity of living organisms at all levels of biological organization, including the diversity within species, between species and of ecosystems (Gaston and Spicer 2004). The neologism biodiversity was coined by renowned biologists from 1986 to make the public at large aware of the global loss of this diversity and the related negative consequences (Potthast 2007).

Biodiversity plays a crucial role in ecosystem functions that are closely linked to human well being (Millennium Ecosystem Assessment 2005). The values derived by people from biodiversity include values arising from the direct use of environmental resources for food, biomass, recreation or health, and the indirect use of ecosystem functions such as flood control and nutrient cycles (Barbier et al. 1994). In contrast, non-use values of biodiversity refer to, among other things, the satisfaction a person may obtain from mere knowledge that a particular biological entity exists even though they may never use it (Barbier et al. 1994).

The extinction of species has been the most widely discussed impact of human activities on biodiversity (Gaston and Spicer 2004). To date, about 1.2 million species have been catalogued, and up to 9 million still await description (Mora et al. 2011). Overall current rates of species extinctions are about 1,000 times greater than recorded through Earth's geological history (Pimm et al. 2014). According to the International Union for the Conservation of Nature (IUCN), inter alia, some $13 \%$ of all birds, $26 \%$ of all mammals and $40 \%$ of all amphibians are threatened with extinction (IUCN 2015).

Principal causes of biodiversity loss include habitat loss and fragmentation, the introduction of non-native species, pollution, overexploitation of populations, and 
climate change (Gaston and Spicer 2004). Habitat loss, primarily associated with agricultural conversion, is the single largest direct cause of global biodiversity loss (Millennium Ecosystem Assessment 2005). Over half of the world's 14 biomes, representing broad habitat and vegetation types, have experienced a 20-50\% conversion to agricultural land use (Millennium Ecosystem Assessment 2005). In some high income countries agricultural area has begun to decline (Millennium Ecosystem Assessment 2005). However, roughly 10-20\% of remaining grassland and forestland is projected to be additionally converted to agriculture until 2050, mainly due to agricultural expansion in developing countries (Millennium Ecosystem Assessment 2005).

\section{Global protected areas}

Habitat destruction, mainly driven by agricultural expansion, will continue to be the main factor affecting biodiversity in terrestrial ecosystems well into the 21th century (Tilman et al. 2001; ten Brink et al. 2010). An effective conservation strategy must include a range of policies that mitigate habitat loss by establishing protected areas, closing yield gaps on underperforming lands, increasing cropping efficiency and reducing food waste (Foley et al. 2011).

A global system of effectively managed protected areas is an indispensable component of biodiversity conservation (Chape et al. 2008). A protected area is a location "especially dedicated to the protection and maintenance of biological diversity and of natural and associated cultural resources, and managed through legal and other effective means" (IUCN 1994). The degree to which protected areas preclude human activities depends on the requirements of biodiversity targets, as well as on compromises between protecting biodiversity and satisfying needs for extractive land use (Chape et al. 2008). As a general rule, when greater amounts of human activities are allowed, a narrower scope of biodiversity is preserved (Redford and Richer 1999).

As of April 2014 155,584 protected areas were officially listed, covering approximately 18.4 million $\mathrm{km}^{2}$, or $12.5 \%$ of the terrestrial area (Watson et al. 2014). In the context of the Convention on Biological Diversity (CBD), governments agreed to expand the global coverage of protected areas from the current $13 \%$ to $17 \%$ of land area by 2020 (Secretariat of the Convention on Biological Diversity 2014). The 
Convention on Biodiversity is one of the three Conventions emerging from the United Nations Conference on Environment and Development in 1992 (Secretariat of the Convention on Biological Diversity 2014). Its key objective is the conservation of biodiversity and the sustainable use of its components (Secretariat of the Convention on Biological Diversity 2014). Currently the Parties of the CBD comprise 193 countries and the European Union (Secretariat of the Convention on Biological Diversity 2014).

Recent growth in protected area coverage suggests that the percentage targets would be met at the current rate of growth (Secretariat of the Convention on Biological Diversity 2014). However, the CBD also recognizes that protected area systems should be ecologically representative, effectively managed, and specifically cover areas of particular importance for biodiversity (Secretariat of the Convention on Biological Diversity 2014). In contrast, most protected areas have been designated in an ad hoc manner, and not specifically for covering sites of high biodiversity value (Pressey 1994; Joppa and Pfaff 2009; Butchart et al. 2015). Even recent expansion of protected areas was largely inadequately targeted (Butchart et al. 2015). Overall, the world's protected areas tend to be biased towards lands with low economic value characterized by steep slope, large distance to roads and cities, high elevation and low agricultural suitability (Joppa and Pfaff 2009). In contrast, areas of high biodiversity value often coincide with areas more attractive to human occupation and use (see e.g. Scharlemann et al. 2004). It would require nearly doubling of current protected area coverage to achieve adequate representation of all countries, ecoregions, important sites, and vertebrate species (Butchart et al. 2015). Further, management effectiveness of many formally protected areas is deficient (Leverington et al. 2010). Although, money is not the only reason for deficient management effectiveness, the funds provided for global protected area management are, for the most part, insufficient (McCarthy et al. 2012). For example, current funds for managing existing protected areas in terrestrial sites of global avian conservation significance in lower income countries only cover $31 \%$ of funding needs for effective management (McCarthy et al. 2012). Despite making commitments associated with the CBD, some governments are even reducing their support through disproportionate funding cuts, reduction in staff and by ignoring their own policies (Watson et al. 2014). 


\section{Global biodiversity conservation priority areas}

Meeting the protected area targets of the Strategic Plan for Biodiversity 2011-2020 (Secretariat of the Convention on Biological Diversity 2014) will require newly established protected areas, much better targeted toward specific sites that contribute towards representing a wide range of species and ecoregions (Butchart et al. 2015). To maximize conservation outcomes, it is important to identify the best expansion areas at the global-scale, i.e. priority areas for global biodiversity conservation (Brooks et al. 2006). In this context, the field of spatial conservation prioritization has emerged in the early 1980s which can be defined as "the process of using spatial analysis of quantitative data to identify locations for conservation investments" (Wilson et al. 2009). Defining conservation priority areas involves normative assumptions about what ecological and socio-economic considerations are important for prioritization (see Ferrier and Wintle 2009).

Identifying global priority areas can boost biodiversity conservation efforts in several ways. First, recent studies have shown that global-scale conservation planning and international coordination is vital for reaching high conservation outcomes (e.g. Kark et al. 2009; Dobrovolski et al. 2014). Second, much of the world's biodiversity is found in the tropics, where countries regularly lack the resources and incentives to protect biological resources whose benefits often flow beyond national borders (Johnson 1995). Therefore, international investments are required, and multinational agencies and international non-governmental organizations seek advice where to invest limited conservation resources most effectively (Johnson 1995; Halpern et al. 2006). A deliberate and well-documented identification of priority areas can make conservation decision making processes more transparent, and enhance the scientific credibility of conservation decisions (Johnson 1995). In turn, this will appeal to conservation funders since they want to see their resources targeted on strategic and well-justified priorities (Johnson 1995). Finally, identification of priority areas can be used as a benchmark against which actual expansion of protected areas can be compared (Butchart et al. 2015). As priorities are identified with increasing geographic specificity, participation of relevant stakeholder groups will become more important (Johnson 1995). Obviously, suggesting priority areas for protected area expansion is the first step of a political decision making process in which opponents and proponents for establishment of a protected area participate (Dixon and Sherman 1991). 
A key objective of spatial conservation prioritization is to select priority areas that achieve intended conservation targets (e.g. protect 10\% of each species' habitat), while aiming to minimize, as far as possible, conservation costs (Moilanen et al. 2009). As such, spatial conservation prioritization is closely related to costeffectiveness analysis, a form of economic analysis that compares the relative costs and outcomes (effects) of alternative projects, decisions, or policies (Moran et al. 1996; Naidoo et al. 2006). The cost-effectiveness of a project option (e.g. a proposed protected area) is calculated by dividing the costs of the option by a quantified measure of the physical effect, such as species covered (Moran et al. 1996). As conservation costs at the global-scale vary by several orders of magnitude, information on the spatial heterogeneity of conservation costs is an indispensable component for identifying cost-effective priority areas for conservation (Balmford et al. 2003; Naidoo and Iwamura 2007).

\section{Integrating economic costs into global conservation prioritization}

Costs of protected areas include budgetary outlays associated with establishing and managing protected areas, which are generally paid for by governmental and nongovernmental conservation organizations (Naidoo et al. 2006). Management costs of protected areas include administration and staff costs, as well as maintenance costs for roads and facilities (Dixon and Sherman 1991). Management may also involve monitoring and research programs to evaluate the effectiveness of conservation actions (Dixon and Sherman 1991). Further, effective management may also require enforcement of regulations and/or education programs for nearby residents and tourists (Dixon and Sherman 1991). Finally, if an area is not already owned by the government or conservation agency, there may also be costs to acquire title to it (Dixon and Sherman 1991).

Another main type of protected area costs is the opportunity costs which represent the benefits that might have been gained from an alternative use of the area, including extraction of timber, mineral raw materials, and agricultural products (Dixon and Sherman 1991). These costs include not only the benefits currently obtained from the site but also those that could have been obtained in the future (Dixon and Sherman 1991). As agriculture is the dominant form of anthropogenic land use that competes with natural habitats (Leff et al. 2004), opportunity costs of 
protected areas are most commonly associated with agricultural land use forgone. Agriculture can raise rural welfare through income from agricultural outputs, and by increasing income in agriculture related services, transportation, and processing (Chomitz 2007). Furthermore, consumer welfare can be raised due to increased food availability and lower food prices (Chomitz 2007). Opportunity costs from agriculture vary substantially between places and range from near zero to thousands of dollars a hectare (Chomitz 2007). Key factors influencing opportunity costs comprise soil and climate conditions, scale of operation, inputs and technology, distance from market, spatial and temporal variation in prices of inputs and outputs, access to credit and assets, and land tenure (Chomitz 2007). Further, costs of conversion to agriculture, and one-off harvesting of commercially valuable timber can affect opportunity costs (Chomitz 2007).

It is regularly discussed that the opportunity costs of protected areas could also be imposed on the beneficiaries of conservation by implementing compensation payments for local downsides generated by protected areas (see e.g. Balmford and Whitten 2003). However, in particular for public land conservation, much land is currently placed under conservation rule without compensating local residents for their opportunity costs (Balmford \& Whitten 2003; McCarthy et al. 2012).

While precise data on the spatial distribution of conservation costs are still scarce, global priority analyses have relied on rough approximations of conservation costs (Armsworth et al. 2014). Global-scale conservation prioritization analyses that have explicitly included conservation costs fall into two main groups. First, studies generate priorities subject to cost-effectiveness in terms of management costs accruing to conservation organizations (Balmford et al. 2003; Wilson et al. 2006; Bode et al. 2008; Loyola et al. 2009; Underwood et al. 2008; Waldron et al. 2013). The analyses estimate spatial heterogeneity of protected area management costs worldwide based on gross national income, purchasing power parity, as well as assumptions about protected area size (Balmford et al. 2003). A second group of studies includes data on agricultural opportunity costs of protected areas (Naidoo and Iwamura 2007; Carwardine et al. 2008; Iwamura et al. 2010; Freudenberger et al. 2013; Dobrovolski et al. 2014; Venter et al. 2014). The choice of the cost type considered (i.e. management costs or agricultural opportunity costs) has important normative implications on whose costs have standing in the prioritization process (see Balmford and Whitten 2003; Zerbe and Bellas 2006). Focusing on costs to 
single interest groups may shift priorities towards areas with high costs for other groups which may compromise the long-term success of conservation (Ban and Klein 2009; Adams et al. 2010). However, only one global prioritization analysis has included both management and opportunity costs by combining both cost types into a single indicator (Wilson et al. 2011).

To account for agricultural opportunity cost, three different indicators have been proposed (Naidoo and Iwamura 2007; Carwardine et al. 2008; Dobrovolski et al. 2014). The different opportunity cost indicators are all based on information of biophysical land suitability for agricultural (Naidoo and Iwamura 2007; Carwardine et al. 2008; Dobrovolski et al. 2014). However, each indicator uses largely different sets of assumptions associated with the size and location of agricultural land, land users' choices of crops and agricultural input levels, and relative crop prices (Naidoo and Iwamura 2007; Carwardine et al. 2008; Dobrovolski et al. 2014).

\section{Aim of thesis}

Although the importance of management and agricultural opportunity cost data in the context of global-scale conservation prioritization is widely recognized, there is still no study that tests how sensitive prioritization outcomes are to normative and methodological degrees of freedom associated with the consideration of conservation costs. This knowledge gap is most unfortunate as small-scale studies suggest that prioritization outcomes are typically sensitive towards the choice of the cost indicator (Ban and Klein 2009; Adams et al. 2010; Weeks et al. 2010).

The general aim of this thesis is to improve the transparency of cost-effective prioritization at the global-scale and to assess the robustness of prioritization solutions by reassessing priorities under alternative methodological and normative assumptions with regard to conservation costs. The thesis focuses on terrestrial mammals as a model because they are a flagship group to represent biodiversity conservation at large, and thus mammals are commonly used as a target group for global prioritization analyses (e.g. Ceballos et al. 2005; Carwardine et al. 2008; Dobrovolski et al. 2014).

Specifically, this thesis addresses three interrelated issues. In chapter II, it is investigated how focusing on management costs or agricultural opportunity costs 
alone differently affects the selection of priority areas for global biodiversity conservation. First, the spatial correlation between indicators of management costs and agricultural opportunity costs is explored. Subsequently, three conservation prioritization scenarios are compared, based respectively on management costs, agricultural opportunity costs, and a scenario combining both management and opportunity costs into a single cost indicator.

In chapter III, three indicators of agricultural opportunity costs used in previous global prioritization analyses are considered: (i) past agricultural revenues (Naidoo and Iwamura 2007), (ii) agricultural production during the $21^{\text {th }}$ century (Dobrovolski et al. 2014), and (iii) maximum potential agricultural revenues (Carwardine et al. 2008). First, the spatial correlation between the indicators is explored. Subsequently, three conservation prioritization scenarios are compared, each using a different indicator of agricultural opportunity costs. Finally, the prioritization outcomes are compared with regard to spatial configuration and cost-effectiveness.

In chapter IV, the hypothesis is tested that the majority of spatial differences between opportunity costs indicators used in previous global-scale prioritization analyses is caused by divergent scenarios of agricultural extent. This is achieved by remapping agricultural opportunity costs indictors, holding all other things - except for agricultural extent - constant. Specifically opportunity costs indicators are mapped assuming (i) past agricultural extent, (ii) agricultural extent according to possible pathways of agricultural expansion during the $21^{\text {th }}$ century, and (iii) extent of all land suitable for agriculture according to biophysical land suitability.

\section{References}

Adams, V.M., Pressey, R.L., Naidoo, R. (2010). Opportunity costs: Who really pays for conservation? Biological Conservation 143:439-448. doi:10.1016/j.biocon.2009.11.011.

Armsworth, P.R. (2014). Inclusion of costs in conservation planning depends on limited datasets and hopeful assumptions. Annals of the New York Academy of Sciences 1322: 61-76. doi:10.1111/nyas.12455.

Balmford, A., Gaston, K.J., Blyth, S., James, A., Kapos, V. (2003). Global variation in terrestrial conservation costs, conservation benefits, and unmet 
conservation needs. Proceedings of the National Academy of Sciences of the United States of America 100: 1046-1050. doi:10.1073/pnas.0236945100.

Balmford, A., Whitten, T. (2003). Who should pay for tropical conservation, and how could the costs be met? Oryx 37: 238-250. doi:10.1017/S0030605303000413.

Ban, N.C., Klein, C.J. (2009). Spatial socioeconomic data as a cost in systematic marine conservation planning. Conservation Letters 2: 206-215. doi:10.1111/j.1755-263X.2009.00071.x.

Barbier, E.B., Burgess, J.C., Folke, C. (1994). Paradise lost? The ecological economics of biodiversity. London: Earthscan.

Bode, M., Wilson, K.A., Brooks, T.M., Turner, W.R., Mittermeier, R.A, McBride, M.F., Underwood, E.C., Possingham, H.P. (2008). Cost-effective global conservation spending is robust to taxonomic group. Proceedings of the National Academy of Sciences of the United States of America 105: 6498-6501. doi:10.1073/pnas.0710705105.

Brooks, T.M., Mittermeier, R.A., da Fonseca, G.A.B., Gerlach, J., Hoffmann, M., Lamoreux, J.F., Mittermeier, C.G., Pilgrim, J.D., Rodrigues, A.S.L. (2006). Global biodiversity conservation priorities. Science 313, 58-61. doi:10.1126/science.1127609.

Butchart, S.H.M., Clarke, M., Smith, R.J., Sykes, R.E., Scharlemann, J.P.W., Harfoot, M., Buchanan, G.M., Angulo, A., Balmford, A., Bertzky, B., Brooks, T.M., Carpenter, K.E., Comeros-Raynal, M.T., Cornell, J., Ficetola, G.F., Fishpool, L.D.C., Fuller, R. a., Geldmann, J., Harwell, H., HiltonTaylor, C., Hoffmann, M., Joolia, A., Joppa, L., Kingston, N., May, I., Milam, A., Polidoro, B., Ralph, G., Richman, N., Rondinini, C., Segan, D., Skolnik, B., Spalding, M., Stuart, S.N., Symes, A., Taylor, J., Visconti, P., Watson, J., Wood, L., Burgess, N.D. (2015). Shortfalls and Solutions for Meeting National and Global Conservation Area Targets. Conservation Letters 8: 329-337. doi:10.1111/conl.12158.

Carwardine, J., Wilson, K.A., Ceballos, G., Ehrlich, P.R., Naidoo, R., Iwamura, T., Hajkowicz, S.A., Possingham, H.P. (2008). Cost-effective priorities for global mammal conservation. Proceedings of the National Academy of 
Sciences of the United States of America 105: 11446-11450. doi:10.1073/pnas.0707157105.

Ceballos, G., Ehrlich, P.R., Soberón, J., Salazar, I., Fay, J.P. (2005). Global mammal conservation: what must we manage? Science 309:603-607. doi:10.1126/science.1114015.

Chape, S., Spalding, M.D., Jenkins, M.D. (eds.) (2008). The World's protected areas: status, values, and prospects in the twenty-first century. Berkeley: University California Press.

Chomitz, K.M. (2007). At loggerheads?: agricultural expansion, poverty reduction, and environment in the tropical forests. Washington DC: The World Bank.

Dixon, J.A., Sherman, P.B. (1991). Economics of Protected Areas: A New Look at Benefits and Costs. London: Earthscan.

Dobrovolski, R., Loyola, R., D.A. Fonseca, G.A.B., Diniz-Filho, J.A.F., Araujo, M.B. (2014). Globalizing Conservation Efforts to Save Species and Enhance Food Production. BioScience 64: 539-545. doi:10.1093/biosci/biu064.

Dobrovolski, R., Loyola, R.D., Guilhaumon, F., Gouveia, S.F., Diniz-Filho, J.A.F. (2013). Global agricultural expansion and carnivore conservation biogeography. Biological Conservation 165: 162-170. doi:10.1016/j.biocon.2013.06.004.

Fierier, S., Wintle, B.A. (2009). Quantitative Approaches to Spatial Conservation Prioritization: Matching the Solution to the Need. In Moilanen, A., Wilson, K.A., Possingham, H.P. (eds.). Spatial conservation prioritisation: quantitative methods and computational tools. Oxford: Oxford University Press. pp. 1-16.

Foley, J.A., Ramankutty, N., Brauman, K.A., Cassidy, E.S., Gerber, J.S., Johnston, M., Mueller, N.D., O’Connell, C., Ray, D.K., West, P.C., Balzer, C., Bennett, E.M., Carpenter, S.R., Hill, J., Monfreda, C., Polasky, S., Rockström, J., Sheehan, J., Siebert, S., Tilman, D., Zaks, D.P.M. (2011). Solutions for a cultivated planet. Nature 478, 337-42. doi:10.1038/nature10452

Freudenberger, L., Hobson, P., Schluck, M., Kreft, S., Vohland, K., Sommer, H., Reichle, S., Nowicki, C., Barthlott, W., Ibisch, P.L. (2013). Nature 
conservation: priority-setting needs a global change. Biodiversity and Conservation 22:1255-1281.doi:10.1007/s10531-012-0428-6.

Gaston, K.J., Spicer, J.I. (2004). Biodiversity: an introduction , second edition. Malden: Blackwell Publishing.

Halpern, B.S., Pyke, C.R., Fox, H.E., Chris Haney, J., Schlaepfer, M.A., Zaradic, P. (2006). Gaps and Mismatches between Global Conservation Priorities and Spending. Conservation Biology 20: 56-64. doi:10.1111/j.1523-1739.2005.00258.x.

IUCN (1994) Guidelines for Protected Area Management Categories. Gland: IUCN.

IUCN (2015). The IUCN Red List of Threatened Species. Version 2015-3. Retrieved from URL: http://www.iucnredlist.org (accessed 09.09.2015).

Iwamura, T., Wilson, K.A., Venter, O., Possingham, H.P. (2010). A climatic stability approach to prioritizing global conservation investments. PLoS One 5: e15103. doi:10.1371/journal.pone.0015103.

Johnson, N. (1995). Biodiversity in the Balance: Approaches to Setting Geographic conservation Priorities. Landover: Corporate Press.

Joppa, L.N., Pfaff, A. (2009). High and Far: Biases in the Location of Protected Areas. PLoS One 4: e8273. doi:10.1371/journal.pone.0008273.

Kark, S., Levin, N., Grantham, H.S., Possingham, H.P. (2009). Between-country collaboration and consideration of costs increase conservation planning efficiency in the Mediterranean Basin. Proceedings of the National Academy of Sciences of the United States of America 106: 15368-15373. doi:10.1073/pnas.0901001106.

Leff, B., Ramankutty, N., Foley, J.A. (2004). Geographic distribution of major crops across the world. Global Biogeochemical Cycles 18: GB1009. doi:10.1029/2003GB002108.

Leverington, F., Costa, K.L., Pavese, H., Lisle, A., Hockings, M. (2010). A Global Analysis of Protected Area Management Effectiveness. Environmental Management 46: 685-698. doi:10.1007/s00267-010-9564-5.

Loyola, R.D., Oliveira-Santos, L.G.R., Almeida-Neto, M., Nogueira, D.M., Kubota, U., Diniz-Filho, J.A.F., Lewinsohn, T.M. (2009). Integrating economic costs 
and biological traits into global conservation priorities for carnivores. PLoS One 4: e6807. doi:10.1371/journal.pone.0006807.

McCarthy, D.P., Donald, P.F., Scharlemann, J.P.W., Buchanan, G.M., Balmford, A., Green, J.M.H., Bennun, L. a, Burgess, N.D., Fishpool, L.D.C., Garnett, S.T., Leonard, D.L., Maloney, R.F., Morling, P., Schaefer, H.M., Symes, A., Wiedenfeld, D.A., Butchart, S.H.M. (2012). Financial costs of meeting global biodiversity conservation targets: current spending and unmet needs. Science 338: 946-949. doi:10.1126/science.1229803.

Millennium Ecosystem Assessment (2005). Ecosystems and human well-being: Biodiversity Synthesis. Washington DC: World Resources Institute.

Moilanen, A ., Possingham, H.P., Polasky, S. (2009). A Mathematical Classification of Conservation Prioritization Problems. In Moilanen, A., Wilson, K.A., Possingham, H.P. (eds.). Spatial conservation prioritisation: quantitative methods and computational tools. Oxford: Oxford University Press. pp. $28-42$.

Moilanen, A., Arponen, A. (2011). Setting conservation targets under budgetary constraints. Biological Conservation 144: 650-653. doi:10.1016/j.biocon.2010.09.006.

Mora, C., Tittensor, D.P., Adl, S., Simpson, A.G.B., Worm, B. (2011). How Many Species Are There on Earth and in the Ocean? PLoS Biology 9: e1001127. doi:10.1371/journal.pbio.1001127.

Moran, D., Pearce, D., Wendelaar, A. (1996). Global biodiversity priorities A costeffectiveness index for investments. Global Environmental Change 6: 103-119. doi:10.1016/0959-3780(95)00017-8.

Naidoo, R., Balmford, A., Ferraro, P.J., Polasky, S., Ricketts, T.H., Rouget, M. (2006). Integrating economic costs into conservation planning. Trends in Ecology \& Evolution 21: 681-687. doi:10.1016/j.tree.2006.10.003.

Naidoo, R., Iwamura, T. (2007). Global-scale mapping of economic benefits from agricultural lands: Implications for conservation priorities. Biological Conservation 140: 40-49. doi:10.1016/j.biocon.2007.07.025.

Pimm, S.L., Jenkins, C.N., Abell, R., Brooks, T.M., Gittleman, J.L., Joppa, L.N., Raven, P.H., Roberts, C.M., Sexton, J.O. (2014). The biodiversity of species 
and their rates of extinction, distribution, and protection. Science 344: 987- 997. doi:10.1126/science.1246752.

Potthast, T. (2007)."Biodiversität" und die Praxisrelevanz theoretischer Grundlagenreflexionen im Naturschutz. In Potthast, T., (ed.) Biodiversität Schlüsselbegriff des Naturschutzes im 21. Jahrhundert. Bonn: Bundesamt für Naturschutz.

Pressey, R.L. (1994). Ad Hoc Reservations: Forward or Backward Steps in Developing Representative Reserve Systems. Conservation Biology 8: 622-668. doi:10.1046/j.1523-1739.1994.08030662.x.

Redford, K.H., Richter, B.D. (1999). Conservation of Biodiversity in a World of Use. Conservation Biology 13: 1246-1256. 10.1046/j.1523-1739.1999.97463.x.

Rockström, J., Steffen, W., Noone, K., Persson, A., Chapin, F.S., Lambin, E.F., Lenton, T.M., Scheffer, M., Folke, C., Schellnhuber, H.J., Nykvist, B., de Wit, C.A., Hughes, T., van der Leeuw, S., Rodhe, H., Sorlin, S., Snyder, P.K., Costanza, R., Svedin, U., Falkenmark, M., Karlberg, L., Corell, R.W., Fabry, V.J., Hansen, J., Walker, B., Liverman, D., Richardson, K., Crutzen, P., Foley, J.A. (2009). A safe operating space for humanity. Nature 461: 472-475. doi:10.1038/461472a.

Scharlemann, J.P.W., Green, R.E., Balmford, A. (2004). Land-use trends in Endemic Bird Areas: global expansion of agriculture in areas of high conservation value. Global Change Biology 10: 2046-2051. doi:10.1111/j.1365-2486.2004.00860.x.

Secretariat of the Convention on Biological Diversity (2014) Global Biodiversity Outlook 4. Montréal.

ten Brink, B.T., van der Esch, S., Kram, T., van Oorschot, M., Alkemade, R., Ahrens, R., Bakkes, M., Bakkes, J., van der Berg, M., Christensen, V., Jansen J., Jeuken, M., Lucas, P., Manders, T., van Meijl, H., Stehfest, E., Tabeau, A., van. Vuuren, D., Wilting, H. (2010). Rethinking Global Biodiversity Strategies. The Hague: PBL - Netherlands Environmental Assessment Agency. 
Tilman, D., Fargione, J., Wolff, B., D’Antonio, C. (2001). Forecasting agriculturally driven global environmental change. Science 292: 281-285. doi10.1126/science.1057544.

Underwood, E.C., Shaw, M.R., Wilson, K.A., Kareiva, P., Klausmeyer, K.R., McBride, M.F., Bode, M., Morrison, S. a, Hoekstra, J.M., Possingham, H.P. (2008). Protecting biodiversity when money matters: maximizing return on investment. PLoS One 3: e1515. doi:10.1371/journal.pone.0001515.

Venter, O., Fuller, R.A., Segan, D.B., Carwardine, J., Brooks, T., Butchart, S.H.M., Di Marco, M., Iwamura, T., Joseph, L., O’Grady, D., Possingham, H.P., Rondinini, C., Smith, R.J., Venter, M., Watson, J.E.M. (2014). Targeting Global Protected Area Expansion for Imperiled Biodiversity. PLoS Biology 12: e1001891. doi:10.1371/journal.pbio.1001891.

Waldron, A., Mooers, A. (2013). Targeting global conservation funding to limit immediate biodiversity declines. Proceedings of the National Academy of Sciences of the United States of America 110: 12144-12148. doi:10.5061/dryad.p69t1.

Watson, J.E.M., Dudley, N., Segan, D.B., Hockings, M. (2014). The performance and potential of protected areas. Nature 515: 67-73. doi:10.1038/nature13947.

Weeks, R., Russ, G.R., Bucol, A.A., Alcala, A.C. (2010). Shortcuts for marine conservation planning: The effectiveness of socioeconomic data surrogates. Biological Conservation 143: 1236-1244. doi:10.1016/j.biocon.2010.02.031.

Wilson, K.A., Cabeza, M.M. Klein, C.J. (2009). Fundamental Concepts of Spatial Conservation Prioritization. In Moilanen, A., Wilson, K.A., Possingham, H.P. (eds.). Spatial conservation prioritisation: quantitative methods and computational tools. Oxford: Oxford University Press. pp. 16-27.

Wilson, K.A., Evans, M.C., Di Marco, M., Green, D.C., Boitani, L., Possingham, H.P., Chiozza, F., Rondinini, C. (2011). Prioritizing conservation investments for mammal species globally. Philosophical Transactions of the Royal Society B: Biological Sciences 366: 2670-2680. doi:10.1098/rstb.2011.0108.

Zerbe R.O., Bellas, A.S. (2006). A primer for benefit-cost analysis. Cheltenham: Edward Elgar Publishing. 


\section{Chapter II}

Cost-effective priority areas for global biodiversity conservation: Trade-offs between management and agricultural opportunity costs

Georg Barth ${ }^{1}$, Jan Barkmann ${ }^{1,2}$, Carsten Meyer $^{3}$, Holger Kreft $^{3}$, Rainer Marggraf ${ }^{1}$

${ }^{1}$ Environmental and Resource Economics, Georg-August-Universität Göttingen, 37077 Göttingen, Germany; ${ }^{2}$ Risk and Sustainability Sciences, Hochschule Darmstadt - University of Applied Sciences, 64295 Darmstadt, Germany; ${ }^{3}$ Biodiversity, Macroecology and Conservation Biogeography, Georg-August-Universität Göttingen, 37077 Göttingen, Germany 


\begin{abstract}
Conservation costs need to be considered when identifying global priority areas for biodiversity conservation. Previous prioritization analyses either accounted for management costs of conservation paid by conservation organizations, or for opportunity costs to land users associated with forgone agricultural production. Considering only one cost type may be problematic if prioritizations are sensitive to diverging cost patterns, but the sensitivity of identified priority areas to different cost types remains unclear. Here, we investigated how the spatial patters of management costs and agricultural opportunity costs differently affect the selection of priority areas for global mammal conservation. Our results demonstrate that the choice of the cost indicator plays a strong role for the selection of priority areas. Either accounting for management costs or opportunity costs alone results in spatial shifts of priority areas as well as in substantial trade-offs between these costs. The trade-offs were significantly mitigated under a prioritization scenario in which a combined cost indicator was used. Our results highlight that focusing either on management or opportunity costs alone results in undue cost burdens, respectively, to conservation organizations or local land users that could compromise the success of conservation. We conclude that global prioritization analyses should explicitly consider alternative cost scenarios to ensure overall cost-effective selection of sites, while at the same time clearly identifying trade-offs between costs accruing to different stakeholder groups. This may lead to overall more economically feasible and more equitable prioritization outcomes.
\end{abstract}

\title{
1. Introduction
}

A representative and effectively managed system of global protected areas is an important requirement for biodiversity conservation (Chape et al. 2008; Leverington et al. 2010). However, the current system of protected areas is far from complete with many species and ecosystems not adequately represented (Butchart et al. 2015) and partially low management effectiveness (Leverington et al. 2010). Under the Convention on Biological Diversity (CBD), governments committed to ensure management effectiveness and to expand the global protected area coverage from the current $13 \%$ to $17 \%$ of land area by 2020 (Convention on Biological Diversity 2011). To maximize the biodiversity benefits associated with this plan, it is crucial to target 
the most important sites for biodiversity that provide representative coverage of species (Butchart et al. 2015).

Protected area establishment and management carries costs, denoting everything that must be given up to establish and maintain protected areas (Naidoo et al. 2006). These costs include opportunity costs to local communities in the form of lost revenue or development opportunities if land use in protected areas becomes more restricted (Naidoo et al. 2006). Costs also include the direct financial costs that accrue to governmental and non-governmental conservation organizations in the form of budgetary outlays for managing the protected area and/or the monetary compensation paid to land users (Naidoo et al. 2006). At the global-scale, however, much land is currently placed under conservation rule without compensating land users for their opportunity costs (Bruner et al. 2004). Thus, the choice of a cost indicator in conservation planning is not a purely methodological matter; it implies a normative choice on whose costs have standing in the prioritization process (see Zerbe and Bellas 2006).

Both direct financial and opportunity costs are major economic barriers towards implementing a representative and effectively managed global system of protected areas (Joppa and Pfaff 2009; McCarthy et al. 2012). Therefore, it is crucial that priority areas for conservation are cost-effective, either because they minimize the costs for meeting intended conservation targets or because they maximize the achievement of targets with limited resources (Naidoo et al. 2006).

Conservation costs of protected areas vary by several orders of magnitude, e.g. depending on protected area size, local economic development, and agricultural land potential (Balmford et al. 2003; Naidoo and Iwamura 2007). Accordingly, improving cost-effectiveness in global conservation prioritization requires spatially explicit and detailed information on conservation costs (Balmford et al. 2003; Naidoo and Iwamura 2007).

Global conservation prioritization analyses that explicitly considered conservation costs often either included indicators of management costs of protected areas (Balmford et al. 2003; Wilson et al. 2006; Bode et al. 2008; Loyola et al. 2009; Underwood et al. 2008; Waldron et al. 2013) or indicators of opportunity costs to land users associated with forgone agricultural production (Naidoo and Iwamura 2007; Carwardine et al. 2008; Iwamura et al. 2010; Freudenberger et al. 2013; 
Dobrovolski et al. 2014; Venter et al. 2014). Only one global prioritization analyses has included both management costs and opportunity costs combining both measures into a single cost indicator (Wilson et al. 2011). Considering only one cost type may be problematic if prioritizations are sensitive to diverging cost patterns (Ban and Klein et al. 2009; Adams et al. 2010), but the sensitivity of identified global priority areas to different cost types remains unknown.

As direct management costs predominantly accrue to governmental and nongovernmental conservation organizations and opportunity costs primarily to land owners/land users (Balmford and Whitten 2003; Naidoo et al. 2006), the exclusive consideration of one cost type in conservation planning may result in an unintended shift of conservation costs to only one main group of stakeholders (see e.g. Ban and Klein 2009; Adams et al. 2010). In addition to fundamental issues of environmental justice, this can decrease the overall effectiveness as well as the long-term success of conservation (see e.g. Adams et al. 2010). Thus, conservation planning should account for costs borne by all groups of stakeholders (Naidoo et al. 2006; Ban and Klein 2009; Adams et al. 2010).

The most direct way to consider cost to all groups of stakeholders is to use the sum of the respective costs. This way, the overall cost can be minimized, but differential effects among different stakeholder groups remain implicit (Ban and Klein et al. 2009). In contrast, including each cost indicator separately in comparative prioritization analyses makes spatially and socially relevant trade-offs between stakeholder groups explicit (see e.g. Cameron et al. 2008; Ban and Klein 2009; Adams et al. 2010). This approach does not lead to a single solution that includes all costs (Ban and Klein 2009), but the single-cost scenarios can additionally be compared to a scenario that combines several cost indicators.

This contribution provides the first detailed analysis of trade-offs between minimizing management and agricultural opportunity costs in global-scale conservation prioritization. First, we investigated the spatial relationship between protected area management costs and agricultural opportunity costs at the globalscale based on cost indicators used in previous prioritization analyses. We evaluated how using each cost type in a separate conservation prioritization scenario influences the spatial configuration and costs of resulting priority areas. We additionally compared the results of these separate costs scenarios to a prioritization scenario that 
used a combined indicator including both management and agricultural opportunity costs. We focus on terrestrial mammals as a model because they are considered a flagship group to leverage support for biodiversity conservation, and are frequently used as a target group for global conservation prioritization (e.g. Ceballos et al. 2005; Carwardine et al. 2008; Wilson et al. 2011).

\section{Methods}

\subsection{Species and economic data}

All analyses were based on an equal-area grid of 12,364 km² (approximately $111 \mathrm{~km}$ $\mathrm{x} 111 \mathrm{~km}$ at the equator) to delineate areas for conservation prioritization. to prioritize areas for conservation. The grid layer was clipped to the spatial extent of the terrestrial area. Additionally, 1,166 of 13,894 grid cells for which species distribution or cost data were unavailable were omitted resulting into 12,728 cells for our analyses. We established species presence/absence data for each grid cell by overlaying the grid with expert-opinion range maps that approximate the extent of occurrence for 5,230 mammal species (IUCN 2012).

We employ a model for estimating protected area management costs that uses protected area size, gross national income per $\mathrm{km}^{2}$ and national purchasing power parity of the constituent country as input data (Balmford et al. 2003). We obtained data on gross national income from the World Bank Data Catalog for the year 2010 (World Bank 2013) and used data for the years 2008 to 2012 from the CIA World Factbook (CIA 2013) for countries not covered by the World Bank dataset. Data on national purchasing power parity for 2010 was obtained from the World Bank Data Catalog and the World Economic Outlook Database (International Monetary Fund 2010; World Bank 2013). Since it is not possible to predict the actual shape and size of potential new protected areas (Bruner et al. 2004), we used the average size of current protected areas (IUCN Categories I-IV; IUCN and UNEP WCMC 2012) within a given ecoregion (Olson and Dinerstein 1998) as a proxy (e.g. Moore et al. 2004; Wilson et al. 2006; Bode et al. 2008). For 153 of 827 ecoregions, protected area data were not available. In these cases, we used the average protected area size of a given biome/realm combination Olson and Dinerstein 1998). In the management cost model, each grid cell was assigned gross national income, purchasing power parity data, and the average protected area size of the respective ecoregion. For grid 
cells intersecting with multiple countries and/or ecoregions, area-weighted averages were used (Bode et al. 2008).

Agricultural income from protected areas was assumed to be zero. We used agricultural revenue (income before costs of production) forgone as a proxy for opportunity costs to local land users (Naidoo and Iwamura 2007), regarding agriculture as the dominant land-use competing with conservation (Hosonuma et al. 2012). Maximum potential revenues were estimated by the maximum of the potential crop and livestock yields per unit area based on biophysical land suitability, multiplied by the producer price (Naidoo and Iwamura 2007; Carwardine et al. 2008). Maximum potential revenues overestimate actual agricultural extent because they assume that all land suitable for agriculture is converted, and do not consider existing knowledge on the socio-economic drivers of global land use change such as population growth or availability of transport and infrastructure (e.g. IMAGE-Team 2001). To account for such factors, we weighted the maximum potential agricultural gross rents of a given grid cell with forecasted land use until the end of the $21 \mathrm{st}$ century (Dobrovolski et al. 2013).

\subsection{Conservation prioritization analyses}

We analyzed mammal conservation priorities across four prioritization scenarios:

(i) The management-costs-scenario, which prioritized cells according to management costs,

(ii) the agricultural-opportunity-costs-scenario, which prioritized cells according to agricultural opportunity costs,

(iii) the combined-costs-scenario, which prioritized cells according to the sum of management costs and agricultural opportunity costs, and

(vi) the area-minimization-scenario, in which costs equaled grid cell area. This scenario was generated in order to compare our results with a prioritization analyses that seeks to minimize overall protected area size required to achieve conservation targets, i.e., without explicitly accounting for regional cost differences.

For each prioritization scenario, we considered two commonly used prioritization approaches, minimum set prioritization and maximum coverage prioritization (Wilson et al. 2009). The objective of minimum set prioritization is to select a set of 
areas that must meet intended conservation targets (e.g. cover 10\% of each target species range) while minimizing, as far as possible, conservation costs (Wilson et al. 2009). To conduct the minimum set prioritization approach, we used the MARXAN software (Ball et al. 2009) which is specifically designated to apply this prioritization approach. For each prioritization scenario, we selected the lowest-cost solution across 250 MARXAN runs. To account for current protected areas, we "locked" 66 grid cells with more than $50 \%$ current protected area coverage in any prioritization solution (IUCN categories I-IV; IUCN and UNEP-WCMC 2012). We defined that the conservation objective of the prioritization was to cover a fraction of the range size of each considered species, and scaled the targets to a given species' global range size (Rodrigues et al. 2004). We gave the most widespread species (red fox, Vulpes vulpes) a conservation target of $1 \%$ of its global range size and a target of $100 \%$ to species occurring only in one grid cell. We scaled the conservation targets for the remaining species between these two extremes using a power function $\left(\right.$ target $_{\text {species } i}=$ range $\left._{\text {species } i}^{0.47}\right)$ such that targets were higher for range-restricted species.

The objective of the maximum coverage prioritization approach is to select priority areas that maximize the achievement of conservation targets as far as possible, while given that a predetermined upper cost limit must not be exceeded (Wilson et al. 2009). With very small resources (i.e. a small upper cost limit), it is a mathematical necessity that one can only select priority areas that have very small cost per unit of conservation value covered (Moilanen and Arponen 2011). When the upper cost limit is increased, more priority areas are selected, but, always the next priority area that is selected is the one that results in the smallest costs per unit of conservation value covered (Moilanen and Arponen 2011). Accordingly, priority areas are selected in increasing order of marginal costs when maximum coverage prioritization is applied (Moilanen and Arponen et al. 2011). Here, we used mammal range equivalents as an indicator of conservation value (Kier and Barthlott 2001). We attributed 1 range equivalent to a grid cell when $100 \%$ of a given species' distribution area fell into the grid cell (Kier and Barthlott 2001). When $50 \%$ of a species' distribution area fell into a grid cell, we attributed 0.5 range equivalents to the planning and so forth. Finally, we calculated the sum of the range equivalents for all species within a given grid cell. For each grid cell previously selected as a priority area under the minimum set prioritization analysis, we determined the marginal costs 
of conservation in terms of the ratio of costs to the sum of mammal range equivalents covered. Depending on the prioritization scenario, marginal cost were determined according management costs, agricultural opportunity costs, combined costs, or grid cell area. To apply the maximum coverage approach, we selected the priority areas stepwise and in increasing order of marginal costs.

\subsection{Comparison of cost data and prioritization scenarios}

We tested the Spearman rank correlation between management costs, agricultural opportunity costs, and combined costs across all grid cells. To account for spatial autocorrelation in the data, we corrected the degrees of freedom to assess the significance of the correlations (Clifford et al. 1989).

To explore the sensitivity of the minimum set prioritization approach towards the choice of the cost scenario, we first determined the spatial overlap across prioritization scenarios by mapping the number of scenarios each grid cell was selected as a priority area. Further, across all priority areas of a given prioritization scenario, we calculated the sum of management costs, agricultural opportunity costs, and combined costs.

To explore the sensitivity of the maximum coverage approach towards the choice of the cost scenario, we produced a set of conservation value - cost curves, that represent the amount of mammal range equivalents covered as a function of upper cost limits. Each set contained three graphs that represent cost limits according to, respectively, management costs, agricultural opportunity costs, and combined costs.

\section{Results}

Spatial patterns of management costs and agricultural opportunity costs were dissimilar and highly variable spatially (Fig. 1). Management costs were only weakly positively correlated with agricultural opportunity costs across grid cells (Spearman rank correlation, corrected for spatial autocorrelation $r=0.20 ; p<0.001)$. Combined costs were highly positively correlated with agricultural opportunity costs $(r=0.91$; $\mathrm{p}<0.001)$ while management expenses were moderately positively correlated with combined costs $(r=0.45 ; \mathrm{p}<0.001)$. 

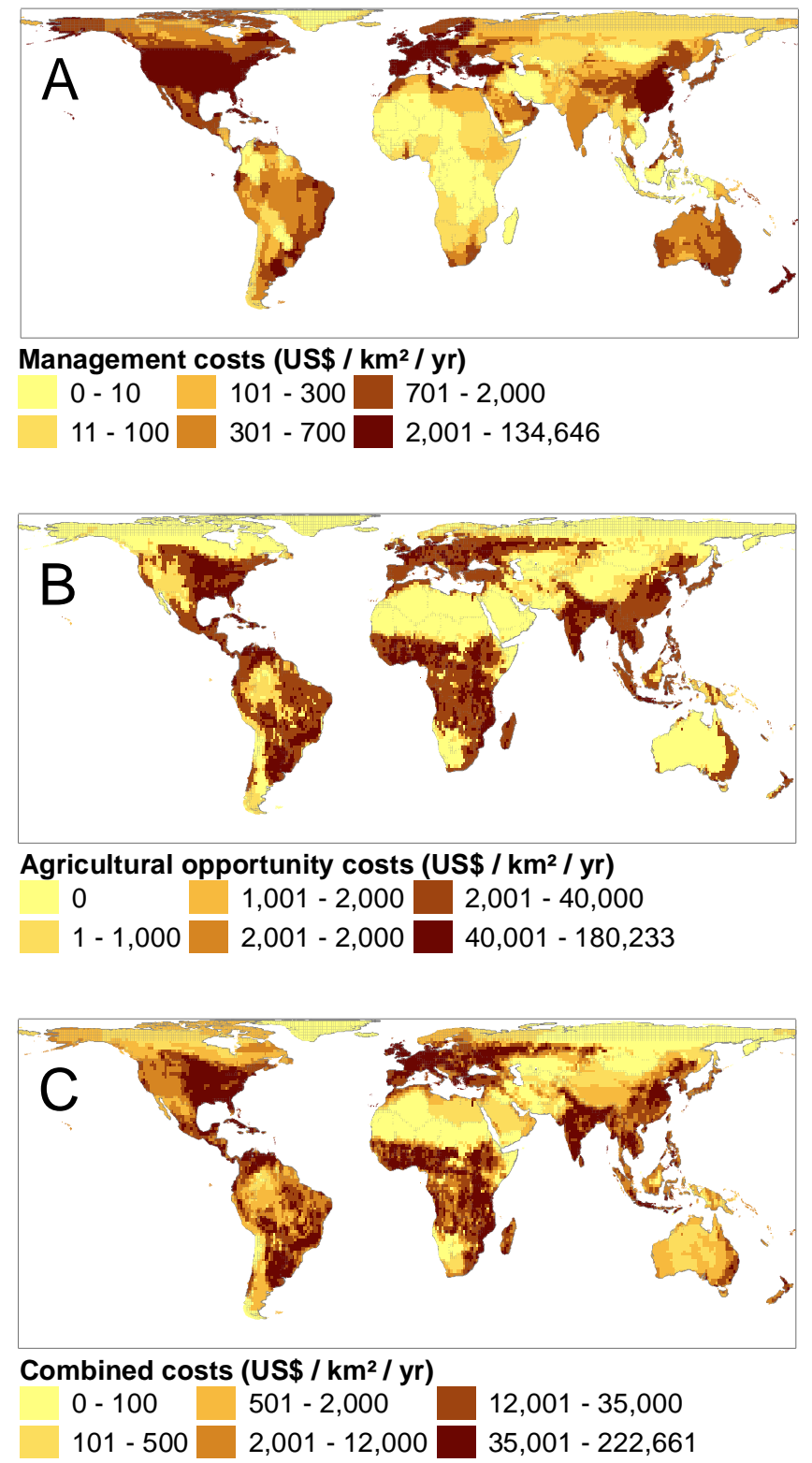

Fig. 1: Spatial distribution of conservation costs. A) management costs, (B) agricultural opportunity costs, and (C) management costs and agricultural opportunity costs combined into a single cost-indicator. Map legends were classified using quantiles, i.e. each color class contains a comparable number of grid cells.

Of a total of 12,728 grid cells available for prioritization (134.5 million $\mathrm{km}^{2}$ ) 3,783 grid cells were selected as priority areas across the management-costs-scenario, the agricultural-opportunity-costs-scenario, the combined costs-scenario and the areaminimization-scenario. The number of grid cells selected in each of these scenarios was between 2,260 (20.1 million $\mathrm{km}^{2}$; area-minimization-scenario) and 2,336 (21.4 million $\mathrm{km}^{2}$; combined-costs-scenario; Tab. 1). 1,319 grid cells were always selected as priority areas. These included 542 grid cells that were entered in any prioritization 
solution due to current protected area coverage, and 563 grid cells that were irreplaceable to meet all intended conservation targets at minimum costs (e.g. because they contained species found nowhere else).

Tab. 1: Number of grid cells, area (million $\mathbf{k m}^{2}$ ), and conservation costs (US\$ billion / yr) required for achieving intended mammal conservation targets under different prioritization scenarios.

\begin{tabular}{lccccc}
\hline Prioritization scenario & Cells & Area & Management costs & Agricultural opportunity costs & Combined costs \\
\hline Management-costs & 2,292 & 20.81 & 21.84 & 292.14 & 313.97 \\
Agricultural-opportunity-costs & 2,335 & 21.96 & 28.63 & 225.96 & 254.59 \\
Combined-costs & 2,336 & 21.39 & 25.26 & 226.26 & 251.52 \\
Area-minimization & 2,260 & 20.11 & 28.62 & 294.85 & 323.47 \\
\hline
\end{tabular}

Regions with low spatial concordance of priority areas between the managementcosts-scenario and the agricultural-opportunity-costs-scenario included Europe, Northern and Central Asia, the desert and grassland regions of Australia, Western and Central Africa, Western Amazonia, and the Eastern United States (Fig. 2). Regions with high spatial concordance of priority areas between the managementcosts-scenario and the agricultural-opportunity-costs-scenario grid cells included Southeastern Asia, Southern India, Eastern and Southern Africa, Madagascar, Western Brazil, the Andes, Central America, and the Southwestern United States (Fig. 2). 


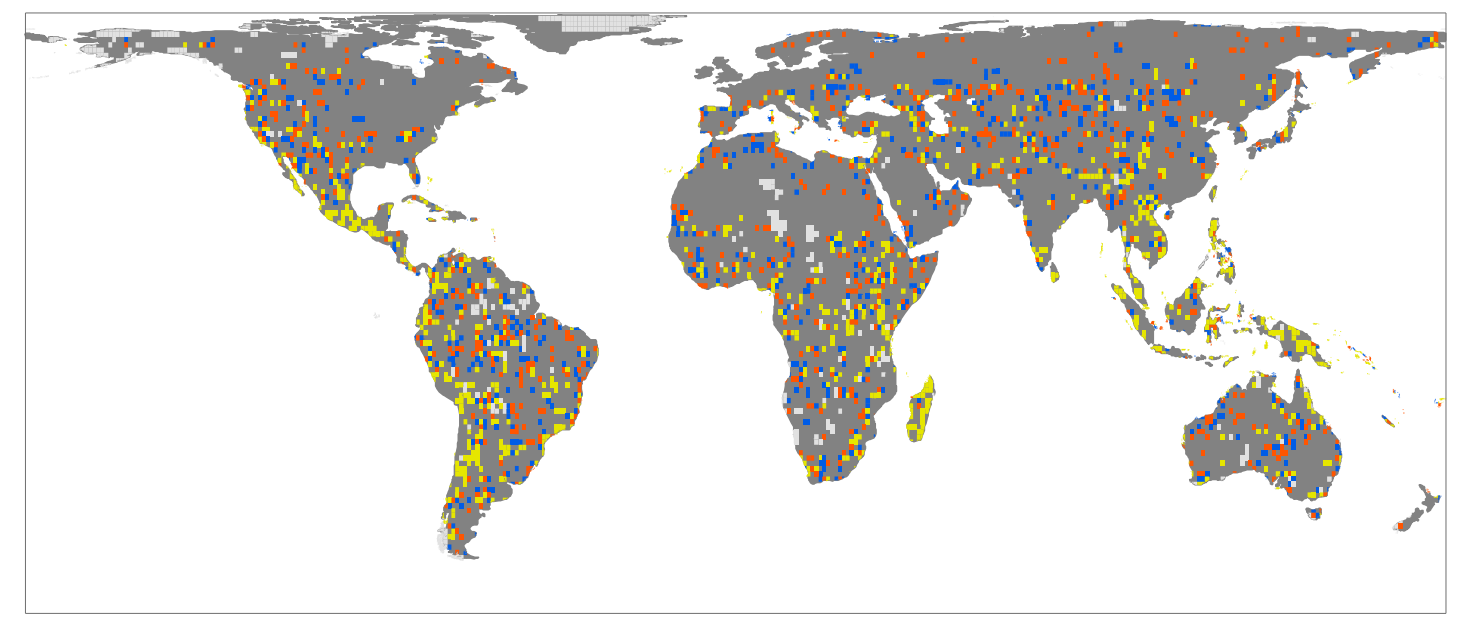

Priority areas

management-costs-scenario $\square$ agricultural-opportunity-costs-scenario both scenarios current protected areas

Fig. 2: Comparison of priority areas associated with meeting intended mammal conservation targets under the management-costs-scenario and the agricultural-opportunity-costs-scenario.

Prioritization scenarios differed in their performance in minimizing managementcosts and agricultural opportunity costs (Tab. 1). The managementcosts-scenario met all intended conservation targets with management costs of US\$ billion 21.84 / yr. This represents a $24 \%$ reduction compared to management costs of the area-minimization-scenario (US\$ billion 28.62 / yr). However, the managementcosts-scenario resulted in agricultural opportunity costs of US\$ billion 292.14 / yr, only slightly less than the opportunity costs sum of the area-minimization scenario, which results in opportunity costs of US\$ billion 294.85 / yr. In contrast, the agricultural-opportunity-costs scenario achieved all intended conservation targets with opportunity costs of US\$ billion 225.96 / yr. This represents a $24 \%$ reduction compared to the agricultural opportunity costs of the area-minimization-scenario (US\$ billon 294.85 / yr). Management costs in the agricultural-opportunity-costsscenario amounted to US\$ billion 28.63 / yr. Thus, the agricultural-opportunity costsscenario performed slightly worse than the area-minimization scenario with regard to management costs. Finally, the combined-costs-scenario resulted in agricultural opportunity costs of US\$ billion 226.26 / yr, which is very similar to opportunity costs in the agricultural-opportunity-costs-scenario. However, the combined costs scenario resulted in lower management costs (US\$ billion 25.26 / yr).

The total number of mammal range equivalents covered by all priority areas of a given scenario was similar across prioritization scenarios and ranged from 2,147 
(area-minimization-scenario) to 2,183 (combined-costs-scenario). Assuming that not all priority areas identified by a given prioritization scenario can be protected due to insufficient conservation resources (i.e. a maximum coverage prioritization approach) aggravated the trade-offs between management costs and agricultural opportunity costs (Fig. 3). For instance, when assuming that management costs of protecting priority areas must not exceed US\$ billion $10 / \mathrm{yr}(\sim 50 \%$ of the minimum management costs required to achieve all intended conservation targets), the management-costs-scenario still covered 2,109 range equivalents (Fig. 3). In contrast, the agricultural opportunity-costs-scenario covered only 960 range equivalents when management costs must not exceed US\$ billion 10 / yr (Fig 3). When assuming that agricultural opportunity costs must not exceed US\$ billion 115 /yr ( 50\% of the minimum agricultural opportunity costs required to achieve all intended conservation targets), the agricultural-opportunity-costs-scenario still covered 2,019 mammal range equivalents (Fig. 3). In contrast, the managementcosts-scenario covered only 930 range equivalents when agricultural opportunity costs must not exceed this threshold (Fig. 3).
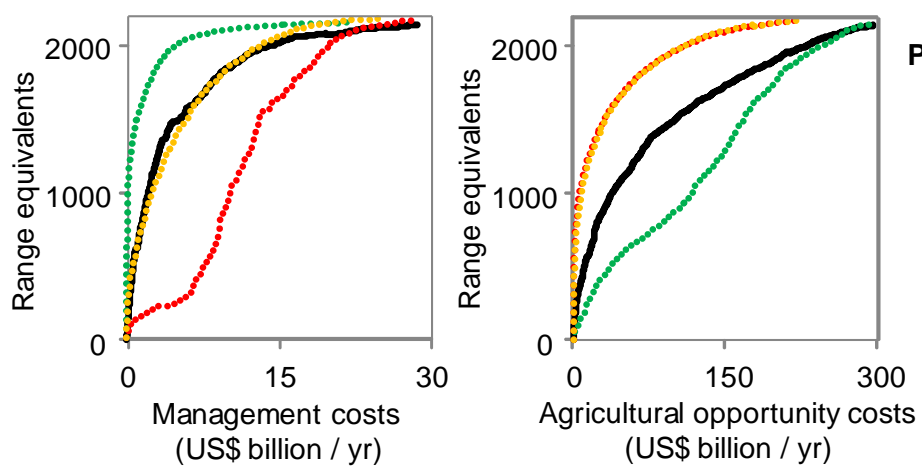

Prioritization scenario:

- area-minimization

... management-costs

... agricultural-opportunity-costs

combined-costs

Fig. 3: Amount of mammal range equivalents covered as the upper cost limits are increased.

Upper cost limits were defined according to management costs and agricultural opportunity costs, respectively. As the upper cost limits increased, more priority areas were selected in increasing order of marginal costs, that is the amount of costs required per additional mammal range equivalent covered. Depending on the prioritization scenario, marginal costs were defined according to management costs, agricultural opportunity costs, combined costs, and grid cell area. 


\section{Discussion}

Our study represents the first detailed assessment of trade-offs between minimizing management and agricultural opportunity costs in global-scale conservation prioritization. Our results show considerable trade-offs between minimizing these costs. As both management costs and agricultural opportunity costs represent key economic constraints to implement and maintain protected areas (Joppa and Pfaff 2009; McCarthy et al. 2012), balancing these trade-offs should be an integral component of cost-effective conservation prioritization. In contrast, the majority of prioritization approaches to date either focused on management costs (Balmford et al. 2003; Wilson et al. 2006; Bode et al. 2008; Underwood et al. 2008; Loyola et al. 2009; Waldron et al. 2013) or agricultural opportunity costs alone (Naidoo and Iwamura 2007; Carwardine et al. 2008; Iwamura et al. 2010; Freudenberger et al. 2013; Dobrovolski et al. 2014; Venter et al. 2014).

Given the fact that management and opportunity costs are regularly borne by differing - partly very poor - stakeholder groups, trade-offs between management and agricultural opportunity costs have several important socio-economic implications. First, minimizing management cost alone shifts costs towards land users. This aggravates social conflicts associated with protected areas, in particular since many countries with low management costs are lower income countries with large populations of rural poor (Balmford et al. 2003; Balmford and Whitten 2003). Without local support, protected areas likely face ongoing resistance from local communities and violation of land use restrictions, ultimately limiting conservation effectiveness (Balmford and Whitten 2003). Even if protected areas can be enforced effectively, the higher the opportunity costs the more likely it may be that impacts that would take place inside the protected area are displaced to a nearby unrestricted areas (Ewers and Rodrigues et al. 2008). Further, high opportunity costs may increase the probability that protected areas are downgraded, downsized or degazetted when demographic changes and increased demand for land further put pressure on natural habitats (Mascia et al. 2014).

Prioritization based on opportunity costs alone may overly exacerbate the present "biodiversity funding crisis", the substantial gap between the financial needs of managing the world's protected areas and the financial funds available (McCarthy et al. 2012). Compared to the agricultural-opportunity-costs-scenario, the combined- 
costs-scenario performed nearly as well in minimizing opportunity costs and was clearly more efficient with regard to management costs. This suggests that even when the main objective of a prioritization analysis is to minimize agricultural opportunity costs of protected areas, incorporating a combined cost indicator may be superior in balancing costs compared to incorporating agricultural opportunity costs alone. The combined-costs-scenario reduced management costs compared to the agricultural opportunity-costs-scenario, but the required management costs were still higher than in the management-costs-scenario. However, this may be justifiable as opportunity costs to local land users are significantly decreased, and local land users already pay the brunt of conservation costs, while receiving only a fraction of the globally dispersed benefits of biodiversity (Balmford and Whitten 2003).

Our results extend previous regional analyses to the global-scale that show that conservation prioritization is sensitive to the type of cost data used (Ban and Klein 2009; Weeks et al. 2010). Furthermore, our analysis also confirms for the globalscale that the selection of priority areas that are essential for meeting intended conservation targets is typically robust to changes in the cost indicator (Carwardine et al. 2010). However, this is only the case when it is assumed that all intended conservation targets must be met, i.e. a minimum set prioritization mode is applied. Assuming that resources are unlikely to suffice for achieving all conservation targets (maximum coverage prioritization), typically increases the sensitivity of prioritization outcomes to costs because even biologically irreplaceable areas may then be excluded in the prioritization solution if they require a disproportionate fraction of available resources (reviewed in Moilanen et al. 2011). Our study quantifies this effect reviewed in Moilanen et al. (2011) for the first time at the global-scale. Specifically, our results highlight that the sensitivity of prioritization to cost data is significantly higher in maximum coverage prioritization than in minimum set prioritization.

The cost datasets used here - and elsewhere in current literature - are subject to a number of limitations. Agricultural revenues as an indicator of opportunity costs do not account for agricultural production costs, which would have to be subtracted from revenues to obtain more realistic estimates of opportunity costs (Naidoo and Iwamura 2007). For example a review of costs of oilseed production found that cash costs of production range from $100 \mathrm{US} \$ \mathrm{t}$ to $400 \mathrm{US} \$ \mathrm{t}$ depending on the crop type and the world region (Zimmer et al. 2008). Since production costs were excluded, the 
cost estimates considered here should be regarded as an upper limit of the agricultural opportunity costs. Furthermore, the calculation of the opportunity cost indicator relies on uncertain scenarios of future agricultural land because actual changes of future land cover patters are difficult to estimate (IMAGE-Team 2001). Previous studies have relied on maximum potential or past agricultural extent, but there is a substantial risk that both alternatives introduce even larger biases (see chapter IV of the present thesis). Finally, there are uncertainties attached to the management cost indicator as well, including the size of new protected areas (Balmford et al. 2003) and potentially biased expert estimates of the cost of effective management (Armsworth et al. 2014).

The cost-effective sets of priority areas from our analysis are meant to be illustrative, and do not represent actual priorities for investment. There are other aspects that factor into real-world conservation planning that were not considered in our stylized prioritization scenarios, e.g. management of biodiversity in human dominated landscapes, other taxonomic groups, ecological processes, known conservation opportunities, governance aspects of conservation effectiveness (Groves 2003).

In sum, global prioritization analyses increasingly seek to integrate economic costs (Balmford et al. 2003; Wilson et al. 2006; Naidoo and Iwamura 2007; Bode et al. 2008; Carwardine et al. 2008; Loyola et al. 2009; Underwood et al. 2008; Iwamura et al. 2010; Freudenberger et al. 2013; Waldron et al. 2013; Dobrovolski et al. 2014; Venter et al. 2014). However, testing the sensitivity towards the choice of the cost data has not been given due scrutiny. Our study clearly highlights that the choice of the cost data substantially affects the selection of global priority areas. Focusing either on management or opportunity costs alone results in undue cost burdens, respectively, to conservation organizations or local land users that could compromise the success of conservation. In contrast, global prioritization analyses should consider several alternative cost scenarios. This approach can not only ensure an overall more cost-effective selection of priority areas. It can also identify spatial trade-offs between costs borne by different stakeholder groups. A detailed consideration of these socio-economic and related normative issues may lead to more equitable, more economically feasible and finally more successful biodiversity conservation. 


\section{References}

Adams, V.M., Pressey, R.L., Naidoo, R. (2010). Opportunity costs: Who really pays for conservation? Biological Conservation 143:439-448. doi:10.1016/j.biocon.2009.11.011.

Armsworth, P.R. (2014). Inclusion of costs in conservation planning depends on limited datasets and hopeful assumptions. Annals of the New York Academy of Sciences 1322: 61-76. doi:10.1111/nyas.12455.

Ball, I.R., Possingham, H.P., Watts, M.E. (2009). Marxan and relatives: software for spatial conservation prioritisation. In Moilanen, A., Wilson, K.A., Possingham, H.P. (eds.). Spatial conservation prioritisation: quantitative methods and computational tools. Oxford: Oxford University Press. pp. 185195.

Balmford, A., Gaston, K.J., Blyth, S., James, A., Kapos, V. (2003). Global variation in terrestrial conservation costs, conservation benefits, and unmet conservation needs. Proceedings of the National Academy of Sciences of the United States of America 100: 1046-1050. doi:10.1073/pnas.0236945100.

Balmford, A., Whitten, T. (2003). Who should pay for tropical conservation, and how could the costs be met? Oryx 37: 238-250. doi:10.1017/S0030605303000413.

Ban, N.C., Klein, C.J. (2009). Spatial socioeconomic data as a cost in systematic marine conservation planning. Conservation Letters 2: 206-215. doi:10.1111/j.1755-263X.2009.00071.x.

Bode, M., Wilson, K.A., Brooks, T.M., Turner, W.R., Mittermeier, R. A, McBride, M.F., Underwood, E.C., Possingham, H.P. (2008). Cost-effective global conservation spending is robust to taxonomic group. Proceedings of the National Academy of Sciences of the United States of America 105: 6498-6501. doi:10.1073/pnas.0710705105.

Bruner, A.G., Gullison, R.E., Balmford, A. (2004). Financial Costs and Shortfalls of Managing and Expanding Protected-Area Systems in Developing Countries. BioScience 54: 1119-1126. doi:10.1641/0006-3568(2004)054[1119:fcasom]2.0.co;2. 
Butchart, S.H.M., Clarke, M., Smith, R.J., Sykes, R.E., Scharlemann, J.P.W., Harfoot, M., Buchanan, G.M., Angulo, A., Balmford, A., Bertzky, B., Brooks, T.M., Carpenter, K.E., Comeros-Raynal, M.T., Cornell, J., Ficetola, G.F., Fishpool, L.D.C., Fuller, R. a., Geldmann, J., Harwell, H., HiltonTaylor, C., Hoffmann, M., Joolia, A., Joppa, L., Kingston, N., May, I., Milam, A., Polidoro, B., Ralph, G., Richman, N., Rondinini, C., Segan, D., Skolnik, B., Spalding, M., Stuart, S.N., Symes, A., Taylor, J., Visconti, P., Watson, J., Wood, L., Burgess, N.D. (2015). Shortfalls and Solutions for Meeting National and Global Conservation Area Targets. Conservation Letters 8: 329-337. doi:10.1111/conl.12158.

Cameron, S.E., Williams, K.J., Mitchell, D.K. (2008). Efficiency and concordance of alternative methods for minimizing opportunity costs in conservation planning. Conservation Biology 22: 886-896. doi:10.1111/j.15231739.2008.00982.x.

Carwardine, J., Wilson, K.A., Ceballos, G., Ehrlich, P.R., Naidoo, R., Iwamura, T., Hajkowicz, S.A., Possingham, H.P. (2008). Cost-effective priorities for global mammal conservation. Proceedings of the National Academy of Sciences of the United States of America 105: 11446-11450. doi:10.1073/pnas.0707157105.

Carwardine, J., Wilson, K.A., Hajkowicz, S.A, Smith, R.J., Klein, C.J., Watts, M., Possingham, H.P. (2010). Conservation planning when costs are uncertain. Conservation Biology 24: 1529-1537. doi:10.1111/j.1523-1739.2010.01535.x.

Ceballos, G., Ehrlich, P.R., Soberón, J., Salazar, I., Fay, J.P. (2005). Global mammal conservation: what must we manage? Science 309:603-607. doi:10.1126/science.1114015.

Chape, S., Spalding, M.D., Jenkins, M.D. (eds.) (2008). The World's protected areas: status, values, and prospects in the twenty-first century. Berkeley: University California Press.

CIA (2013). The World Fact Book. Retrieved from URL: https://www.cia.gov/library/publications/the-world-factbook/ (accessed 25.06.2013). 
Clifford, P., Richardson, S., Hemon, D. (1989). Assessing the Significance of the Correlation between Two Spatial Processes. Biometrics 45: 123-134. doi:0.2307/2532039.

Convention on Biological Diversity (2011). Conference of the Parties Decision X/2: Strategic plan for biodiversity 2011-2020. Retrieved from URL: www.cbd.int/decision/cop/ ?id=12268 (accessed 25.08.2015).

Dobrovolski, R., Loyola, R., D.A. Fonseca, G.A.B., Diniz-Filho, J.A.F., Araujo, M.B. (2014). Globalizing Conservation Efforts to Save Species and Enhance Food Production. BioScience 64: 539-545. doi:10.1093/biosci/biu064.

Dobrovolski, R., Loyola, R.D., Guilhaumon, F., Gouveia, S.F., Diniz-Filho, J.A.F. (2013). Global agricultural expansion and carnivore conservation biogeography. Biological Conservation 165: 162-170. doi:10.1016/j.biocon.2013.06.004.

Ewers, R.M., Rodrigues, A.S.L. (2008). Estimates of reserve effectiveness are confounded by leakage. Trends in Ecology \& Evolution 23:113-116. doi:10.1016/j.tree.2007.11.008.

Freudenberger, L., Hobson, P., Schluck, M., Kreft, S., Vohland, K., Sommer, H., Reichle, S., Nowicki, C., Barthlott, W., Ibisch, P.L. (2013). Nature conservation: priority-setting needs a global change. Biodiversity and Conservation 22: 1255-1281.doi:10.1007/s10531-012-0428-6.

Groves, C. (2003). Drafting a Conservation Blueprint - A Practitioner's Guide to Planning for Biodiversity. Washington, DC: Island Press.

Hosonuma, N., Herold, M., De Sy, V., De Fries, R.S., Brockhaus, M., Verchot, L., Angelsen, A., Romijn, E. (2012). An assessment of deforestation and forest degradation drivers in developing countries. Environmental Research Letters 7: 044009. doi:10.1088/1748-9326/7/4/044009.

IMAGE-Team (2001).The IMAGE 2.2 Implementation of the SRES Scenarios. A Comprehensive Analysis of Emissions, Climate Change and Impacts in the 21st Century. Bilthoven: Netherlands Environmental Assessment Agency. International Monetary Fund (2010). World Economic Outlook Database, October 2010. Retrieved from URL: 
https://www.imf.org/external/pubs/ft/weo/2010/02/weodata/index.aspx (accessed 27.06.2013).

IUCN (2012). IUCN Red List of Threatened Species. Retrieved from URL: http://www.iucredlist.org/. (accessed 01.09.2014).

IUCN and UNEP-WCMC (2012). The World Database on Protected Areas (WDPA) [On-line], Cambridge, UK: UNEP-WCMC. Retrieved from URL: www.protectedplanet.net (accessed 15.09 2012).

Iwamura, T., Wilson, K.A., Venter, O., Possingham, H.P. (2010). A climatic stability approach to prioritizing global conservation investments. PLoS One 5: e15103. doi:10.1371/journal.pone.0015103.

Joppa, L.N., Pfaff, A. (2009). High and Far: Biases in the Location of Protected Areas. PLoS One 4: e8273. doi:10.1371/journal.pone.0008273.

Kier, G., Barthlott, W. (2001). Measuring and mapping endemism and species richness : a new methodological approach and its application on the flora of Africa. Biodiversity and Conservation 10: 1513-1529. doi:0.1023/A:1011812528849.

Leverington, F., Costa, K.L., Pavese, H., Lisle, A., Hockings, M. (2010). A Global Analysis of Protected Area Management Effectiveness. Environmental Management 46: 685-698. doi:10.1007/s00267-010-9564-5.

Loyola, R.D., Oliveira-Santos, L.G.R., Almeida-Neto, M., Nogueira, D.M., Kubota, U., Diniz-Filho, J.A.F., Lewinsohn, T.M. (2009). Integrating economic costs and biological traits into global conservation priorities for carnivores. PLoS One 4: e6807. doi:10.1371/journal.pone.0006807.

Mascia, M.B., Pailler, S., Krithivasan, R., Roshchanka, V., Burns, D., Mlotha, M.J., Murray, D.R., Peng, N. (2014). Protected area downgrading, downsizing, and degazettement (PADDD) in Africa, Asia, and Latin America and the Caribbean, 1900-2010. Biological Conservation 169: 355-361. doi:10.1016/j.biocon.2013.11.021.

McCarthy, D.P., Donald, P.F., Scharlemann, J.P.W., Buchanan, G.M., Balmford, A., Green, J.M.H., Bennun, L.A., Burgess, N.D., Fishpool, L.D.C., Garnett, S.T., Leonard, D.L., Maloney, R.F., Morling, P., Schaefer, H.M., Symes, A., Wiedenfeld, D.A., Butchart, S.H.M. (2012). Financial costs of meeting global 
biodiversity conservation targets: current spending and unmet needs. Science 338: 946-949. doi:10.1126/science.1229803.

Moilanen, A., Arponen, A. (2011). Setting conservation targets under budgetary constraints. Biological Conservation 144: 650-653. doi:10.1016/j.biocon.2010.09.006.

Moore, J., Balmford, A., Allnutt, T., Burgess, N. (2004). Integrating costs into conservation planning across Africa. Biological Conservation 117: 343-350. doi:10.1016/j.biocon.2003.12.013.

Naidoo, R., Balmford, A., Ferraro, P.J., Polasky, S., Ricketts, T.H., Rouget, M. (2006). Integrating economic costs into conservation planning. Trends in Ecology \& Evolution 21: 681-687. doi:10.1016/j.tree.2006.10.003.

Naidoo, R., Iwamura, T. (2007). Global-scale mapping of economic benefits from agricultural lands: Implications for conservation priorities. Biological Conservation 140: 40-49. doi:10.1016/j.biocon.2007.07.025.

Olson, D., Dinerstein, E. (1998). The Global 200: a representation approach to conserving the Earth's most biologically valuable ecoregions. Conservation Biology 12:502-515. doi:10.1046/j.1523-1739.1998.012003502.x.

Rodrigues, A.S.L., Akçakaya, H.R., Andelman, S.J., Bakarr, M.I., Boitani, L., Brooks, T.M., Chanson, J.S., Fishpool, L.D.C., Da Fonseca, G. a. B., Gaston, K.J., Hoffmann, M., Marquet, P.A., Pilgrim, J.D., Pressey, R.L., Schipper, J., Sechrest, W., Stuart, S.N., Underhill, L.G., Waller, R.W., Watts, M.E.J., Yan, X. (2004). Global Gap Analysis: Priority Regions for Expanding the Global Protected-Area Network. Bioscience 54: 1092-1100. doi:10.1641/0006-3568(2004)054[1092:GGAPRF]2.0.CO;2.

Underwood, E.C., Shaw, M.R., Wilson, K.A., Kareiva, P., Klausmeyer, K.R., McBride, M.F., Bode, M., Morrison, S. a, Hoekstra, J.M., Possingham, H.P. (2008). Protecting biodiversity when money matters: maximizing return on investment. PLoS One 3: e1515. doi:10.1371/journal.pone.0001515

Venter, O., Fuller, R.A.., Segan, D.B., Carwardine, J., Brooks, T., Butchart, S.H.M., Di Marco, M., Iwamura, T., Joseph, L., O’Grady, D., Possingham, H.P., Rondinini, C., Smith, R.J., Venter, M., Watson, J.E.M. (2014). Targeting Global 
Protected Area Expansion for Imperiled Biodiversity. PLoS Biology 12: e1001891. doi:10.1371/journal.pbio.1001891.

Waldron, A., Mooers, A. (2013). Targeting global conservation funding to limit immediate biodiversity declines. Proceedings of the National Academy of Sciences of the United States of America 110: 12144-12148. doi:10.5061/dryad.p69t1.

Weeks, R., Russ, G.R., Bucol, A.A., Alcala, A.C. (2010). Shortcuts for marine conservation planning: The effectiveness of socioeconomic data surrogates. Biological Conservation 143: 1236-1244. doi:10.1016/j.biocon.2010.02.031.

Wilson, K.A., Carwardine, J., Possingham, H.P. (2009). Setting conservation priorities. Annals of the New York Academy of Sciences 1162: 237-64. doi:10.1111/j.1749-6632.2009.04149.x.

Wilson, K.A., Evans, M.C., Di Marco, M., Green, D.C., Boitani, L., Possingham, H.P., Chiozza, F., Rondinini, C. (2011). Prioritizing conservation investments for mammal species globally. Philosophical Transactions of the Royal Society B: Biological Sciences 366: 2670-2680. doi:10.1098/rstb.2011.0108.

Wilson, K.A., McBride, M.F., Bode, M., Possingham, H.P. (2006). Prioritizing global conservation efforts. Nature 440: 337-340. doi:10.1038/nature04366.

World Bank (2013). World Bank Data Catalog. Retrieved from URL: http://datacatalog.worldbank.org/ (accessed 19.06.2013).

Zerbe, R.O., Bellas, A.S. (2006). A primer for benefit-cost analysis. Cheltenham: Edward Elgar Publishing.

Zimmer, Y. (ed.) (2008). Cash Crop Report 2008. vTI Braunschweig. 


\section{Chapter III}

\section{Divergent indicators of agricultural opportunity costs lead to inconclusive global conservation priorities}

Georg Barth $^{1}$, Jan Barkmann ${ }^{1,2}$, Carsten Meyer ${ }^{3}$, Holger Kreft $^{3}$, Rainer Marggraf ${ }^{1}$

\footnotetext{
${ }^{1}$ Environmental and Resource Economics, Georg-August-Universität Göttingen, 37077 Göttingen,

Germany; ${ }^{2}$ Risk and Sustainability Sciences, Hochschule Darmstadt - University of Applied

Sciences, 64295 Darmstadt, Germany; ${ }^{3}$ Biodiversity, Macroecology and Conservation Biogeography,

Georg-August-Universität Göttingen, 37077 Göttingen, Germany
} 


\begin{abstract}
Conservation prioritization needs to consider opportunity costs associated with foregone agricultural production. As no detailed global information exists on actual agricultural opportunity costs, global-scale prioritization analyses have approximated such costs using differing indicators, each with relative advantages and limitations. We assess how sensitive the selection of cost-effective priority areas for global biodiversity conservation is to this methodological choice. We compare three prioritization scenarios each using a different indicator of agricultural opportunity costs: (i) past agricultural revenue, (ii) agricultural production in the $21^{\text {th }}$ century, and (iii) potential agricultural revenue. We find that the different cost indicators correlate only weakly to moderately in space. When aiming to adequately represent all target species (minimum set prioritization), these prioritization scenarios were at best only $3-7 \%$ more efficient in minimizing agricultural opportunity costs across indicators than a scenario that assumed uniform conservation costs worldwide. Accordingly, our analyses demonstrates that uncertainty in agricultural opportunity costs leads to inconclusive global conservation priorities because the perceived cost-effectiveness varies widely depending on which cost indicator is considered, while at the same time it is uncertain how well each cost indicator corresponds to the true agricultural opportunity costs of conservation. We also found that the sensitivity of prioritization solutions towards the choice of the cost indicator increased substantially when the prioritization objective was to maximize the achievements of targets with a fixed upper cost limit (maximum coverage prioritization). We suggest that working towards a single more authoritative indicator of agricultural opportunity costs, combining advantages of current indicators, is ultimately required to ensure more conclusive prioritization results.
\end{abstract}

\title{
1. Introduction
}

The loss and degradation of natural habitats, mainly driven by changes in agricultural land use, are the main drivers of biodiversity loss (Pereira et al 2012; Newbold et al. 2015). Establishing additional protected areas is of crucial importance for biodiversity conservation (see e.g. Butchart et al. 2015), but often incurs significant opportunity costs of forgone agricultural production on the surrounding communities and the countries in which they are implemented (Chomitz 2007; Naidoo and 
Iwamura 2007; McCarthy et al. 2012). Tropical countries in particular are under increasing pressure to balance trade-offs between conservation of habitats with exceptional biodiversity value, and providing income and livelihood to a growing populace (Laurance et al. 2014). Given socio-economic constraints, conservation priorities must be identified that are cost-effective, either because they meet intended conservation targets while minimizing conservation costs, or because they maximize the achievement of targets with a given upper limit of acceptable costs.

Analyses about priority areas for global biodiversity conservation regularly used area as a surrogate for conservation costs, implicating that costs, e.g. agricultural opportunity costs, are uniform across potential reserves (e.g. Rodrigues et al. 2004; Ceballos et al. 2005). However, recent analyses have shown that the agricultural opportunity costs of conservation may be reduced substantially if their spatial variability is explicitly taken into account at the outset of the prioritization process (Naidoo and Iwamura 2007; Carwardine et al. 2008; Wilson et al. 2011; Dobrovolski et al. 2014). It has also been found that the magnitude of potential efficiency gains from including cost data depends on the prioritization objective (Moilanen and Arponen 2011). Potential efficiency gains from considering spatial variability in costs will be highest under maximum coverage prioritization which aims to maximize the achievement of conservation targets given that the overall costs of priority areas must not exceed a predetermined upper cost limit (Moilanen and Arponen 2011). In contrast, potential efficiency gains will typically be smaller in minimum set prioritization which aims to achieve a set of areas that must meet a full set of predetermined conservation targets, while minimizing costs as far as possible (Moilanen and Arponen 2011).

While precise data on the spatial distribution of agricultural opportunity costs of conservation is not available, global-scale prioritization analyses have relied on three different indicators to approximate the spatial heterogeneity of such costs: (i) past agricultural revenue (Naidoo and Iwamura 2007; Iwamura et al. 2010; Wilson et al. 2011; Larsen et al. 2011; Freudenberger et al. 2013; Venter et al. 2014), (ii) potential agricultural revenue (Carwardine et al. 2008), and (iii) agricultural production in the $21^{\text {th }}$ century (Dobrovolski et al. 2014).

While previous small-scale case studies highlight that conservation prioritization outcomes are potentially sensitive towards the choice of the cost indicator (Ban and 
Klein 2009; Adams et al. 2010; Carwardine et al. 2010; Weeks et al. 2010), the sensitivity of broad scale prioritization towards diverging cost indicators remains unclear. Furthermore, previous assessments of the sensitivity of prioritization towards diverging cost data exclusively focused on minimum set prioritization. Thus, they may have underestimated the potential sensitivity of prioritization towards diverging cost data because maximum coverage prioritization is generally more sensitive towards consideration of costs (see Margules and Arponen 2011).

Here, we provide a detailed sensitivity analysis of how using different indicators of agricultural opportunity costs affects spatial conservation prioritization at the globalscale. We exemplarily focus on terrestrial mammals, a flagship taxonomic group to leverage support for biodiversity conservation at large (Ceballos et al. 2005, Carwardine et al. 2008), and on tropical and subtropical moist broadleaf forests, a hyper diverse global biome (Olson and Dinerstein 1998) under increasing pressure from agricultural expansion (Laurance et al. 2014). First, we investigate the spatial relationship between three indicators of agricultural opportunity costs used in previous global-scale prioritization analyses. We identify cost-effective priority areas for conservation according to each indicator and compare the resulting priority areas with regard to their spatial configuration and perceived cost-effectiveness across different indicators of agricultural opportunity costs. In addition, we evaluate how the choice of the prioritization approach (minimum set, or maximum coverage) influences the sensitivity of prioritization towards the choice of the agricultural opportunity cost indicator.

\section{Methods}

\subsection{Species and economic data}

We based all analysis on an equal-area grid of $12,364 \mathrm{~km}^{2}$ (approximately $111 \mathrm{~km} \mathrm{x}$ $111 \mathrm{~km}$ at the equator) to delineate areas for conservation prioritization. to prioritize areas for conservation. We clipped the grid layer to the spatial extent of the tropical and subtropical moist broadleaf forest biome (Olson and Dinerstein 1998). Additionally, we excluded 288 of 2,308 grid cells for which species distribution or economic data were unavailable, resulting into 2020 grid cells for our analyses. We used expert-opinion maps that approximate the extent of occurrence of mammal 
species, to establish presence/absence data for 3,327 species that intersected these grid cells (IUCN 2012).

We considered three indicators of agricultural opportunity costs of conservation previously used in global prioritization analyses. Indicators of agricultural opportunity costs were defined as described below and average indicator values were calculated for each $12,364 \mathrm{~km}^{2}$ grid cell.

(i) past agricultural revenue

This agricultural opportunity cost indicator was taken from Naidoo and Iwamura (2007). It estimates the revenues from agriculture in the mid 1990s at a spatial resolution of 5'. Specifically, Naidoo and Iwamura (2007) calculated potential agricultural revenues across pasture and 42 crop types by integrating information on land suitability and producer prices for the period from 1991 to 2002. Subsequently, they multiplied these potential agricultural revenues by the fraction of each grid cell that was estimated to be occupied by pasture and each crop type in the mid 1990.

(ii) agricultural production in the $21^{\text {th }}$ century

Following Dobrovolski et al. (2014), we calculated this agricultural opportunity cost indicator by integrating information on potential productivity of agricultural lands and possible pathways of agricultural land cover during the $21^{\text {th }}$ century. We used land cover simulations from 2000 to 2100 (IMAGE version 2.2, IMAGE Team 2001) to produce a map at a spatial resolution of $0.5^{\circ}$ that indicates the average number of years each grid cell is used for agriculture over the 21th century and across six possible development pathways (see Dobrovolski 2013; 2014). In line with Dobrovolski et al. (2014), we obtained estimates of the rainfed potential agricultural productivity $(0-100 \%)$ for each grid cell corresponding to climate, terrain and soil constraints (van Velthuizen et al. 2007). Further, following Dobrovolski et al. (2014), we also considered gains in potential productivity due to the impact of irrigation (Fischer et al. 2002). The final opportunity cost indicator was calculated for each $0.5^{\circ}$ grid cell by multiplying the potential productivity percentage with the average time that the grid cell is forecast to be cultivated over the $21^{\text {th }}$ century and across all six socio-economic development pathways (Dobrovolski et al. 2014). 
(iii) potential agricultural revenue

This indicator was taken from Carwardine et al. (2008). They calculated potential agricultural revenues using the same method as Naidoo and Iwamura (2007) but did not weight potential revenues by the area occupied by each crop. In contrast, their indicator estimates the revenue of the most valuable crop type that could be produced in each cell, regardless of past or forecast agricultural land use.

\subsection{Conservation prioritization analyses}

We analyzed three spatial prioritization scenarios for mammal conservation, each using a different indicator of agricultural opportunity costs to prioritize grid cells according to conservation cost-effectiveness: (i) past-revenue-scenario, (ii) $21^{\text {th }}$ cenutry-production-scenario, and (iii) potential-revenue-scenario. Furthermore, we added an (iv) area-minimization-scenario, which assumes uniform conservation costs worldwide.

For each scenario, we investigated two commonly used prioritization approaches, minimum set prioritization and maximum coverage prioritization (Wilson et al. 2009). The objective of the minimum set prioritization approach is to identify a set of priority areas that must achieve intended conservation targets (e.g. 10\% of each target species range) while minimizing, as far as possible, conservation costs (Wilson et al. 2009). To investigate the minimum set prioritization problem, we used the MARXAN software (Ball et al. 2009) which is specifically designated to conduct this prioritization approach. For each prioritization scenario, we selected the lowestcost solution across 250 MARXAN runs. To account for current protected areas, we "locked" 66 grid cells with more than $50 \%$ current protected area coverage in any prioritization solution (IUCN categories I-IV; IUCN and UNEP-WCMC 2012). We assumed that the conservation objective of priority areas is to cover a predetermined fraction of the range size of each considered species and scaled the targets to a given species' global range size (Rodrigues et al. 2004). The most widespread species (red fox, Vulpes vulpes) was assigned a conservation target of $1 \%$ of its global range size while species occurring only in one grid cell were assigned conservation targets of $100 \%$ of their range. We scaled targets for the remaining species between these two extremes using a power function $\left(\right.$ target $_{\text {species } i}=$ range $\left._{\text {species } i}^{0.47}\right)$ such that proportional conservation targets would be higher for range-restricted species. 
Finally, we scaled these targets linearly to the proportion of each species' range that overlaps with the tropical and subtropical moist broadleaf forest biome.

The objective of the maximum coverage prioritization approach is to identify a set of priority areas that maximizes the achievement of conservation targets as far as possible, while given that a predetermined upper cost limit must not be exceeded (Wilson et al. 2009). A maximum coverage approach to prioritization generally selects priority areas in increasing order of marginal costs (Moilanen and Arponen et al. 2011). This is because with very small resources, it is a mathematical necessity that one can only select priority areas that have very small cost per unit of conservation value covered (Moilanen and Arponen 2011). When the upper cost limit is increased, more priority areas are selected, but, always the next priority area that is selected is the one that results in the smallest costs per unit of biodiversity covered (Moilanen and Arponen 2011). Here, we used the sum of mammal range equivalents to assess a given grid cells contribution to total mammal diversity (Kier and Barthlott 2001). We attributed 1 range equivalent to a given grid cell when $100 \%$ of a given species' distribution area exclusively fell into the grid cell (Kier \& Barthlott 2011). When $50 \%$ of a species' distribution area fell into a grid cell, we attributed 0.5 range equivalents to the grid cell and so on. We used the sum of range equivalents for all species within a given grid cell as an indicator of the conservation value. For each priority area of a given prioritization scenario selected previously under the minimum set prioritization approach, we determined the marginal costs of conservation in terms of the ratio of agricultural opportunity costs to the sum of mammal range equivalents covered. The maximum coverage approach to conservation was investigated by selecting priority areas in a stepwise manner and in increasing order of marginal costs starting, while gradually raising the upper cost limit from 0 to the full costs of protecting all priority areas of a given prioritization scenario.

\subsection{Comparison of conservation prioritization scenarios}

We tested the Spearman rank correlations between the three indicators of agricultural opportunity costs across $12,364 \mathrm{~km}^{2}$ grid cells. To account for spatial autocorrelation in the data, we corrected the degrees of freedom for the statistical tests (Clifford et al. 1989). 
To explore the sensitivity of the minimum set prioritization approach towards the choice of the cost indicator, we first determined the spatial overlap across prioritization scenarios by mapping the number of scenarios each grid cell was selected as a priority area. Further, across all priority areas under a given prioritization scenario, we calculated the sum of the agricultural opportunity costs according to past agricultural revenues, agricultural production in the $21^{\text {th }}$ century, and potential agricultural revenues.

To explore the sensitivity of the maximum coverage approach towards the choice of the cost indicator, we produced a set of conservation value - cost curves, that represent the amount of mammal range equivalents covered as a function of upper cost limits. Each set contained three graphs that represent cost limits according to, respectively, past agricultural revenues, agricultural production in the $21^{\text {th }}$ century, and potential agricultural revenues.

\section{Results}

Indicators of agricultural opportunity costs of conservation were only weakly to moderately related to each other spatially (Fig.1). Past agricultural revenue was not correlated with potential agricultural revenue $(\mathrm{p}=0.12)$, and it was moderately positively correlated with agricultural production in the $21^{\text {th }}$ century $(r=0.61, p<$ 0.001). Potential agricultural revenue was moderately positively correlated with agricultural production in the $21^{\text {th }}$ century $(\mathrm{r}=0.43, \mathrm{p}<0.001)$.

In particular, grid cells in Southeast Asia ranked much higher with regard to opportunity costs when past agricultural revenue or forecast agricultural production in the $21^{\text {th }}$ century was regarded, as compared to potential agricultural revenue (Fig. 1). The opposite pattern was found for Eastern Amazonia (Fig. 1). Land in Central Africa did not carry any agricultural opportunity costs according to the past agricultural revenue indicator but carried medium to high costs for any of the other two cost indicators (Fig. 1). 


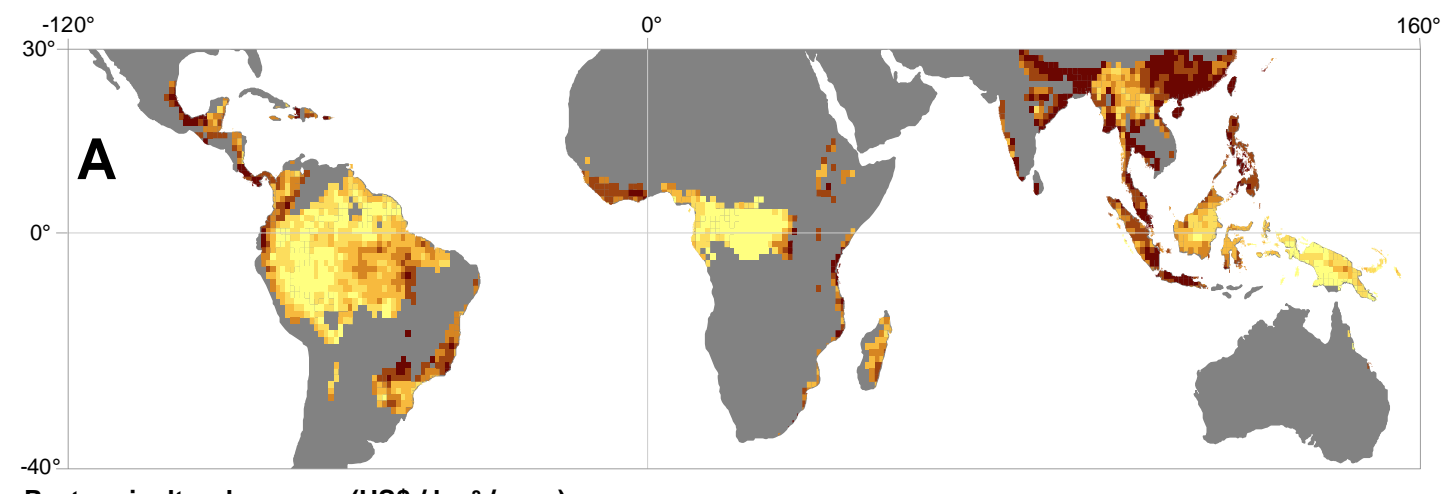

Past agricultural revenue (US $\$ / \mathbf{~ k m}^{2} /$ year)

0 - $300-301-1,500 \square 1,501-4,000 \square 4,001-8,000 \backsim 8,001-17,000 \square 17,001-117,652$

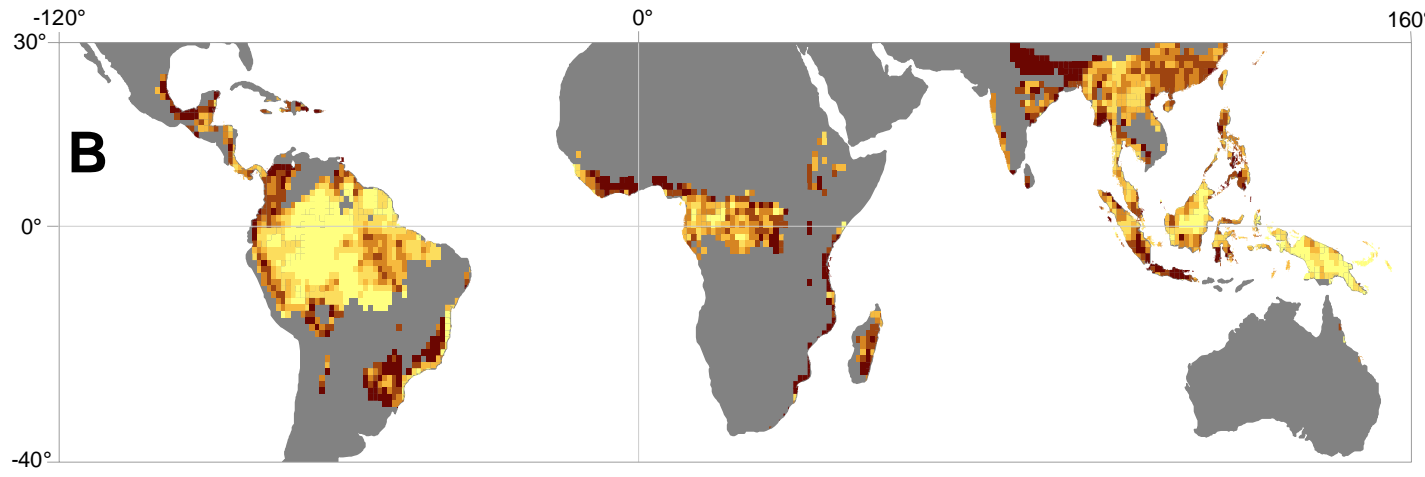

Agricultural production in the 21th century (attained \% of maximum potential rainfed productivity)

$0-1 \square 2-7 \square 8-15 \square 16-25 \square 26-41 \square 42-160$

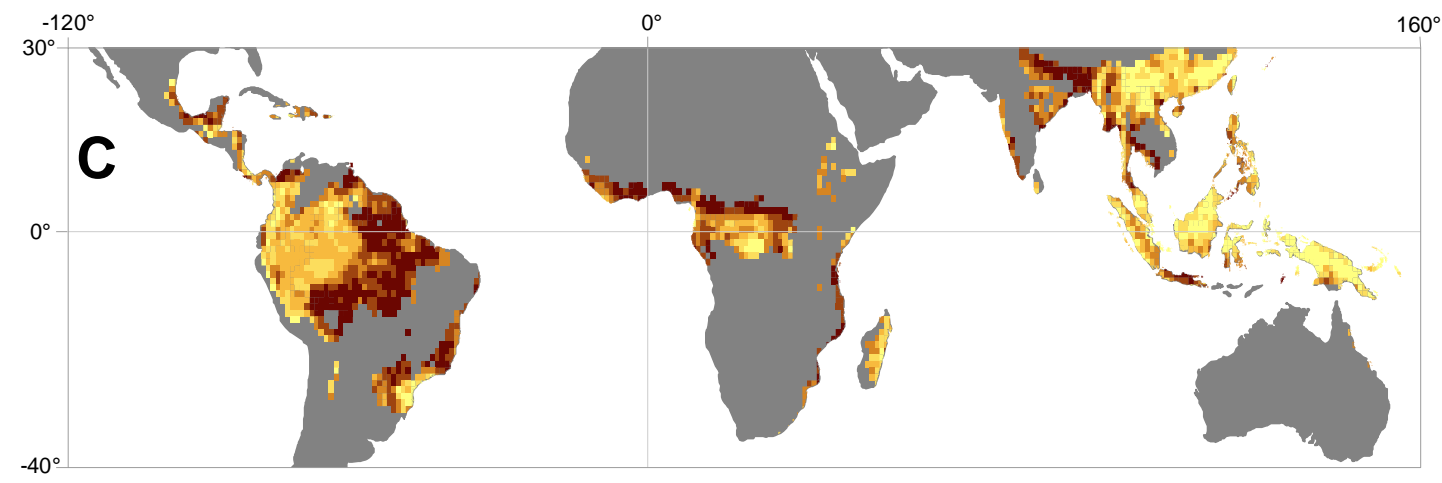

Potential agricultural revenue (US $\$$ / $\mathbf{k m}^{2} /$ year)

$0-16,000-16,001-26,000-26,001-37,000 \square 37,001-60,000 \square 60,001-95,000 \square 95,001-180,233$

Fig. 1: Indicators of agricultural opportunity costs of conservation across the tropical and subtropical moist broadleaf forest biome (A) past agricultural revenue, (B) agricultural production in the $21^{\text {th }}$ century, and (C) potential agricultural revenue. In (B) attained maximum values exceed $100 \%$ of potential rainfed productivity due to productivity gains from irrigation. Map legends were classified using quantiles, i.e. each color class contains a comparable number of grid cells.

Under the minimum set prioritization approach 853 grid cells were selected as priority areas across the past-revenue-scenario, the $21^{\text {th }}$-century-production-scenario, and the potential-revenue-scenario (Fig. 2). The number of grid cells selected in each 
of these scenarios was between $602\left(5.4\right.$ million $\left.\mathrm{km}^{2}\right)$ and $609\left(5.7\right.$ million $\left.\mathrm{km}^{2}\right) .416$ grid cells were always selected as priority areas under the minimum set prioritization approach (Fig. 2). These included 66 "locked" grid cells with high current protection area coverage, and 280 grid cells that were irreplaceable for achieving conservation targets at minimum costs (e.g. because they contained species found nowhere else). Grid cells that were selected in all three prioritization scenarios based on agricultural opportunity cost indicators were found across all continents with particularly high concentrations in the tropical Andes, the southeastern coast of Brazil, Madagascar, Sumatra, the Philippines and New Guinea (Fig. 2). Relatively low concordance of priority areas between the prioritization scenarios was found throughout Amazonia, Central and Western Africa, and Borneo, and in parts of continental Southeast Asia (Fig. 2).

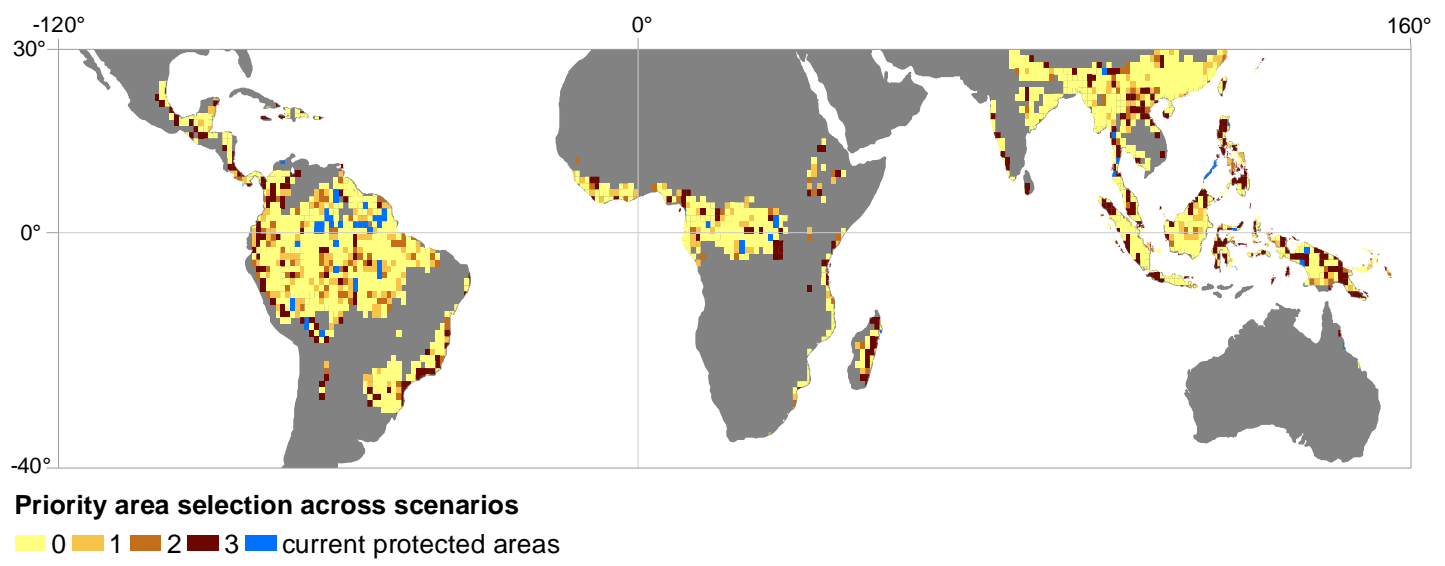

Fig. 2: The sum of prioritization scenarios grid cells were selected as priority areas for mammal conservation in the tropical and subtropical moist broadleaf forest biome. The priority areas mapped refer to the minimum set prioritization approach, which required that all intended mammal conservation targets were met. The scenarios shown include the past-revenue-scenario, the $21^{\text {th }}$ century-production-scenario, and the potential-revenue-scenario, i.e. the area-minimization-scenario is not shown.

Minimum set prioritization based on one agricultural opportunity costs indicator resulted in priority areas with high costs according to any of the two other cost indicators (Tab. 1). For instance, the past-revenue-scenario resulted in priority areas that minimized costs of achieving all intended conservation targets according to past agricultural revenues, but increased opportunity costs according to agricultural 
production in the $21^{\text {th }}$ century by $13 \%$. Thus, the past-revenue-scenario was only slightly more effective in minimizing opportunity costs according to agricultural production in the $21^{\text {th }}$ century than the area-minimization scenario which resulted in a cost increase of $16 \%$ (Tab. 1). Additionally, opportunity costs according to potential agricultural revenue were even lower in the area-minimization-scenario (7\% above minimum) than in the past-revenue-scenario (13\% above minimum).

Tab. 1: Agricultural opportunity costs associated with achieving all intended mammal conservation targets (minimum set prioritization approach) under different prioritization scenarios.

\begin{tabular}{|c|c|c|c|}
\hline \multirow[b]{2}{*}{ Prioritization scenario } & \multicolumn{3}{|c|}{ Agricultural opportunity cost } \\
\hline & Past agricultural revenue & $\begin{array}{l}\text { Agricultural production } \\
\text { in the } 21 \text { th century }\end{array}$ & Potential agricultural revenue \\
\hline Past-revenue & $\begin{array}{l}\text { Minimum } \\
\text { costs }\end{array}$ & $\begin{array}{c}1.13 \text { times minimum } \\
\text { costs }\end{array}$ & $\begin{array}{c}1.13 \text { times minimum } \\
\text { costs }\end{array}$ \\
\hline 21th-century-production & $\begin{array}{c}1.13 \text { times minimum } \\
\text { costs }\end{array}$ & $\begin{array}{l}\text { Minimum } \\
\text { costs }\end{array}$ & $\begin{array}{c}1.14 \text { times minimum } \\
\text { costs }\end{array}$ \\
\hline Potential-revenue & $\begin{array}{l}1.11 \text { times minimum } \\
\text { costs }\end{array}$ & $\begin{array}{l}1.11 \text { times minimum } \\
\text { costs }\end{array}$ & $\begin{array}{l}\text { Minimum } \\
\text { costs }\end{array}$ \\
\hline Area-minimization & $\begin{array}{c}1.18 \text { times minimum } \\
\text { costs }\end{array}$ & $\begin{array}{c}1.16 \text { times minimum } \\
\text { costs }\end{array}$ & $\begin{array}{c}1.07 \text { times minimum } \\
\text { costs }\end{array}$ \\
\hline
\end{tabular}

The sum of range equivalents across the 2,020 grid cells and the 3,327 mammal species included in our analysis was 2,217. Under the minimum set prioritization approach grid cells selected as priority areas covered between 1,118 (50.4\%) and $1,135(51.2 \%)$ mammal range equivalents, depending on the prioritization scenario. We found substantial differences between the prioritization scenarios under maximum coverage prioritization (Fig. 3). For instance, setting the upper cost limit at, respectively, $3 \%, 5 \%$, and $10 \%$ of the total agricultural production in the 21 th century, resulted in a mammal range equivalent coverage of, respectively, 30\%, 35\% and $44 \%$ in the $21^{\text {th }}$-century-production scenario, but in the past-revenue-scenario only, respectively, $10 \%, 22 \%$, and $34 \%$ of the range equivalents were covered (Fig. 3 ). While this is only one example, we found that the relative differences regarding the amount of range equivalents covered for a given upper cost limit generally 
increased between the prioritization scenarios the lower the upper cost limits were set (Fig 3).
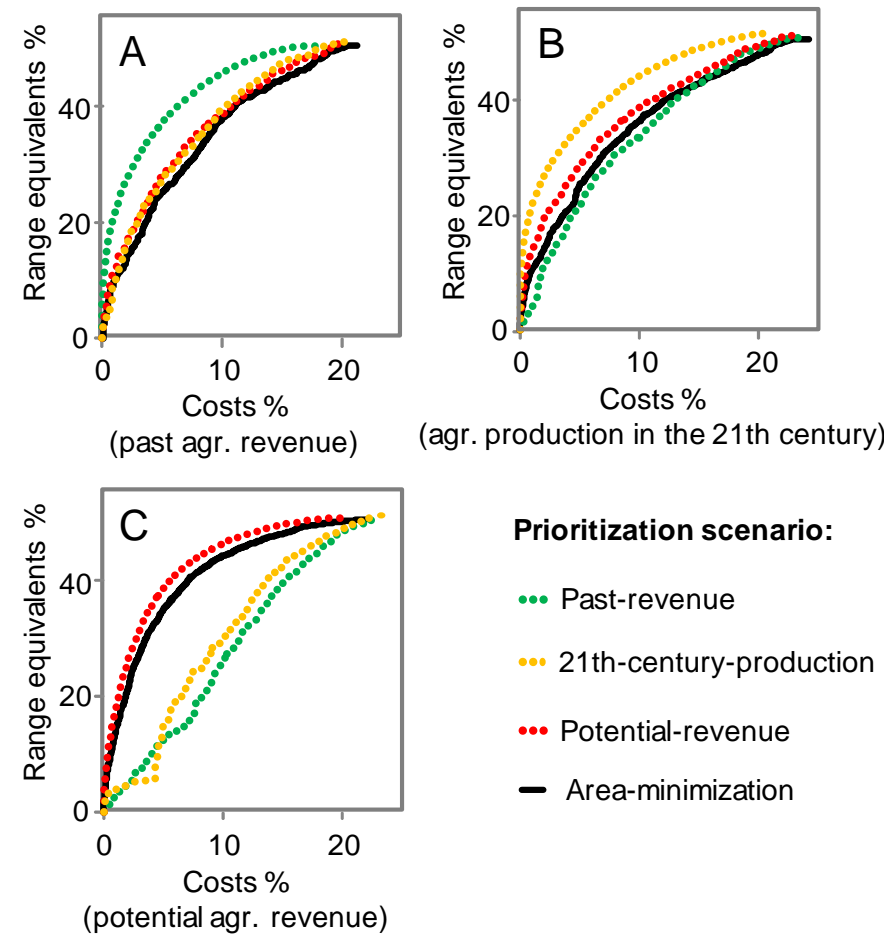

Prioritization scenario:

..P Past-revenue

21th-century-production

..P Potential-revenue

- Area-minimization

Fig. 3: Amount of mammal range equivalents covered as the upper agricultural opportunity cost limits increase. $100 \%$ of costs and range equivalents, respectively, refer to the sum across all considered grid cells $(n=2020)$. Upper opportunity cost limits were defined according to (A) past agricultural revenue, (B) agricultural production in the $21^{\text {th }}$ century, and (C) potential agricultural revenue. As the upper cost limit increased, more priority areas were selected in increasing order of marginal costs, that is the amount of agricultural opportunity costs required per additional mammal range equivalent covered. Depending on the prioritization scenario, marginal costs were defined according to past agricultural revenue, agricultural production during the $21^{\text {th }}$ century, potential agricultural revenue, and grid cell area.

\section{Discussion}

As no detailed global information exists on actual agricultural opportunity costs, global-scale prioritization analyses have approximated such costs using differing indicators (Naidoo and Iwamura 2007; Carwardine et al. 2008; Iwamura et al. 2010; Wilson et al. 2011; Larsen et al. 2011; Freudenberger et al. 2013; Dobrovolski et al. 2014; Venter et al. 2014). We present the first detailed analysis of how different 
indicators of agricultural opportunity costs differently affect the selection of priority areas for global biodiversity conservation. Our analyses revealed that different indicators of agricultural opportunity costs correlate only weakly to moderately in space. Most importantly, our results show that the choice of the agricultural opportunity cost indicator has a strong effect on the selection, and the perceived costeffectiveness of global priority areas for biodiversity conservation. Our results demonstrate that current state-of-the-art approaches for minimizing agricultural opportunity costs of conservation at the global-scale (Naidoo and Iwamura 2007; Carwardine et al. 2008; Iwamura et al. 2010; Wilson et al. 2011; Larsen et al. 2011; Freudenberger et al. 2013; Dobrovolski et al. 2014; Venter et al. 2014) deliver inconclusive results because the perceived cost-effectiveness of priority areas varies widely depending on which cost indicator is considered, while at the same time it is uncertain how well each cost indicator corresponds to the true agricultural opportunity costs of conservation.

Previous work has shown that accounting for spatial heterogeneity in costs generally has a greater impact under maximum coverage prioritization than under minimum set prioritization (Moilanen and Arponen 2011). This is because, when conservation resources are assumed to be insufficient for meeting all intended conservation targets, even areas of the highest biodiversity value may not be selected as priority areas when they incur a disproportionally high amount of costs (Moilanen and Arponen 2011). Building on this body of research, our results demonstrate that also the sensitivity of prioritization towards differing indicators of costs increases when maximum coverage prioritization is applied, in particular under low upper cost limits. Assuming that not all intended conservation targets can be met more realistically reflects the socio-economic constraints of conservation efforts worldwide (see e.g. Joppa and Pfaff 2009; McCarthy et al. 2012). For instance, it has recently been shown that providing adequate protected coverage for all terrestrial vertebrates is unlikely to be achievable because it would require nearly doubling the size of the current global protected area system (Butchart 2015). Thus, our results demonstrate that the arguably most relevant prioritization approach for conservation decision making is also the least robust to uncertainty in cost data.

The majority of priority areas that were selected in any scenario under minimum set prioritization represented areas that were irreplaceable for meeting all indented conservation targets $(n=280)$. This result confirms for the global-scale that sites with 
high importance for meeting conservation targets are typically robust to diverging cost scenarios, at least if minimum set prioritization is applied (Carwardine et al. 2010).

We acknowledge that a part of the spatial divergence of priority areas across scenarios under the minimum set prioritization approach may come from inherent flexibility of the site selection algorithm used by the MARXAN software, which occurs when multiple planning units have similar costs and species compositions (see Ball et al. 2009). However, we also found that minimizing agricultural opportunity costs associated with achieving all intended conservation targets according to one cost indicator resulted in considerably increased costs according to any of the other opportunity cost indicators. In particular, we found that the agricultural opportunity costs according to any of the other indicators at best were only between $3 \%$ to $7 \%$ lower across prioritization scenarios that incorporated cost indicators than what would have been achieved with a mere area-minimization scenario. The areaminimization-scenario even outperformed the past-revenue-scenario and the 21thcentury-production-scenario by at least $6 \%$ according to potential agricultural revenues.

Carwardine et al. (2008) found that compared to assuming uniform costs inclusion of potential agricultural revenues as an opportunity cost indicator reduced the costs associated with protecting $10 \%$ of every mammal species' range by at least $30 \%$. In comparison, in our analyses assuming uniform costs (area-minimization-scenario) increased opportunity costs according to potential agricultural revenues only by $7 \%$. First, perceived efficiency gains from including cost data were lower in our analysis because we focused on the tropical and subtropical moist broadleaf forests biome which contains a high number of range restricted mammal species (IUCN 2012). Therefore, the proportion of areas that were always required to represent each species regardless of costs was relatively high which decreased the spatial options to reduce conservation costs (Pressey et al. 1999). In addition, we used proportionally higher conservation targets for species with smaller range sizes which typically also increased the number of areas that are essential for achieving all intended conservation targets. Given the relatively high proportion of sites essential for meeting all intended conservation targets in our analysis, we suggests that we underestimated rather than overestimated the general sensitivity of minimum set prioritization towards the choice of the cost indicator. 
The cost-effective sets of priority areas from our analysis are meant to be illustrative, focusing on mammal species distributions and agricultural opportunity costs. They do not consider other aspects that factor into real-world conservation planning, e.g. opportunity costs from other land uses, other taxonomic groups, management of biodiversity in human dominated landscapes, ecological processes, known conservation opportunities, and governance effectiveness (Groves 2003).

Each opportunity cost indicator considered here is associated with relative advantages and limitations. The maximum potential agricultural revenue indicator (Carwardine et al. 2008) indicates the revenue of the most valuable crop that could be produced according to land suitability. However, land suitability alone may be a relatively weak indicator of the actual probability of conversion to agriculture because socio-economic factors such as regional demand, and existence of transport and other infrastructure are also key determinants of land use change (Lambin et al. 2003; Chomitz 2007). The forecast agricultural production indicator (Dobrovolski et al. 2014) considers the probability of conversion to agricultural land use according to land cover maps produced by the Integrated Model to Assess the Global Environment (IMAGE) based on a set of alternative socio-economic scenarios for the 21 th century. Ideally, a measure of opportunity costs would also consider the probability of conversion to different agricultural land uses such as cash crops, food crops, or grassland. Unfortunately, though, while the development scenarios used by IMAGE model report agricultural extent for both crops and pasture, the land cover maps derived from the scenarios do not break down agricultural extent into different land uses (IMAGE-Team 2001). Thus, similar to Carwardine et al. (2008), Dobrovolski et al. (2014) assume that farmers' choice of crops would follow the objective to maximize the agronomic productivity of each area. However, this assumptions results in inconsistencies with the initial land cover maps according to which approximately $50 \%$ of the mapped agricultural extent is reported to be used for low return grassland (see IMAGE-Team 2001). Finally, the past agricultural revenue indicator from Naidoo and Iwamura (2007) provides a relatively well established picture of past opportunity costs as it incorporates a dataset of the spatial distribution of crops and pasture that is consistent with past agricultural census data (Leff et al. 2004). However, its key limitation is that it cannot be used to predict how agricultural revenues might evolve over time. According to this indicator, many 
wilderness regions without current agriculture do not appear to carry any opportunity costs, although they are susceptible to future land use change.

Inevitably, global-scale conservation prioritization will have to continue to rely on imperfect estimates of agricultural opportunity costs of conservation (Armsworth et al. 2014). However, given relative advantages and limitations of different agricultural opportunity cost indicators, we suggest that an evaluation of how much each input parameter (e.g. agricultural extent, fraction of agricultural extent occupied by different crop types and pasture, consideration of crop prices) is contributing to the spatial divergence across indicators may assist in setting research priorities for producing a single more authoritative indicator of agricultural opportunity costs. Such a consolidated cost indicator is likely increase the conclusiveness and credibility of identifying cost-effective priority areas for global conservation prioritization.

\section{References}

Armsworth, P.R. (2014). Inclusion of costs in conservation planning depends on limited datasets and hopeful assumptions. Annals of the New York Academy of Sciences 1322: 61-76. doi:10.1111/nyas.12455.

Ball, I.R., Possingham, H.P., Watts, M.E. (2009). Marxan and relatives: software for spatial conservation prioritisation. In Moilanen, A., Wilson, K.A., Possingham, H.P. (eds.). Spatial conservation prioritisation: quantitative methods and computational tools. Oxford: Oxford University Press. pp. 185195.

Ban, N.C., Klein, C.J. (2009). Spatial socioeconomic data as a cost in systematic marine conservation planning. Conservation Letters 2: 206-215. doi:10.1111/j.1755-263X.2009.00071.x.

Butchart, S.H.M., Clarke, M., Smith, R.J., Sykes, R.E., Scharlemann, J.P.W., Harfoot, M., Buchanan, G.M., Angulo, A., Balmford, A., Bertzky, B., Brooks, T.M., Carpenter, K.E., Comeros-Raynal, M.T., Cornell, J., Ficetola, G.F., Fishpool, L.D.C., Fuller, R.A., Geldmann, J., Harwell, H., HiltonTaylor, C., Hoffmann, M., Joolia, A., Joppa, L., Kingston, N., May, I., Milam, A., Polidoro, B., Ralph, G., Richman, N., Rondinini, C., Segan, D., 
Skolnik, B., Spalding, M., Stuart, S.N., Symes, A., Taylor, J., Visconti, P., Watson, J., Wood, L., Burgess, N.D. (2015). Shortfalls and Solutions for Meeting National and Global Conservation Area Targets. Conservation Letters 8: 329-337. doi:10.1111/conl.12158.

Carwardine, J., Wilson, K.A, Hajkowicz, S.A., Smith, R.J., Klein, C.J., Watts, M., Possingham, H.P. (2010). Conservation planning when costs are uncertain. Conservation Biology 24: 1529-1537. doi:10.1111/j.1523-1739.2010.01535.x.

Carwardine, J., Wilson, K.A., Ceballos, G., Ehrlich, P.R., Naidoo, R., Iwamura, T., Hajkowicz, S.A., Possingham, H.P. (2008). Cost-effective priorities for global mammal conservation. Proceedings of the National Academy of Sciences of the United States of America 105: 11446-11450. doi:10.1073/pnas.0707157105.

Ceballos, G., Ehrlich, P.R., Soberón, J., Salazar, I., Fay, J.P. (2005). Global mammal conservation: what must we manage? Science 309:603-607. doi:10.1126/science.1114015.

Chomitz, K.M. (2007). At loggerheads?: agricultural expansion, poverty reduction, and environment in the tropical forests. Washington DC: The World Bank.

Clifford, P., Richardson, S., Hemon, D. (1989). Assessing the Significance of the Correlation between Two Spatial Processes. Biometrics 45: 123-134. doi:0.2307/2532039.

Convention on Biological Diversity (2011). Conference of the Parties Decision X/2: Strategic plan for biodiversity 2011-2020. Retrieved from URL: www.cbd.int/decision/cop/ ?id=12268 (accessed 25.08.2015).

Dobrovolski, R., Loyola, R., D.A. Fonseca, G.A.B., Diniz-Filho, J.A.F., Araujo, M.B. (2014). Globalizing Conservation Efforts to Save Species and Enhance Food Production. BioScience 64: 539-545. doi:10.1093/biosci/biu064.

Dobrovolski, R., Loyola, R.D., Guilhaumon, F., Gouveia, S.F., Diniz-Filho, J.A.F. (2013). Global agricultural expansion and carnivore conservation biogeography. Biological Conservation 165: 162-170. doi:10.1016/j.biocon.2013.06.004. 
Fischer, G., van Velthuizen, H., Shah, M., Nachtergaele, F. (2002). Global Agroecological Assessment for Agriculture in the 21st Century: Methodology and Results. Laxenburg: International Institute for Applied Systems Analysis.

Freudenberger, L., Hobson, P., Schluck, M., Kreft, S., Vohland, K., Sommer, H., Reichle, S., Nowicki, C., Barthlott, W., Ibisch, P.L. (2013). Nature conservation: priority-setting needs a global change. Biodiversity and Conservation 22: 1255-1281.doi:10.1007/s10531-012-0428-6.

Groves, C. (2003). Drafting a Conservation Blueprint - A Practitioner's Guide to Planning for Biodiversity. Washington, DC: Island Press.

IMAGE Team (2001).The IMAGE 2.2 Implementation of the SRES Scenarios. A Comprehensive Analysis of Emissions, Climate Change and Impacts in the 21st Century. Bilthoven: Netherlands Environmental Assessment Agency.

IUCN (2012). IUCN Red List of Threatened Species. Retrieved from URL: http://www.iucredlist.org/. (accessed 01.09.2014).

IUCN and UNEP-WCMC (2012). The World Database on Protected Areas (WDPA) [On-line], Cambridge, UK: UNEP-WCMC. Retrieved from URL: www.protectedplanet.net (accessed 15.09 2012).

Iwamura, T., Wilson, K.A., Venter, O., Possingham, H.P. (2010). A climatic stability approach to prioritizing global conservation investments. PLoS One 5: e15103. doi:10.1371/journal.pone.0015103.

Joppa, L.N., Pfaff, A. (2009). High and Far: Biases in the Location of Protected Areas. PLoS One 4: e8273. doi:10.1371/journal.pone.0008273.

Kier, G., Barthlott, W. (2001). Measuring and mapping endemism and species richness : a new methodological approach and its application on the flora of Africa. Biodiversity and Conservation 10: 1513-1529. doi:0.1023/A:1011812528849.

Lambin, E.F., Geist, H.J., Lepers, E. (2003). Dynamics of land-use and land-cover change in tropical regions. Annual Review of Environment and Resources 28: 205-241. doi:10.1146/annurev.energy.28.050302.105459.

Larsen, F.W., Londoño-Murcia, M.C., Turner, W.R. (2011). Global priorities for conservation of threatened species, carbon storage, and freshwater services: 
scope for synergy? Conservation Letters 4, 355-363.

doi:10.1111/j.1755-263X.2011.00183.X.

Laurance, W.F., Sayer, J., Cassman, K.G. (2014). Agricultural expansion and its impacts on tropical nature. Trends in Ecology \& Evolution 29: 107-116. doi:10.1016/j.tree.2013.12.001.

Leff, B., Ramankutty, N., Foley, J.A. (2004). Geographic distribution of major crops across the world. Global Biogeochemical Cycles 18: GB1009. doi:10.1029/2003GB002108.

McCarthy, D.P., Donald, P.F., Scharlemann, J.P.W., Buchanan, G.M., Balmford, A., Green, J.M.H., Bennun, L.A., Burgess, N.D., Fishpool, L.D.C., Garnett, S.T., Leonard, D.L., Maloney, R.F., Morling, P., Schaefer, H.M., Symes, A., Wiedenfeld, D.A., Butchart, S.H.M. (2012). Financial costs of meeting global biodiversity conservation targets: current spending and unmet needs. Science 338: 946-949. doi:10.1126/science.1229803.

Moilanen, A., Arponen, A. (2011). Setting conservation targets under budgetary constraints. Biological Conservation 144: 650-653. doi:10.1016/j.biocon.2010.09.006.

Naidoo, R., Iwamura, T. (2007). Global-scale mapping of economic benefits from agricultural lands: Implications for conservation priorities. Biological Conservation 140: 40-49. doi:10.1016/j.biocon.2007.07.025.

Newbold, T., Hudson, L.N., Hill, S.L.L., Contu, S., Lysenko, I., Senior, R.A., Borger, L., Bennett, D.J., Choimes, A., Collen, B., Day, J., De Palma, A., Diaz, S., Echeverria-Londono, S., Edgar, M.J., Feldman, A., Garon, M., Harrison, M.L.K., Alhusseini, T., Ingram, D.J., Itescu, Y., Kattge, J., Kemp, V., Kirkpatrick, L., Kleyer, M., Correia, D.L.P., Martin, C.D., Meiri, S., Novosolov, M., Pan, Y., Phillips, H.R.P., Purves, D.W., Robinson, A., Simpson, J., Tuck, S.L., Weiher, E., White, H.J., Ewers, R.M., Mace, G.M., Scharlemann, J.P.W., Purvis, A. (2015). Global effects of land use on local terrestrial biodiversity. Nature 520: 45-50. doi:10.1038/nature14324.

Olson, D., Dinerstein, E. (1998). The Global 200: a representation approach to conserving the Earth's most biologically valuable ecoregions. Conservation Biology 12: 502-515. doi:10.1046/j.1523-1739.1998.012003502.x. 
Pereira, H.M., Navarro, L.M., Martins, I.S. (2012). Global Biodiversity Change: The Bad, the Good, and the Unknown. Annual Review of Environment and Resources 37: 25-50. doi:10.1146/annurev-environ-042911-093511.

Pressey, R.L., Possingham, H.P., Logan, V.S., Day, J.R., Williams, P.H. (1999).

Effects of data characteristics on the results of reserve selection algorithms. Journal of Biogeography 26: 179-191. doi:10.1046/j.1365-2699.1999.00258.x.

Rodrigues, A.S.L., Akçakaya, H.R., Andelman, S.J., Bakarr, M.I., Boitani, L., Brooks, T.M., Chanson, J.S., Fishpool, L.D.C., Da Fonseca, G.A.B., Gaston, K.J., Hoffmann, M., Marquet, P.A., Pilgrim, J.D., Pressey, R.L., Schipper, J., Sechrest, W., Stuart, S.N., Underhill, L.G., Waller, R.W., Watts, M.E.J., Yan, X. (2004). Global Gap Analysis: Priority Regions for Expanding the Global Protected-Area Network. Bioscience 54: 1092-1100. doi:10.1641/0006-3568(2004)054[1092:GGAPRF]2.0.CO;2.

van Velthuizen, H., Huddelston, B., Fischer, G., Salvatore, M., Ataman, E., Nachtergaele, F., Zanetti, M., Bloise, M. (2007). Mapping biophysical factors that influence agricultural production and rural vulnerability. Rome: FAO.

Venter, O., Fuller, R.A.., Segan, D.B., Carwardine, J., Brooks, T., Butchart, S.H.M., Di Marco, M., Iwamura, T., Joseph, L., O’Grady, D., Possingham, H.P., Rondinini, C., Smith, R.J., Venter, M., Watson, J.E.M. (2014). Targeting Global Protected Area Expansion for Imperiled Biodiversity. PLoS Biology 12: e1001891. doi:10.1371/journal.pbio.1001891.

Weeks, R., Russ, G.R., Bucol, A.A., Alcala, A.C. (2010). Shortcuts for marine conservation planning: The effectiveness of socioeconomic data surrogates. Biological Conservation 143: 1236-1244. doi:10.1016/j.biocon.2010.02.031.

Wilson, K.A., Carwardine, J., Possingham, H.P. (2009). Setting conservation priorities. Annals of the New York Academy of Sciences 1162: 237-64. doi:10.1111/j.1749-6632.2009.04149.x.

Wilson, K.A., Evans, M.C., Di Marco, M., Green, D.C., Boitani, L., Possingham, H.P., Chiozza, F., Rondinini, C. (2011). Prioritizing conservation investments for mammal species globally. Philosophical Transactions of the Royal Society B: Biological Sciences 366: 2670-2680. doi:10.1098/rstb.2011.0108. 


\title{
Chapter IV
}

\section{Cost-effective priorities for global biodiversity conservation require consideration of possible pathways of agricultural expansion}

\author{
Georg Barth $^{1}$, Jan Barkmann ${ }^{1,2}$, Carsten Meyer ${ }^{3}$, Holger Kreft ${ }^{3}$, Rainer Marggraf ${ }^{1}$
}

${ }^{1}$ Environmental and Resource Economics, Georg-August-Universität Göttingen, 37077 Göttingen, Germany; ${ }^{2}$ Risk and Sustainability Sciences, Hochschule Darmstadt - University of Applied Sciences, 64295 Darmstadt, Germany; ${ }^{3}$ Biodiversity, Macroecology and Conservation Biogeography, Georg-August-Universität Göttingen, 37077 Göttingen, Germany 


\section{Abstract}

To date, approaches in global conservation prioritization often incorporate agricultural opportunity costs either based on past agricultural extent (mid 1990s) or based on maximum potential agricultural extent with reference to biophysical land suitability. However, recent studies suggest that it is crucial to consider possible pathways of agricultural expansion in the $21^{\text {th }}$ century to accurately account for opportunity costs of conservation. However, proposed approaches to calculate agricultural opportunity costs cannot directly be compared with regard to divergent scenarios of agricultural extent because they also use varying assumptions on agricultural land use composition, input levels, and prices. Here, we conducted a specifically targeted sensitivity analyses to quantify how divergent scenarios of agricultural extent affect estimates of agricultural opportunity costs and associated cost-effective conservation priorities at the global-scale. We exemplarily focus on mammals, a flagship group to represent biodiversity conservation at large, and on tropical and subtropical moist broadleaf forests, a hyper diverse global biome under increasing threat from agricultural expansion. We recalculated and mapped agricultural opportunity costs and identified priority areas for conservation based on three alternative scenarios of agricultural extent: (i) past extent, (ii) forecast extent according to possible pathways of agricultural expansion during the $21^{\text {th }}$ century, and (iii) maximum potential extent. After eliminating confounding factors, the resulting spatial distributions of global agricultural opportunity costs still differed substantially. Agricultural expansion during the $21^{\text {th }}$ century can not exactly be predicted, but our results clearly demonstrate that estimates of opportunity costs based on past-, or maximum potential agricultural extent are not congruent with possible pathways of agricultural expansion in the future. Most importantly, our results indicate that substantial efficiency gains in global conservation prioritization in the order of magnitude of several billion US\$ per year can be realized by more fully considering available information on possible pathways of agricultural expansion during the 21 th century.

\section{Introduction}

Conversion of natural habitats to agriculture is one of the main causes of global biodiversity loss (Pereira et al 2012; Newbold et al. 2015). With growing human 
demand, the global extent of cropland is currently expanding faster than at any time in the past 50 years (Grassini et al. 2013). As part of a global strategy to halt biodiversity loss, nations have agreed to expand the global protected area coverage from $13 \%$ to $17 \%$ of land area by 2020 (Convention on Biological Diversity 2011). Protecting habitats by excluding human uses generally incurs opportunity costs associated with forgone opportunities for production (Naidoo et al. 2006). For the feasibility of conservation, it is important that biodiversity goals are achieved in a way that minimizes, as far as possible, opportunity costs (Faith and Walker 2002; Polasky et al. 2008).

To minimize opportunity costs for achieving conservation targets, setting systematic conservation priorities is essential (Margules and Sarkar 2006; Polasky et al. 2008). Prioritization analyses are required at local, national, global-scales (Margules and Sarkar 2006; Venter et al. 2014). Carefully selecting priority areas requires spatially explicit data on both, conservation values and costs (Faith and Walker 2002; Polasky et al. 2008). In general, foregone agricultural profit (farming income minus production costs) is regarded as a convenient measure of the agricultural opportunity costs of conservation (Chomitz 2007). Globally, however, precise data on the spatial distribution of agricultural profits are not available (Naidoo and Iwamura 2007). As a result, global prioritization analyses have used different indicators of agricultural opportunity costs, each with relative merits and limitations (see chapter III of this thesis). Revenue (income before cost of production) of agricultural land was estimated by Naidoo and Iwamura (2007) at a 5' resolution by integrating spatially explicit information on land suitability, livestock density, and agricultural output prices (Tab. 1). Their study was focused on past agricultural land (mid 1990s), however. Thus, large wilderness areas such as the Amazon Basin and the Congo Basin without agriculture during the 1990s do not appear to carry any opportunity costs, although, they are likely subject to agricultural expansion in the future (Strassburg et al. 2009). In addition to this very conservative approach, Naidoo and Iwamura (2007) also mapped maximum potential agricultural revenue, indicating the revenue of the most valuable crop that could be produced based on biophysical land suitability, regardless of whether the area is used for agriculture or not (see Carwardine et al. 2008; Strassburg et al. 2009). This map represents a maximum estimate of global opportunity costs. Both approaches are highly valuable as first estimates of minimum and maximum opportunity costs, but they disregard existing, 
much more detailed scenarios of relevant socio-economic drivers of land-use change, including accessibility and regional human demand as driven by population growth (Lambin et al. 2003).

The need to understand the long-term dynamics of global land-use change led to the detailed description of possible pathways of future agricultural expansion congruent with key drivers of land-use change (IMAGE-Team 2001). Recently, Dobrovolski et al. (2014) calculated and mapped global agricultural opportunity costs of conservation based on such possible pathways of agricultural expansion. Unlike previous studies, opportunity costs were not defined in terms of prices (revenues), but instead were defined in terms of physical measures of production forgone, and different assumptions on land use composition and agricultural input levels were used (Tab. 1). Thus, the opportunity cost estimates from Dobrovolski et al. (2014), and previous studies could not be compared directly with regard to the effect of considering scenarios of future agricultural expansion instead of past-, or maximum potential agricultural extent.

Tab. 1: Approaches to estimate agricultural opportunity costs of conservation at the globalscale.

\begin{tabular}{|c|c|c|c|c|}
\hline Reference & Agricultural extent & Land use composition & $\begin{array}{l}\text { Agricultural } \\
\text { input level }\end{array}$ & $\begin{array}{l}\text { Opportunity cost } \\
\text { measure }\end{array}$ \\
\hline $\begin{array}{l}\text { Naidoo and } \\
\text { Iwamura } \\
(2007)\end{array}$ & $\begin{array}{l}\text { Congruent with } \\
\text { agricultural census in } \\
\text { the mid 1990s }\end{array}$ & $\begin{array}{l}\text { Crop and grassland fractions in each } \\
\text { grid cell congruent with agricultural } \\
\text { census in the mid 1990s }\end{array}$ & $\begin{array}{l}\text { Intermediate } \\
\text { Input level }\end{array}$ & $\begin{array}{l}\text { Revenue } \\
\text { (US\$ / ha / y) }\end{array}$ \\
\hline $\begin{array}{l}\text { Carwardine } \\
\text { et al. (2008) }\end{array}$ & $\begin{array}{l}\text { Maximum potential } \\
\text { extent based on } \\
\text { biophysical land } \\
\text { suitability }\end{array}$ & $\begin{array}{l}\text { Crops that maximize revenue in each } \\
\text { grid cell }\end{array}$ & $\begin{array}{l}\text { Intermediate } \\
\text { Input level }\end{array}$ & $\begin{array}{l}\text { Revenue } \\
\text { (US\$ / ha / y) }\end{array}$ \\
\hline $\begin{array}{l}\text { Dobrovolski } \\
\text { et al. (2014) }\end{array}$ & $\begin{array}{l}\text { Possible pathways for } \\
\text { the } 21 \text { th century }\end{array}$ & $\begin{array}{l}\text { Crops that maximize the extent of } \\
\text { suitable land in each grid cell (sensu } \\
\text { Fischer et al. 2008) }\end{array}$ & $\begin{array}{c}\text { Mix of low, } \\
\text { intermediate, } \\
\text { and high input } \\
\text { level }\end{array}$ & $\begin{array}{l}\text { Physical production } \\
\text { (\% of attained potential } \\
\text { productivity) }\end{array}$ \\
\hline $\begin{array}{l}\text { Present } \\
\text { paper }\end{array}$ & $\begin{array}{l}\text { Three Scenarios: } \\
\text { Past-, forecast-, and } \\
\text { maximum potential } \\
\text { agricultural extent }\end{array}$ & $\begin{array}{l}\text { Crops that maximize revenue in each } \\
\text { grid cell }\end{array}$ & $\begin{array}{l}\text { Intermediate } \\
\text { input level }\end{array}$ & $\begin{array}{l}\text { Revenue } \\
\left(\mathrm{US} \$ / \mathrm{km}^{2} / \mathrm{y}\right)\end{array}$ \\
\hline
\end{tabular}

Here, we expand previous work on the cost-effective identification of priority areas for conservation at the global-scale (see chapter III of the present thesis) by a sensitivity analysis specifically targeting the effect of divergent scenarios of agricultural extent. Specifically, we estimated and mapped opportunity costs for 
three scenarios of agricultural extent, while holding all other things such as assumptions regarding land use composition, constant: (i) past extent, (ii) future extent according to possible pathways of agricultural expansion in the $21^{\text {th }}$ century, and (iii) maximum potential extent based on biophysical land suitability. We used these data to answer the following research questions:

(i) How are global-scale indicators of agricultural opportunity costs affected by divergent scenarios of agricultural extent?

(ii) How is global-scale conservation prioritization affected by incorporating indicators of agricultural opportunity based on divergent scenarios of agricultural extent?

We focus our analysis on tropical and subtropical moist broadleaf forests (Olson and Dinerstein 1998) - a biome that has consistently emerged as a focal point for global biodiversity conservation (Brooks et al. 2006). These forests likely contain more than half of all species (Olson and Dinerstein 1998), and are under substantial threat from agricultural expansion (Laurance et al. 2014). To address research question (ii), we analyzed prioritization scenarios for mammal conservation. Mammals are a flagship taxonomic group to leverage support for biodiversity conservation at large and are frequently used as a target group for global prioritization analyses (Ceballos et al. 2005; Dobrovolski et al. 2014)

\section{Methods}

\subsection{Species and economic data}

We used global equal-area grids of $12,364 \mathrm{~km}^{2}$ (approximately $111 \mathrm{~km} \times 111 \mathrm{~km}$ at the equator) to delineate planning units for conservation prioritization. We clipped the grid layer to the spatial extent of the tropical and subtropical moist broadleaf forest biome (Olson and Dinerstein 1998). Subsequently, 288 of the 2,308 planning units for which cost data were not available were omitted. We used expert-opinion maps that indicate the extent of occurrence of mammals, to establish presence/absence data for 3,327 species that intersected the considered planning units (IUCN 2012).

To estimate agricultural opportunity costs, we calculated agricultural revenues (US\$ / $\mathrm{km}^{2} / \mathrm{yr}$ ) across all grids of planning units, based either on, (i) agricultural extent 
from 1990 to 2000 (past extent), possible pathways of agricultural extent from 2000 to 2100 (forecast extent), (iii) and maximum potential extent with regard to biophysical land suitability.

We defined maximum potential agricultural extent based on a database of biophysical land suitability at 5' resolution (Fischer et al. 2002), and assumed that all land suitable for cultivation of crops would be converted to agriculture (Carwardine et al. 2008; Strasburg et al. 2009). To define agricultural extent from 1990 to 2000 and from 2000 to 2100 , we used land cover maps at a spatial resolution of $0.5^{\circ}$ produced by the Integrated Model to Assess the Global Environment (IMAGE, version 2.2, IMAGE-Team, 2001). The maps comprise land cover data for six socioeconomic scenarios from the Special Report on Emissions Scenarios (SRES) report (IPCC 2000). The scenarios represent alternative possible pathways about future demographic, economic, and technological driving forces of land-use change that human societies can follow. Following Dobrovolski et al. (2013), we regarded all SRES scenarios as equally likely to actualize, and calculated the average time (in years) that each $0.5^{\circ}$ grid cell is forecast to be cultivated over the $21^{\text {th }}$ century and across all six socio-economic scenarios .

We assumed that agricultural land is always occupied by the most valuable crop that could be produced based on biophysical land suitability (Carwardine et al. 2008; Strassburg et al. 2009). Maximum potential revenues were taken from Naidoo and Iwamura (2007), who estimated maximum potential revenues at a 5 ' resolution by the maximum potential crop yield based on biophysical land suitability, multiplied by the global average crop price from 1991-2002.

We rescaled maps of agricultural extent from 1990 to 2000 as well as from 2000 to 2100 to a 5 'resolution to match the spatial resolution of the maximum potential revenue map. Subsequently, agricultural revenues (US\$ / $\mathrm{km}^{2} / \mathrm{yr}$ ) for each 5' grid cell were calculated by weighting maximum potential revenues by agricultural extent. Finally, the agricultural revenue data were aggregated across $12,364 \mathrm{~km}^{2}$ planning units. 


\subsection{Conservation prioritization analyses}

We investigated three prioritization scenarios for global mammal conservation, each using revenues based on a different scenario of agricultural extent as an indicator of agricultural opportunity costs.

(i) the past-extent-scenario which used revenues based on agricultural extent from 1990 to 2000 as a cost and,

(ii) the forecast-extent-scenario which used revenues based on agricultural extent from 2000 to 2100 as a cost.

(iii) the maximum-extent-scenario which used revenues based on maximum potential agricultural extent as a cost,

(iv) Furthermore, an area-minimization scenario was added. This scenario implicitly assumes uniform conservation costs worldwide.

We identified priority areas for mammal conservation using a minimum set approach to prioritization. The objective of minimum set prioritization is to select a set of areas that must meet intended conservation targets (e.g. cover $10 \%$ of each target species range) while minimizing, as far as possible, conservation costs (Wilson et al. 2009). We identified priority areas using the MARXAN software (Ball et al. 2009) which is specifically designated to apply this prioritization approach. For each prioritization scenario, we selected the lowest-cost solution across 250 MARXAN runs. To account for current protected areas, we "locked" 66 planning units with more than $50 \%$ current protected area coverage in any prioritization solution (IUCN categories I-IV; IUCN and UNEP-WCMC 2012). We defined that the conservation objective of the prioritization was to cover a fraction of the range size of each considered species, and scaled the targets to a given species' global range size (Rodrigues et al. 2004). We gave the most widespread species (red fox, Vulpes vulpes) a conservation target of $1 \%$ of its global range size and we gave a target of $100 \%$ to species occurring only in one planning unit. We scaled the conservation targets for the remaining species between these two extremes using a power function $\left(\right.$ target $_{\text {species } i}=$ range $\left._{\text {species } i}^{0.47}\right)$ such that targets were higher for range-restricted species. Finally, global mammal representation targets were scaled linearly to the proportion of each species' range that overlaps with the tropical and subtropical moist broadleaf forest biome. 


\subsection{Comparison of conservation prioritization scenarios and cost data}

We used the spearman rank correlations between differing estimates of agricultural revenues across planning units to explore how different scenarios of agricultural extent affected the estimation of agricultural opportunity costs. To account for spatial autocorrelation in the data, we corrected the degrees of freedom for the statistical tests (Clifford et al. 1989).

To explore the sensitivity of the minimum set prioritization approach towards differing scenarios of agricultural extent, we first determined the spatial overlap across prioritization scenarios by mapping the number of scenarios each planning unit was selected as a priority area. Furthermore, we explored the relative efficiency of the past-extent-scenario, the maximum-extent-scenario, and the areaminimization-scenario in meeting the prioritization solution as obtained from the forecast-extent-scenario. Although the future-extent-scenario is, obviously, not a "true" prediction of agricultural opportunity costs in the $21^{\text {st }}$ century, this comparison sheds a light on the economic order of magnitude of the effects discussed in this paper.

\section{Results}

Estimates of agricultural opportunity costs based on divergent scenarios of agricultural extent had different spatial patterns (Fig. 1). Compared to opportunity cost estimates based on past agricultural extent, estimates increased much when forecast extent was considered (Fig. 1). In particular, this was the case for large areas of the Congo Basin and Amazon Basin. However, several areas were not associated with opportunity costs even when forecast agricultural extent was considered (Fig. 1). This was the case, for example, in the most remote parts of the Congo Basin and the Amazonia, and also in parts of Borneo and New Guinea (Fig. 1). In most areas, opportunity cost estimates based on maximum potential agricultural extent were much higher than estimates based on past- or forecast agricultural extent (Fig. 1).

Overall, forecast agricultural extent results on agricultural opportunity costs were slightly less positively correlated with results on maximum potential agricultural extent (spearman correlation coefficient $\mathrm{r}=0.60 ; \mathrm{p}<0.001$ ) than with current agricultural extent $(r=0.73 ; p<0.001)$. Opportunity costs according to maximum 
potential agricultural extent and according to current agricultural extent were only weakly correlated $(\mathrm{r}=0.19 ; \mathrm{p}<0.001)$.
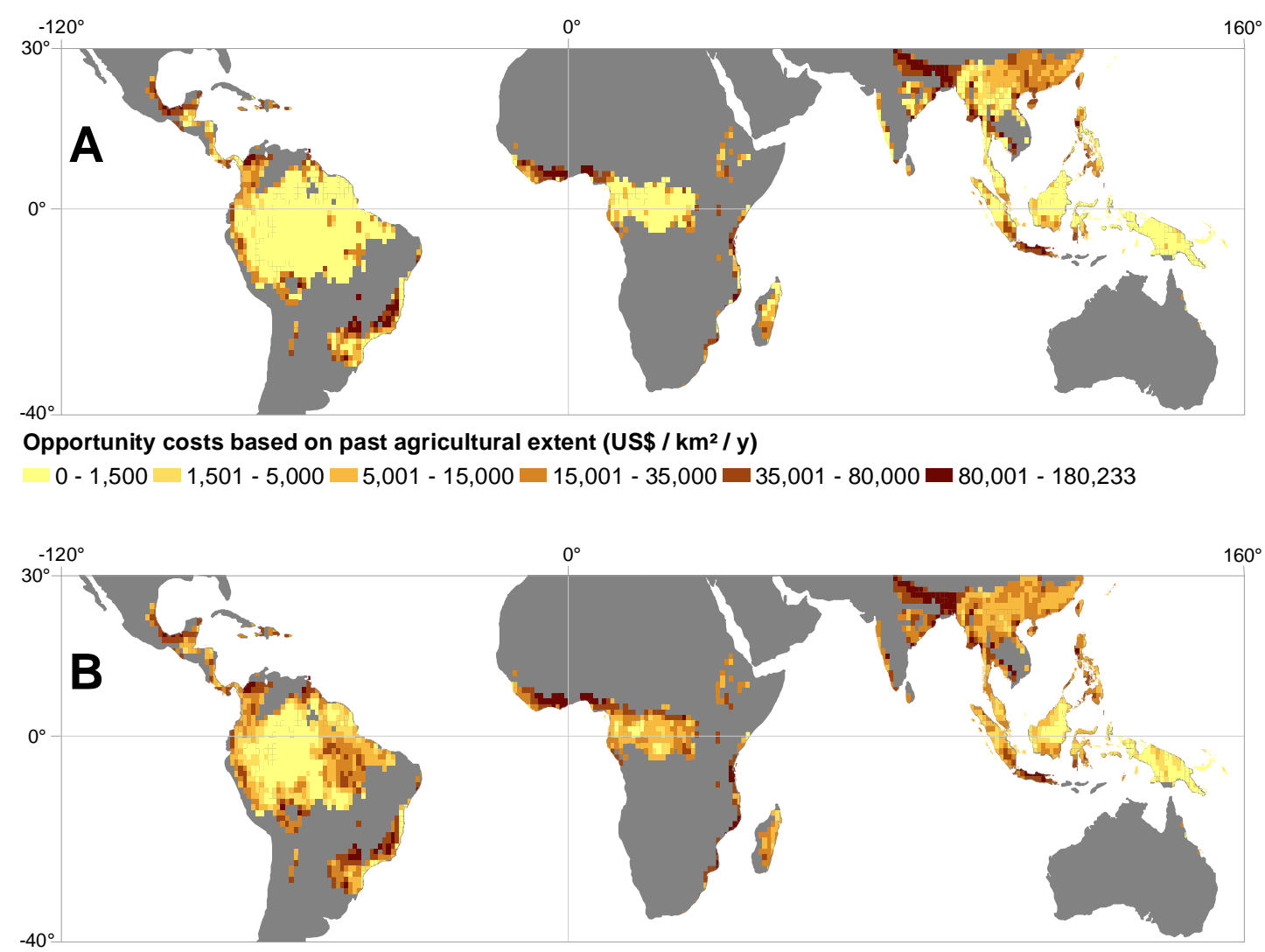

Opportunity costs based on forecast agricultural extent (US\$ / $\left.\mathbf{k m}^{\mathbf{2}} / \mathbf{y}\right)$

$0-1,500-1,501-5,000=5,001-15,000=15,001-35,000=35,001-80,000=80,001-180,233$

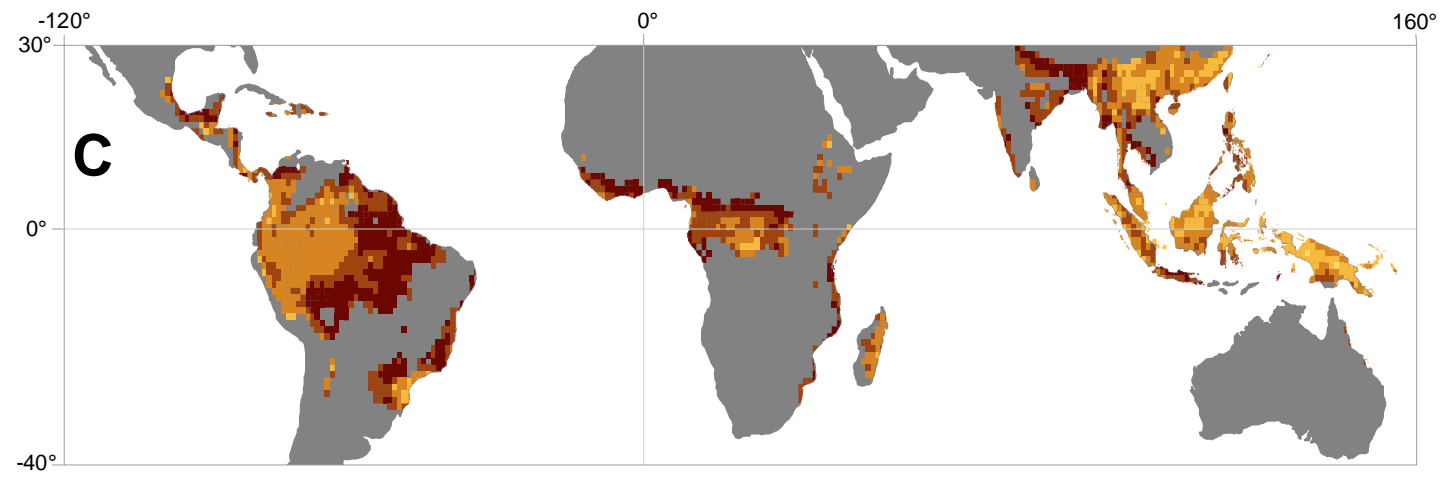

Opportunity costs based on maximum potential agricultural extent (US $\mathbf{~ / ~} \mathbf{k m}^{2} / \mathbf{y}$ )

$0-1,500-1,501-5,000-5,001-15,000=15,001-35,000=35,001-80,000=80,001-180,233$

Fig. 2: Estimates of agricultural opportunity costs across the tropical and sub tropical moist broadleaf forest biome for three different scenarios of agricultural extent (a) Past agricultural extent (1990-2000), (B) forecast agricultural extent according to possible pathways of agricultural expansion (2000-2100), and (C) maximum potential agricultural extent according to biophysical land suitability. 
Of a total of 2,020 planning units considered (20.1 million $\mathrm{km}^{2}$ ), a total of 850 different planning units were selected as priority areas across the four prioritization scenarios analyzed. The number of planning units selected in each scenario ranged between 590 (5.3 million $\mathrm{km}^{2}$; area-minimization-scenario) and 610 (5.7 million $\mathrm{km}^{2}$; forecast-extent-scenario). 417 planning units were selected as priority areas in each of the prioritization scenarios. These included 66 planning units that were "locked" in the prioritization solutions due to current protected area coverage, and 280 planning units that were biologically irreplaceable to meet mammal conservation targets at minimum costs (e.g. because they contained species found nowhere else). Planning units that were selected in each of the prioritization scenarios were predominantly found in the tropical Andes, the southeastern coast of Brazil, Madagascar, Sumatra, the Philippines and New Guinea (Fig. 2). In contrast, larger differences between prioritization scenarios were found throughout the Amazon Basin, Continental Africa, Borneo, and in most areas of continental Southeast Asia (Fig.2).

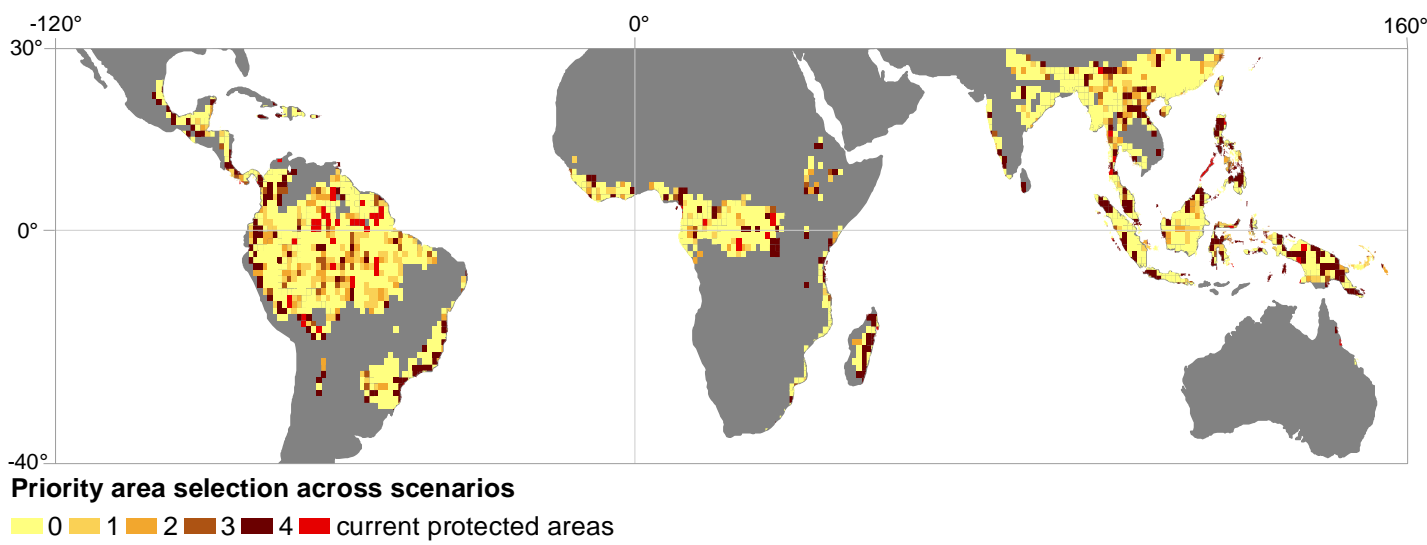

Fig. 3: The cumulative number of prioritization scenarios each planning unit was selected as a priority area to meet intended mammal conservation targets across the tropical and subtropical moist broadleaf forest biome. Scenarios considered comprise: (i) past-extent-scenario, (ii) forecastextent-scenario (iii) maximum-extent-scenario, and (iv) area-minimization-scenario.

In the forecast-extent-scenario, achieving mammal conservation targets incurred US\$ billion 82.4 / yr of opportunity costs according to forecast agricultural extent. Based on the past-extent-scenario, US\$ billion 89.2 / yr were required to achieve mammal conservation targets, and US\$ billion 90.6 / yr were required based on the maximum- 
extent-scenario. The uniform costs-scenario was by far the most expensive by requiring US\$ billion 98.4 / yr.

\section{Discussion}

Approaches in global conservation prioritization have usually incorporated indicators of agricultural opportunity costs either based on past agricultural extent (mid 1990s; Naidoo and Iwamura 2007; Iwamura et al. 2010; Wilson et al. 2011; Larsen et al. 2011; Freudenberger et al. 2013; Venter et al. 2014) or based on maximum potential agricultural extent with reference to biophysical land suitability (Carwardine et al. 2008). Ideally estimation of agricultural opportunity costs of conservation should consider the probability with which natural habitats will be converted to agriculture (see e.g. Grieg-Gram 2006). However, it is unknown to what degree global opportunity cost estimates based on past agricultural extent or based on maximum potential extent reflect the probability of agricultural expansion in the future.

Here, present the first sensitivity analysis specifically targeted to determine how diverging scenarios of agricultural extent affect indicators of agricultural opportunity costs and the identification of cost-effective conservation priorities at the globalscale. In addition to past- and maximum potential agricultural extent, we also estimated opportunity costs using improved data based on possible socio-economic pathways of agricultural expansion during the $21^{\text {th }}$ century (IMAGE-Team- 2001). While agricultural expansion in the future can not exactly be predicted (IMAGETeam 2001), our results clearly demonstrate that estimates of opportunity costs based on past-, or maximum potential agricultural extent are not congruent with possible pathways of agricultural expansion during the $21^{\text {th }}$ century. Most importantly, our results indicate that substantial efficiency gains in global conservation prioritization in the order of magnitude of several billion US\$ per year can be achieved by more fully considering available information on drivers of land use change and possible agricultural development pathways. We found large differences in opportunity cost estimates, exclusively dependent on whether past-, forecast-, or maximum potential agricultural extent was considered. This demonstrates that the spatial dissimilarity of previously proposed indicators of agricultural opportunity costs (see chapter III of this thesis) is substantially affected by the divergent scenarios of agricultural extent. 
Our results confirm previous concerns (Strassburg et al. 2009) that focusing on opportunity costs based on current agricultural extent largely underestimates opportunity cost of protecting wilderness areas of major global importance such as the Amazon Basin and the Congo Basin - both of which are prone to agricultural expansion in the $21^{\text {st }}$ Century. On the other hand, pathways of agricultural expansion are also determined by interacting socio-economic drivers, e.g. related to accessibility and regional demand (reviewed in Lambin et al. 2003). Our results highlight that cultivation potential alone is also a relatively poor indicator of the actual opportunity cost that land users would face (Phalan et al. 2013). Specifically, we found that indicators of opportunity cost based on maximum potential agricultural extent tended to overestimate opportunity costs, particularly in remote and uninhabited areas. In fact, differences between opportunity cost estimates based on maximum potential agricultural extent and forecast agricultural extent were even more pronounced than differences between estimates based on past agricultural extent compared to forecast agricultural extent. In sum, these differences demonstrate that consideration of detailed and internally consistent socio-economic scenarios of future of agricultural expansion is of utmost importance for mapping agricultural opportunity cost at the global-scale.

Recently, Dobrovolski et al. (2014) have shown that consideration of agricultural expansion data in global-scale prioritization can substantially reduce agricultural opportunity costs compared to prioritization without consideration of any cost data. Our results are in line with this conclusion: The equivalent area-minimizationscenario required an additional US\$ billion 16 / yr to protect the same planning units as the future-extent -scenario. While Dobrovolski et al. (2014) were the first to define cost-effective conservation priories at the global-scale incorporating future scenarios of agricultural expansion, we expand their results by an important dimension. If it is assumed that a forecast-extent-scenario accounts accurately for the future distribution of agricultural opportunity costs, than a past-extent-scenario and a potential-extent scenario also appear inefficient as they carried an additional opportunity cost of US\$ billion 6.8 / yr and US\$ billion 8.2 / yr, respectively. In total, this is only a fraction of the opportunity cost required to meet the intended conservation targets. However, prioritization was particularly sensitive towards consideration of agricultural expansion data in the Amazon Basin and in the Congo Basin. These regions have the largest land areas with unexploited agricultural potential worldwide and offer many 
spatial options for priority-setting as there is only a moderate number of biologically irreplaceable areas (e.g. areas that contain species found nowhere else).

The priority areas from our analysis are meant to be illustrative as we focused on mammal conservation and agricultural opportunity costs. They do not consider other factors that usually matter in real-world conservation planning, e.g. opportunity costs from other land uses, other taxonomic groups, management of biodiversity in human dominated landscapes, ecological processes, known conservation opportunities, and governance effectiveness (Groves 2003).

It needs to be considered that revenues overestimate opportunity costs of conservation as they indicate income from agriculture before costs of production. For example, in a typical market oriented farm in Brazil, costs of soy production account for more than half of the attained revenues (Zimmer et al. 2008). In this context, Naidoo and Iwamura (2007) noted that they did not consider costs of production to estimate past- and maximum potential returns from agriculture because a comprehensive dataset on global costs of agricultural production was not available at the time of their analysis. Recently, however, a comprehensive database on costs of production for 14 main crop groups in over 40 countries has become available (IHS 2015). To our knowledge, the utility of this new data source to improve global conservation planning has not been explored.

Ideally, a measure of opportunity costs should consider how much land will probably be cleared for different agricultural land uses, whether grassland, cash crops, subsistence crops etc (see Grieg-Gran 2006 for an example). Unfortunately, though, the land cover maps produced by IMAGE (version 2.2; IMAGE-Team 2001) do not break down agricultural extent into different land uses. To deal with this limitation, we assumed that each agricultural area is occupied by the most valuable crop that could be produced (see also Carwardine et al. 2008; Strassburg et al. 2009). Actual crop composition on the ground, however, will also depend on factors we did not consider such as local production costs and commercialization options (Chomitz 2007). Thus, the future extent results are likely to systematically overestimate average annual agricultural opportunity costs in the $21^{\text {st }}$ century making results structurally too similar to the potential-maximum-extent scenario.

A new version of the IMAGE model (Version 3.0) has been announced recently, which will feature an updated crop model, and information on crop- and grassland 
composition at 5' (Stehfest et al. 2014). Therefore, more detailed analyses of agricultural opportunity cost during the $21^{\text {th }}$ century appear in reach, once the model results become available. Accounting for opportunity costs of conservation based on the refined descriptions of possible pathways of agricultural expansion, interlinked with information on agricultural production costs should be a priority for future research.

\section{References}

Armsworth, P.R. (2014). Inclusion of costs in conservation planning depends on limited datasets and hopeful assumptions. Annals of the New York Academy of Sciences 1322: 61-76. doi:10.1111/nyas. 12455.

Ball, I.R., Possingham, H.P., Watts, M.E. (2009). Marxan and relatives: software for spatial conservation prioritisation. In Moilanen, A., Wilson, K.A., Possingham, H.P. (eds.). Spatial conservation prioritisation: quantitative methods and computational tools. Oxford: Oxford University Press. pp. 185195.

Balmford, A., Gaston, K.J., Blyth, S., James, A., Kapos, V. (2003). Global variation in terrestrial conservation costs, conservation benefits, and unmet conservation needs. Proceedings of the National Academy of Sciences of the United States of America 100: 1046-1050. doi:10.1073/pnas.0236945100.

Brooks, T.M., Mittermeier, R.A., da Fonseca, G.A.B., Gerlach, J., Hoffmann, M., Lamoreux, J.F., Mittermeier, C.G., Pilgrim, J.D., Rodrigues, A.S.L. (2006). Global biodiversity conservation priorities. Science 313: 58-61. doi:10.1126/science.1127609.

Butchart, S.H.M., Clarke, M., Smith, R.J., Sykes, R.E., Scharlemann, J.P.W., Harfoot, M., Buchanan, G.M., Angulo, A., Balmford, A., Bertzky, B., Brooks, T.M., Carpenter, K.E., Comeros-Raynal, M.T., Cornell, J., Ficetola, G.F., Fishpool, L.D.C., Fuller, R. a., Geldmann, J., Harwell, H., HiltonTaylor, C., Hoffmann, M., Joolia, A., Joppa, L., Kingston, N., May, I., Milam, A., Polidoro, B., Ralph, G., Richman, N., Rondinini, C., Segan, D., Skolnik, B., Spalding, M., Stuart, S.N., Symes, A., Taylor, J., Visconti, P., Watson, J., Wood, L., Burgess, N.D. (2015). Shortfalls and Solutions for 
Meeting National and Global Conservation Area Targets. Conservation Letters 8: 329-337. doi:10.1111/conl.12158.

Carwardine, J., Wilson, K.A., Ceballos, G., Ehrlich, P.R., Naidoo, R., Iwamura, T., Hajkowicz, S.A., Possingham, H.P. (2008). Cost-effective priorities for global mammal conservation. Proceedings of the National Academy of Sciences of the United States of America 105: 11446-11450. doi:10.1073/pnas.0707157105.

Carwardine, J., Wilson, K.A., Hajkowicz, S.A, Smith, R.J., Klein, C.J., Watts, M., Possingham, H.P. (2010). Conservation planning when costs are uncertain. Conservation Biology 24: 1529-1537. doi:10.1111/j.1523-1739.2010.01535.x.

Ceballos, G., Ehrlich, P.R., Soberón, J., Salazar, I., Fay, J.P. (2005). Global mammal conservation: what must we manage? Science 309: 603-607. doi:10.1126/science.1114015.

Chomitz, K.M. (2007). At loggerheads?: agricultural expansion, poverty reduction, and environment in the tropical forests. Washington DC: The World Bank.

Clifford, P., Richardson, S., Hemon, D. (1989). Assessing the Significance of the Correlation between Two Spatial Processes. Biometrics 45: 123-134. doi:0.2307/2532039.

Convention on Biological Diversity (2011). Conference of the Parties Decision X/2: Strategic plan for biodiversity 2011-2020. Retrieved from URL: www.cbd.int/decision/cop/ ?id=12268 (accessed 25.08.2015).

Dixon, J.A., Sherman, P.B. (1991). Economics of Protected Areas: A New Look at Benefits and Costs. London: Earthscan.

Dobrovolski, R., Loyola, R., D.A. Fonseca, G.A.B., Diniz-Filho, J.A.F., Araujo, M.B. (2014). Globalizing Conservation Efforts to Save Species and Enhance Food Production. BioScience 64: 539-545. doi:10.1093/biosci/biu064.

Dobrovolski, R., Loyola, R.D., Guilhaumon, F., Gouveia, S.F., Diniz-Filho, J.A.F. (2013). Global agricultural expansion and carnivore conservation biogeography. Biological Conservation 165: 162-170. doi:10.1016/j.biocon.2013.06.004. 
Faith, D.P., Walker, P.A (2002). The role of trade-offs in biodiversity conservation planning: linking local management, regional planning and global conservation efforts. Journal of Biosciences 27: 393-407.

Fischer G, Nachtergaele F, Prieler S, van Velthuizen HT, Verelst L, Wiberg D. (2008). Global Agro-ecological Zones: Assessment for agriculture (GAEZ 2008). Food and Agriculture Organization of the United Nations.

Fischer, G., van Velthuizen, H., Shah, M., Nachtergaele, F. (2002). Global Agroecological Assessment for Agriculture in the 21st Century: Methodology and Results. Analysis Laxenburg: International Institute for Applied Systems.

Freudenberger, L., Hobson, P., Schluck, M., Kreft, S., Vohland, K., Sommer, H., Reichle, S., Nowicki, C., Barthlott, W., Ibisch, P.L. (2013). Nature conservation: priority-setting needs a global change. Biodiversity and Conservation 22: 1255-1281.doi:10.1007/s10531-012-0428-6.

Grieg-Gran, M. (2006). The Costs of Avoiding Deforestation Report prepared for the Stern Review of the Economics of Climate Change. London: International Institute for Environment and Development.

Groves, C. (2003). Drafting a Conservation Blueprint - A Practitioner's Guide to Planning for Biodiversity. Washington, DC: Island Press.

IHS (2015) Global Crops Cost of Production. Retrieved from URL: https://www.ihs.com/products/global-crops-cost-of-production.html (accessed 26.05.2015).

IMAGE-Team (2001).The IMAGE 2.2 Implementation of the SRES Scenarios. A Comprehensive Analysis of Emissions, Climate Change and Impacts in the 21st Century. Bilthoven: Netherlands Environmental Assessment Agency.

IPCC (Intergovernmental Panel on Climate Change) (2000). Special Report on Emissions Scenarios. Cambridge: Cambridge University Press.

IUCN (2012). IUCN Red List of Threatened Species. Retrieved from URL: http://www.iucredlist.org/. (accessed 01.09.2014).

IUCN and UNEP-WCMC (2012). The World Database on Protected Areas (WDPA) [On-line], Cambridge, UK: UNEP-WCMC. Retrieved from URL: www.protectedplanet.net (accessed 15.09 2012). 
Iwamura, T., Wilson, K.A., Venter, O., Possingham, H.P. (2010). A climatic stability approach to prioritizing global conservation investments. PLoS One 5: e15103. doi:10.1371/journal.pone.0015103.

Kier, G., Barthlott, W. (2001). Measuring and mapping endemism and species richness : a new methodological approach and its application on the flora of Africa. Biodiversity and Conservation 10:1513-1529. doi:0.1023/A:1011812528849.

Lambin, E.F., Geist, H.J., Lepers, E. (2003). Dynamics of land-use and land-cover change in tropical regions. Annual Review of Environment and Resources 28: 205-241. doi:10.1146/annurev.energy.28.050302.105459.

Larsen, F.W., Londoño-Murcia, M.C., Turner, W.R. (2011). Global priorities for conservation of threatened species, carbon storage, and freshwater services: scope for synergy? Conservation Letters 4: 355-363. doi:10.1111/j.1755-263X.2011.00183.x.

Laurance, W.F., Sayer, J., Cassman, K.G. (2014). Agricultural expansion and its impacts on tropical nature. Trends in Ecology \& Evolution 29: 107-116. doi:10.1016/j.tree.2013.12.001.

Margules, C.R., Sarkar, S. (2006). Systematic Conservation Planning. New York: Cambridge University Press.

Naidoo, R., Balmford, A., Ferraro, P.J., Polasky, S., Ricketts, T.H., Rouget, M. (2006). Integrating economic costs into conservation planning. Trends in Ecology \& Evolution 21: 681-687. doi:10.1016/j.tree.2006.10.003.

Naidoo, R., Iwamura, T. (2007). Global-scale mapping of economic benefits from agricultural lands: Implications for conservation priorities. Biological Conservation 140: 40-49. doi:10.1016/j.biocon.2007.07.025.

Newbold, T., Hudson, L.N., Hill, S.L.L., Contu, S., Lysenko, I., Senior, R.A., Borger, L., Bennett, D.J., Choimes, A., Collen, B., Day, J., De Palma, A., Diaz, S., Echeverria-Londono, S., Edgar, M.J., Feldman, A., Garon, M., Harrison, M.L.K., Alhusseini, T., Ingram, D.J., Itescu, Y., Kattge, J., Kemp, V., Kirkpatrick, L., Kleyer, M., Correia, D.L.P., Martin, C.D., Meiri, S., Novosolov, M., Pan, Y., Phillips, H.R.P., Purves, D.W., Robinson, A., Simpson, J., Tuck, S.L., Weiher, E., White, H.J., Ewers, R.M., Mace, G.M., 
Scharlemann, J.P.W., Purvis, A. (2015). Global effects of land use on local terrestrial biodiversity. Nature 520: 45-50. doi:10.1038/nature14324.

Olson, D., Dinerstein, E. (1998). The Global 200: a representation approach to conserving the Earth's most biologically valuable ecoregions. Conservation Biology 12: 502-515. doi:10.1046/j.1523-1739.1998.012003502.x.

Pereira, H.M., Navarro, L.M., Martins, I.S. (2012). Global Biodiversity Change: The Bad, the Good, and the Unknown. Annual Review of Environment and Resources 37: 25-50. doi:10.1146/annurev-environ-042911-093511.

Phalan, B., Bertzky, M., Butchart, S.H.M., Donald, P.F., Scharlemann, J.P.W., Stattersfield, A.J., Balmford, A. (2013). Crop expansion and conservation priorities in tropical countries. PLoS One 8: e51759. doi:10.1371/journal.pone.0051759.

Polasky, S., Nelson, E., Camm, J., Csuti, B., Fackler, P., Lonsdorf, E., Montgomery, C., White, D., Arthur, J., Garberyonts, B. (2008). Where to put things? Spatial land management to sustain biodiversity and economic returns. Biological Conservation 141: 1505-1524. doi:10.1016/j.biocon.2008.03.022.

Rodrigues, A.S.L., Akçakaya, H.R., Andelman, S.J., Bakarr, M.I., Boitani, L., Brooks, T.M., Chanson, J.S., Fishpool, L.D.C., Da Fonseca, G. a. B., Gaston, K.J., Hoffmann, M., Marquet, P.A., Pilgrim, J.D., Pressey, R.L., Schipper, J., Sechrest, W., Stuart, S.N., Underhill, L.G., Waller, R.W., Watts, M.E.J., Yan, X. (2004). Global Gap Analysis: Priority Regions for Expanding the Global Protected-Area Network. Bioscience 54: 1092-1100. doi:10.1641/0006-3568(2004)054[1092:GGAPRF]2.0.CO;2.

Stehfest, E., van Vuuren, D., Kram, T., Bouwman, L. (eds.) (2014). Integrated Assessment of Global Environmental Change with IMAGE 3.0. Model description and policy applications. The Hague: Netherlands Environmental Agency.

Strassburg, B., Turner, R.K., Fisher, B., Schaeffer, R., Lovett, A. (2009). Reducing emissions from deforestation-The "combined incentives" mechanism and empirical simulations. Global Environmental Change 19: 265-278. doi:10.1016/j.gloenvcha.2008.11.004. 
Venter, O., Fuller, R.A.., Segan, D.B., Carwardine, J., Brooks, T., Butchart, S.H.M., Di Marco, M., Iwamura, T., Joseph, L., O’Grady, D., Possingham, H.P., Rondinini, C., Smith, R.J., Venter, M., Watson, J.E.M. (2014). Targeting G lobal Protected Area Expansion for Imperiled Biodiversity. PLoS Biology 12: e1001891. doi:10.1371/journal.pbio.1001891.

Wilson, K.A., Carwardine, J., Possingham, H.P. (2009). Setting conservation priorities. Annals of the New York Academy of Sciences 1162: 237-64. doi:10.1111/j.1749-6632.2009.04149.x.

Wilson, K.A., Evans, M.C., Di Marco, M., Green, D.C., Boitani, L., Possingham, H.P., Chiozza, F., Rondinini, C. (2011). Prioritizing conservation investments for mammal species globally. Philosophical Transactions of the Royal Society B: Biological Sciences 366: 2670-2680. doi:10.1098/rstb.2011.0108.

Zimmer, Y. (ed.) (2008). Cash Crop Report 2008. vTI Braunschweig. 


\section{Chapter V}

\section{Synopsis}

Georg Barth ${ }^{1}$

${ }^{1}$ Environmental and Resource Economics, Georg-August-Universität Göttingen, 37077 Göttingen, Germany 


\section{Main messages}

\subsection{Introduction}

Establishing and maintaining protected areas is a crucial component for biodiversity conservation worldwide (Chape et al. 2008) but can be costly, including management costs associated with staff and infrastructure, and opportunity costs associated with the forgone economic returns from the land in its next best use (Dixon and Sherman 1991; Naidoo and Iwamura 2006). It is crucial for the feasibility of conservation to identify priority areas for biodiversity that are cost-effective, either because they meet intended conservation targets for the smallest possible costs, or because they achieve the most conservation for a given amount of costs (Faith and Walker 2002; Naidoo et al. 2006; Polasky et al. 2008).

To date, global-scale analyses of cost-effective priorities predominantly either accounted for management costs of conservation lands (Balmford et al. 2003; Wilson et al. 2006; Bode et al. 2008; Loyola et al. 2009; Underwood et al. 2008; Waldron et al. 2013), or for opportunity costs associated with forgone agricultural production (Naidoo and Iwamura 2007; Carwardine et al. 2008; Iwamura et al. 2010; Freudenberger et al. 2013; Dobrovolski et al. 2014; Venter et al. 2014). Management costs are the main costs paid by governmental and non-governmental conservation organizations (Naidoo et al. 2006). In contrast, agricultural opportunity costs are largely paid by local land users because much land is currently placed under conservation rule without compensation for forgone land use (Balmford and Whitten 2003; McCarthy et al. 2012). Thus, the choice of the cost type has important normative implications on whose costs have standing when identifying priority areas for conservation (see Zerbe and Bellas 2006). It must also be considered that different indicators have been proposed to approximate agricultural opportunity costs (Naidoo and Iwamura 2007; Carwardine et al. 2008; Dobrovolski et al. 2014), and that the choice of the cost indicator itself may influence prioritization results (Weeks et al. 2010).

The present thesis investigates how alternative normative and methodological degrees of freedom with regard to conservation costs differently affect global-scale conservation prioritization results. The analyses presented in chapters II, III and IV of this thesis yield a consistent message: The choice of the cost data has a major 
impact on the location and perceived cost-effectiveness of global priority areas for biodiversity conservation.

\subsection{Differences between management and agricultural opportunity costs}

In chapter II, it is examined how accounting for management costs or agricultural opportunity costs alone differently affected the identification of cost-effective priority areas for global mammal conservation. The results demonstrate that the choice of the cost type plays a major role for the identification priority areas as management costs and agricultural opportunity costs are only weakly correlated spatially. Accordingly, it was found that minimizing management costs of achieving predetermined mammal conservation targets resulted in priority areas with disproportionally high agricultural opportunity costs. When prioritization incorporated management costs alone, management costs of achieving all intended mammal conservation targets amounted to US\$ billion 21.8 / yr. In contrast, the required management costs were US\$ billion 28.6 / yr (an increase of $31 \%$ ) when priority areas were identified based on agricultural opportunity costs alone. Minimizing agricultural opportunity costs of achieving all intended mammal conservation targets resulted in opportunity costs of US\$225.9 billion / yr. In contrast, required agricultural opportunity costs were US\$292.14 billion / yr (an increase of 29\%) when priority areas were identified according to management costs. Perhaps most importantly, it was also found that the implicated trade-offs between minimizing management and agricultural opportunity costs were reduced significantly when a combined cost indicator was used. With this combined cost indicator management costs of achieving all intended mammal conservation targets were US\$ billion 25.26 / yr, and agricultural opportunity costs were US\$ billion $226.26 /$ yr.

According to the results presented in chapter II, selecting priority areas based on management costs alone may excessively increase social conflicts associated with protected areas because it results in high costs to local land users which already pay the brunt of the overall conservation costs, while receiving only a fraction of the globally dispersed benefits of biodiversity (see Balmford and Whitten 2003). This may also compromise the long term success of conservation, because high opportunity costs of protected areas are regularly associated with resistance from 
local communities and the violation of land use restrictions, potentially resulting in protected area downgrading or degazettment (see Balmford and Whitten 2003; Mascia et al. 2014). However, the results presented in chapter II also suggest that minimizing opportunity costs alone would overly exacerbate the present "biodiversity funding crisis". This is because the combined-costs-scenario may be considered superior to agricultural opportunity costs alone, as it results in considerably lower management costs, without significantly increasing opportunity costs. Thus, the combined-costs-scenario did not only result in the overall most costeffective priority areas but may also be considered to result in a socially more equitable distribution of costs among different stakeholder groups.

\subsection{Differences among varying indicators of agricultural opportunity costs}

In chapter III, it is investigated how global-scale conservation prioritization for mammals is affected by the choice of differing indicators of agricultural opportunity costs. The analysis exemplarily focuses on tropical and subtropical moist broadleaf forests, a hyper diverse global biome (Olson and Dinerstein 1998) subject to particularly severe conflicts between conservation land use and agriculture (Laurance et al. 2014). Three opportunity cost indicators used in previous global prioritization analyses were considered: (ii) past agricultural revenue, (ii) agricultural production in the $21^{\text {th }}$ century, and (iii) maximum potential agricultural revenue. Three spatial prioritization scenarios were compared, each using one of the three agricultural opportunity cost indicators to prioritize planning units according to conservation cost-effectiveness. It was found that the different opportunity cost indicators were at best only weakly to moderately correlated in space. Most importantly, it was discovered that minimizing agricultural opportunity costs of priority areas with regard to one cost indicator shifted priorities to areas with high costs according to any of the other two cost indicators. In particular, across all prioritization scenarios, agricultural opportunity costs associated with achieving all intended conservation targets according to any of the alternative cost indicators were at best only between $3 \%$ to $7 \%$ lower than what would have been achieved with assuming uniform conservation costs worldwide. Assuming uniform conservation costs worldwide even resulted in at least $6 \%$ lower costs according to potential agricultural revenues, than in the past-revenue-scenario and the $21^{\text {th }}$-century-production-scenario. 
Out of 2020 planning units considered for selection as priority areas in chapter II, 280 grid cells were essential for achieving all intended conservation targets regardless of the cost indicator considered (henceforth "irreplaceable areas"), e.g. because they contained species found nowhere else in the study area. Compared to a previous analyses of cost-effective priorities for global mammal conservation by Carwardine et al. (2008), the proportion of irreplaceable areas in the analysis presented in chapter III was relatively high. This is because the latter analysis focused on the tropical and subtropical broadleaf forests biome which contains a high number of range restricted mammal species (IUCN 2012). Further, Carwardine et al. (2008) used a 10\% representation target for each mammal species, while the analysis presented in chapter III assumed proportionally higher targets for species with smaller range sizes. The relatively high proportion of irreplaceable areas in the analysis presented in chapter III, suggests that the general sensitivity of prioritization towards the choice of the cost indicator was underestimated rather than overestimated, at least if it was assumed that all intended conservation targets must be achieved (=minimum set prioritization).

In sum the results presented in chapter III demonstrate that current state-of-the-art prioritization analyses that consider differing indicators of agricultural opportunity costs deliver inconclusive results because the perceived cost-effectiveness of priority areas depends widely on which cost indicator is considered, while at the same time it is unknown how well each cost indicator represents the actual agricultural opportunity cost of conservation. Arguably, global-scale prioritization analyses will have to continue to rely on uncertain indicators of agricultural opportunity cost of conservation (Armsworth et al. 2014). However, in addition to greater sensitivity testing, producing a single more authoritative indicator of agricultural opportunity costs is likely to increase the conclusiveness of cost-effective priority areas for global-scale biodiversity conservation.

\subsection{Differences among varying scenarios of agricultural extent}

To date, most approaches in global conservation prioritization incorporated opportunity costs indicators either based on past agricultural extent (mid 1990; Naidoo and Iwamura 2007; Iwamura et al. 2010; Wilson et al. 2011; Larsen et al. 2011; Freudenberger et al. 2013; Venter et al. 2014) or based on maximum potential 
agricultural extent according to biophysical land suitability (Carwardine et al. 2008). Ideally, estimates of agricultural opportunity cost of conservation should also include consideration of the probability that natural habitats are converted to agriculture (see e.g. Grieg-Gram 2006). However, only one analysis estimated opportunity costs considering available information on possible pathways of agricultural expansion in the $21^{\text {th }}$ century (Dobrovolski et al. 2014). This analysis has demonstrated that opportunity costs during the $21^{\text {th }}$ century may be reduced significantly if their spatial distribution is considered during the prioritization process, rather than assuming spatially uniform costs. The results presented in chapter III of the present thesis indicate, that opportunity costs based on past-, or maximum potential agricultural extent are similarly inefficient in minimizing opportunity costs during the 21th century. However, the different cost indicators cannot directly be compared with regard to the affect of different scenarios of agricultural extent because they also use divergent sets of assumptions with regard to agricultural land use composition, agricultural input levels, and crop prices.

In chapter IV, a specifically targeted sensitivity analysis is presented quantifying how considering pathways of agricultural expansion during the 21th century affects estimates of agricultural opportunity costs, and associated cost-effective conservation priorities at the global-scale. In line with chapter III, the analysis focuses on the global tropical and subtropical moist broadleaf forests biome and on mammal species. Agricultural opportunity costs were recalculated and mapped based on three different scenarios of agricultural extent: (i) past extent, (ii) forecast extent according to possible pathways of agricultural expansion during the $21^{\text {th }}$ century, and (iii) maximum potential extent. It was found that, even after eliminating confounding factors, the resulting spatial distributions of agricultural opportunity costs still differed significantly. Obviously the forecast-extent scenario not a "true" prediction of agricultural opportunity costs in the $21^{\text {th }}$ century, but the results presented in chapter IV highlight that indicators of opportunity costs based on past-, or maximum potential agricultural extent are not in line with possible pathways of agricultural expansion during the $21^{\text {th }}$ century. Furthermore, the relative efficiency of conservation priorities based on the past-extent-scenario and the maximum-extentscenario was tested with regard to minimizing opportunity costs according to forecast agricultural extent. It was found that explicitly minimizing opportunity costs with regard to forecast agricultural extent resulted in such opportunity costs of US\$ billion 
82.4 / y in order to meet all intended conservation targets. However, based on the past-extent-scenario, US\$ billion 89.2 / yr were needed to achieve the intended conservation targets, and US\$ billion 90.6 / yr were required based on the maximumextent-scenario. These results suggest that large efficiency gains in global conservation prioritization in the order of magnitude of several billion US\$ per year can be attained by more fully using available information on possible pathways of agricultural expansion during the 21 th century.

\subsection{Comparison of minimum set and maximum coverage prioritization}

Previous work has shown that potential efficiency gains from considering spatial heterogeneity of conservation costs (as opposed to assuming spatially uniform costs) are particularly high when a maximum coverage approach to prioritization is applied (Moilanen and Arponen 2011). This is because when conservation resources are assumed to be insufficient for meeting all intended conservation targets, even areas of high biological irreplaceability may not be selected in the final prioritization solution if they are associated with disproportionally high costs (Moilanen and Arponen 2011). In contrast, it has been shown previously that biologically irreplaceable areas are robust to the consideration of costs when a minimum set prioritization approach is applied (Carwardine et al. 2010). The results of the present thesis confirm for the global-scale that biologically irreplaceable areas are robust to diverging cost data. For example, in chapter II it was found that 1,319 grid cells were always selected to achieve all intended conservation targets at minimum costs, regardless of whether management costs, agricultural opportunity costs, combined costs, or uniform costs were considered. These grid cells included 563 grid cells that were biologically irreplaceable and 542 grid cells that were "locked" in any prioritization solution due to current protected area coverage. Most importantly, building on the body of previous research, the results of the present thesis demonstrate that the sensitivity of prioritization towards diverging cost data increases when maximum coverage prioritization is applied, in particular when low upper cost limits are set. For instance, in chapter II it was found that setting the upper cost limit at, respectively, 3\%, 5\%, and $10 \%$ of the total costs according to agricultural production in the $21^{\text {th }}$ century, achieved a mammal range equivalent coverage of, respectively, $30 \%, 35 \%$ and $44 \%$ in the $21^{\text {th }}$-century-production-scenario, but in the 
past-revenue-scenario only, respectively $10 \%, 22 \%$, and $34 \%$ of the range equivalents were covered. Assuming that not all intended conservation targets can be met when they incur an disproportionate amount of costs more directly reflects the actual socio-economic-constraints of protected area establishment since current protected areas are usually biased towards lands with relatively low agricultural value (Joppa and Pfaff 2009). In order to comprehensively acquire titles to priority areas for conservation with relatively high agricultural productivity current conservation spending would have to increase by at least an order of magnitude (McCarthy et al. 2012). Therefore, the findings of the present thesis demonstrate that the arguably most relevant prioritization approach for conservation decision making is also the most susceptible towards methodological and normative uncertainty with regard to conservation costs.

\section{References}

Armsworth, P.R. (2014). Inclusion of costs in conservation planning depends on limited datasets and hopeful assumptions. Annals of the New York Academy of Sciences 1322: 61-76. doi:10.1111/nyas.12455.

Balmford, A., Gaston, K.J., Blyth, S., James, A., Kapos, V. (2003). Global variation in terrestrial conservation costs, conservation benefits, and unmet conservation needs. Proceedings of the National Academy of Sciences of the United States of America 100: 1046-1050. doi:10.1073/pnas.0236945100.

Balmford, A., Whitten, T. (2003). Who should pay for tropical conservation, and how could the costs be met? Oryx 37: 238-250. doi:10.1017/S0030605303000413.

Bode, M., Wilson, K.A., Brooks, T.M., Turner, W.R., Mittermeier, R.A, McBride, M.F., Underwood, E.C., Possingham, H.P. (2008). Cost-effective global conservation spending is robust to taxonomic group. Proceedings of the National Academy of Sciences of the United States of America 105: 6498-6501. doi:10.1073/pnas.0710705105.

Carwardine, J., Wilson, K.A., Ceballos, G., Ehrlich, P.R., Naidoo, R., Iwamura, T., Hajkowicz, S.A., Possingham, H.P. (2008). Cost-effective priorities for global mammal conservation. Proceedings of the National Academy of 
Sciences of the United States of America 105: 11446-11450.

doi:10.1073/pnas.0707157105.

Carwardine, J., Wilson, K.A., Hajkowicz, S.A, Smith, R.J., Klein, C.J., Watts, M., Possingham, H.P. (2010). Conservation planning when costs are uncertain. Conservation Biology 24: 1529-1537. doi:10.1111/j.15231739.2010.01535.x.

Chape, S., Spalding, M.D., Jenkins, M.D. (eds.) (2008). The World's protected areas: status, values, and prospects in the twenty-first century. Berkeley: University California Press.

Dixon, J.A., Sherman, P.B. (1991). Economics of Protected Areas: A New Look at Benefits and Costs. London: Earthscan.

Dobrovolski, R., Loyola, R., D.A. Fonseca, G.A.B., Diniz-Filho, J.A.F., Araujo, M.B. (2014). Globalizing Conservation Efforts to Save Species and Enhance Food Production. BioScience 64: 539-545. doi:10.1093/biosci/biu064.

Faith, D.P., Walker, P.A. (2002). The role of trade-offs in biodiversity conservation planning: linking local management, regional planning and global conservation efforts. Journal of Biosciences 27: 393-407.

Freudenberger, L., Hobson, P., Schluck, M., Kreft, S., Vohland, K., Sommer, H., Reichle, S., Nowicki, C., Barthlott, W., Ibisch, P.L. (2013). Nature conservation: priority-setting needs a global change. Biodiversity and Conservation 22: 1255-1281. doi:10.1007/s10531-012-0428-6.

Grieg-Gran, M. (2006). The Costs of Avoiding Deforestation Report prepared for the Stern Review of the Economics of Climate Change. London: International Institute for Environment and Development.

IUCN (2012). IUCN Red List of Threatened Species. Retrieved from URL: http://www.iucredlist.org/ (accessed 01.09.2014).

Iwamura, T., Wilson, K.A., Venter, O., Possingham, H.P. (2010). A climatic stability approach to prioritizing global conservation investments. PLoS One 5: e15103. doi:10.1371/journal.pone.0015103.

Joppa, L.N., Pfaff, A. (2009). High and Far: Biases in the Location of Protected Areas. PLoS One 4: e8273. doi:10.1371/journal.pone.0008273. 
Larsen, F.W., Londoño-Murcia, M.C., Turner, W.R. (2011). Global priorities for conservation of threatened species, carbon storage, and freshwater services: scope for synergy? Conservation Letters 4: 355-363. doi:10.1111/j.1755-263X.2011.00183.x.

Laurance, W.F., Sayer, J., Cassman, K.G. (2014). Agricultural expansion and its impacts on tropical nature. Trends in Ecology \& Evolution 29: 107-116. doi:10.1016/j.tree.2013.12.001.

Loyola, R.D., Oliveira-Santos, L.G.R., Almeida-Neto, M., Nogueira, D.M., Kubota, U., Diniz-Filho, J.A.F., Lewinsohn, T.M. (2009). Integrating economic costs and biological traits into global conservation priorities for carnivores. PLoS One 4: e6807. doi:10.1371/journal.pone.0006807.

Mascia, M.B., Pailler, S., Krithivasan, R., Roshchanka, V., Burns, D., Mlotha, M.J., Murray, D.R., Peng, N. (2014). Protected area downgrading, downsizing, and degazettement (PADDD) in Africa, Asia, and Latin America and the Caribbean, 1900-2010. Biological Conservation 169: 355-361. doi:10.1016/j.biocon.2013.11.021.

McCarthy, D.P., Donald, P.F., Scharlemann, J.P.W., Buchanan, G.M., Balmford, A., Green, J.M.H., Bennun, L. a, Burgess, N.D., Fishpool, L.D.C., Garnett, S.T., Leonard, D.L., Maloney, R.F., Morling, P., Schaefer, H.M., Symes, A., Wiedenfeld, D.A., Butchart, S.H.M. (2012). Financial costs of meeting global biodiversity conservation targets: current spending and unmet needs. Science 338: 946-949. doi:10.1126/science.1229803.

Moilanen, A., Arponen, A. (2011). Setting conservation targets under budgetary constraints. Biological Conservation 144: 650-653. doi:10.1016/j.biocon.2010.09.006.

Naidoo, R., Balmford, A., Ferraro, P.J., Polasky, S., Ricketts, T.H., Rouget, M. (2006). Integrating economic costs into conservation planning. Trends in Ecology \& Evolution 21: 681-687. doi:10.1016/j.tree.2006.10.003.

Naidoo, R., Iwamura, T. (2007). Global-scale mapping of economic benefits from agricultural lands: Implications for conservation priorities. Biological Conservation 140: 40-49. doi:10.1016/j.biocon.2007.07.025. 
Olson, D., Dinerstein, E. (1998). The Global 200: a representation approach to conserving the Earth's most biologically valuable ecoregions. Conservation Biology 12: 502-515. doi:10.1046/j.1523-1739.1998.012003502.x.

Polasky, S., Nelson, E., Camm, J., Csuti, B., Fackler, P., Lonsdorf, E., Montgomery, C., White, D., Arthur, J., Garberyonts, B. (2008). Where to put things? Spatial land management to sustain biodiversity and economic returns. Biological Conservation 141, 1505-1524. doi:10.1016/j.biocon.2008.03.022.

Underwood, E.C., Shaw, M.R., Wilson, K.A., Kareiva, P., Klausmeyer, K.R., McBride, M.F., Bode, M., Morrison, S.A., Hoekstra, J.M., Possingham, H.P. (2008). Protecting biodiversity when money matters: maximizing return on investment. PLoS One 3: e1515. doi:10.1371/journal.pone.0001515.

Venter, O., Fuller, R.A.., Segan, D.B., Carwardine, J., Brooks, T., Butchart, S.H.M., Di Marco, M., Iwamura, T., Joseph, L., O’Grady, D., Possingham, H.P., Rondinini, C., Smith, R.J., Venter, M., Watson, J.E.M. (2014). Targeting Global Protected Area Expansion for Imperiled Biodiversity. PLoS Biology 12: e1001891. doi:10.1371/journal.pbio.1001891.

Waldron, A., Mooers, A. (2013). Targeting global conservation funding to limit immediate biodiversity declines. Proceedings of the National Academy of Sciences of the United States of America 110: 12144-12148. doi:10.5061/dryad.p69t1.

Weeks, R., Russ, G.R., Bucol, A.A., Alcala, A.C. (2010). Shortcuts for marine conservation planning: The effectiveness of socioeconomic data surrogates. Biological Conservation 143: 1236-1244. doi:10.1016/j.biocon.2010.02.031.

Wilson, K.A., Evans, M.C., Di Marco, M., Green, D.C., Boitani, L., Possingham, H.P., Chiozza, F., Rondinini, C. (2011). Prioritizing conservation investments for mammal species globally. Philosophical Transactions of the Royal Society B: Biological Sciences 366: 2670-2680. doi:10.1098/rstb.2011.0108.

Wilson, K.A., McBride, M.F., Bode, M., Possingham, H.P. (2006). Prioritizing global conservation efforts. Nature 440: 337-340. doi:10.1038/nature04366.

Zerbe, R.O., Bellas, A.S., (2006). A primer for benefit-cost analysis. Cheltenham: Edward Elgar Publishing 
